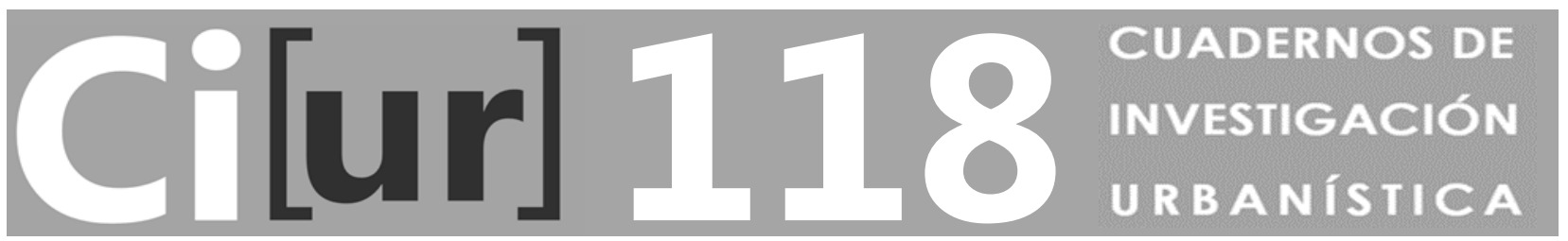

\title{
EL MODELO "SOSTENIBLE" HEREDADO POR LOS INSTRUMENTOS DE SOSTENIBILIDAD
}

\author{
MIRIAM ALONSO NAVEIRO \\ Doctora Arquitecta
}

Este documento contiene parte de la tesis: "Los sistemas de indicadores. Un instrumento para facilitar el desarrollo de políticas de regeneración urbana", dirigida por la profesora María Rosario Alonso Ibañez de la Universidad de Oviedo, y leída por su autora el 19 de julio de 2017 en la Universidad de Oviedo, por la que obtuvo doctorado cum laude.

Mayo / Junio 2018 


\begin{tabular}{|c|c|}
\hline Director: & José Fariña Tojo \\
\hline \multicolumn{2}{|c|}{ Consejo de Redacción: } \\
\hline Director & Ester Higueras García \\
\hline Subdirector & María Cristina García González \\
\hline Jefe de redacción & María Emilia Román López \\
\hline Vocales & $\begin{array}{l}\text { Isabel Aguirre de Urcola (Escola Galega da Paisaxe Juana de Vega, A Coruña), Pilar Chías } \\
\text { Navarro (Univ. Alcalá de Henares, Madrid), José Antonio Corraliza Rodríguez (Univ. Autónoma } \\
\text { de Madrid), Alberto Cuchí Burgos (Univ. Politécnica de Cataluña), José Fariña Tojo (Univ. } \\
\text { Politécnica de Madrid), Agustín Hernández Aja (Univ. Politécnica de Madrid), Francisco } \\
\text { Lamíquiz Daudén (Univ. Politécnica de Madrid), María Asunción Leboreiro Amaro (Univ. } \\
\text { Politécnica de Madrid), Rafael Mata Olmo (Univ. Autónoma de Madrid), Luis Andrés Orive } \\
\text { (Centro de Estudios Ambientales, Vitoria-Gasteiz), Javier Ruiz Sánchez (Univ. Politécnica de } \\
\text { Madrid), Carlos Manuel Valdés (Univ. Carlos III de Madrid) }\end{array}$ \\
\hline Consejo Asesor: & $\begin{array}{l}\text { José Manuel Atienza Riera (Vicerrector de Estrategia Académica e Internacionalización, Univ. } \\
\text { Politécnica de Madrid), Manuel Blanco Lage (Director de la Escuela Superior de Arquitectura, } \\
\text { Univ. Politécnica de Madrid), José Miguel Fernández Güell (Director del Departamento de } \\
\text { Urbanística y Ordenación del Territorio, Univ. Politécnica de Madrid), Antonio Elizalde Hevia, } \\
\text { Julio García Lanza, Josefina Gómez de Mendoza, José Manuel Naredo, Fernando Roch Peña, } \\
\text { Julián Salas Serrano, Fernando de Terán Troyano }\end{array}$ \\
\hline Comité Científico: & $\begin{array}{l}\text { Antonio Acierno (Univ. Federico II di Napoli, Nápoles, ITALIA), Miguel Ángel Barreto (Univ. } \\
\text { Nacional del Nordeste, Resistencia, ARGENTINA), José Luis Carrillo (Univ. Veracruzana, Xalapa, } \\
\text { MÉXICO), Luz Alicia Cárdenas Jirón (Univ. de Chile, Santiago de Chile, CHILE), Marta Casares } \\
\text { (Univ. Nacional de Tucumán, Tucumán, ARGENTINA), María Castrillo (Univ. de Valladolid, } \\
\text { ESPAÑA), Dania Chavarría (Univ. de Costa Rica, COSTA RICA), Mercedes Ferrer (Univ. del } \\
\text { Zulia, Maracaibo, VENEZUELA), Fernando Gaja (Univ. Politécnica de Valencia, ESPAÑA), } \\
\text { Alberto Gurovich (Univ. de Chile, Santiago de Chile, CHILE), Josué Llanque (Univ. Nacional de } \\
\text { S. Agustín, Arequipa, PERÚ), Angelo Mazza (Univ. degli Studi di Napoli, Nápoles, ITALIA), Luis } \\
\text { Moya (Univ. Politécnica de Madrid, ESPAÑA), Joan Olmos (Univ. Politécnica de Valencia, } \\
\text { ESPAÑA), Ignazia Pinzello (Univ. degli Studi di Palermo, Palermo, ITALIA), Julio Pozueta (Univ. } \\
\text { Politécnica de Madrid, ESPAÑA), Alfonso Rivas (Univ. A. Metropolitana Azcapotzalco, Ciudad de } \\
\text { México, MÉXICO), Silvia Rossi (Univ. Nacional de Tucumán, ARGENTINA), Adalberto da Silva } \\
\text { (Univ. Estadual Paulista, Sao Paulo, BRASIL), Carlos Soberanis (Univ. Francisco Marroquín, } \\
\text { Guatemala, GUATEMALA), Carlos A. Torres (Univ. Nacional de Colombia, Bogotá, COLOMBIA), } \\
\text { Graziella Trovato (Univ. Politécnica de Madrid, ESPAÑA), Carlos F. Valverde (Univ. } \\
\text { Iberoamericana de Puebla, MÉXICO), Fernando N. Winfield (Univ. Veracruzana, Xalapa, } \\
\text { MÉXICO), Ana Zazo (Univ. del Bio-Bio, Concepción, CHILE) }\end{array}$ \\
\hline
\end{tabular}

\section{Realización y maquetación:}

Maquetación: Raquel Clemente Pereiro. ciur.urbanismo.arquitectura@upm.es

Distribución: Mairea Libros: distribucion@mairea-libros.com

\section{(C) COPYRIGHT 2018}

\section{MIRIAM ALONSO NAVEIRO}

Fecha de recepción: mayo de 2018

Fecha de aceptación: mayo de 2018

I.S.S.N. (edición impresa): 1886-6654

I.S.S.N. (edición digital): 2174-5099

DOI: $10.20868 /$ ciur.2018.118

Depósito Legal: M-41356-2011

Año XI, Núm. 118, mayo - junio 2018, 78 págs.

Edita: Instituto Juan de Herrera

Imprime: FASTER, San Francisco de Sales 1, Madrid 


\title{
El modelo "sostenible" heredado por los instrumentos de sostenibilidad
}

\section{Indicator systems. One tool to make the development of urban regeneration policy easy}

\author{
DOI: $10.20868 /$ ciur.2018.118.3752
}

\section{DESCRIPTORES:}

Regeneración urbana integrada / Sistemas de Indicadores / Herramientas cualitativas / Sistemas de evaluación

\section{KEY WORDS:}

Integrated Urban Regeneration / Indicator systems / Cualitative tools / Evaluation systems

\section{RESUMEN:}

La sostenibilidad, como abanderada de la equidad y el reequilibrio de las disfunciones observadas en las dimensiones social, medioambiental, cultural y económica, se constituyó como la respuesta internacional a los síntomas de colapso. Constituyéndose como la tendencia internacional aceptada, se apostó por su incorporación a todas las políticas públicas tratando de forma progresiva de consolidar la transición de un modelo basado en el crecimiento económico, a un modelo basado en los principios de sostenibilidad urbana. Principio que finalmente se instituyó bajo la nota común denominado Regeneración urbana Integrada.

La transición a este modelo urbano sostenible desencadenó la creación de herramientas para el análisis, evaluación y proposición de soluciones para el reequilibrio de las relaciones, ahora desproporcionadas, entre el hombre y el medio. Estas nuevas herramientas, que derivaron en la creación de sistemas de indicadores cuantitativos, serán el núcleo central de la presente investigación que, a través de su análisis, tratara de mostrar la relación que subyace entre la metodología empleada para su definición, el modelo sostenible heredado de los documentos internacionales, y la permanencia de las tendencias insostenibles en los sistemas urbanos.

\section{ABSTRACT:}

Sustainability, as the standard-bearer of equity and rebalancing of dysfunctions observed in the social, environmental, cultural and economic dimensions, was established as the international response to these sings of imminent collapse. Becoming itself as the accepted international trend, the firm commitment to its incorporation in all public policies was established, trying progressively to consolidate the transition from a model based on economic growth to a model based on the principles of urban sustainability. This principle was finally established under the common approach called Integrated Urban Regeneration.

The transition to this sustainable urban model triggered the creation of tools for the analysis, evaluation and proposition of solutions for the rebalancing of the unbalanced relationships between human beings and the environment. These new instruments that led to the creation of quantitative indicators systems will be the core of the present research that, through its analysis, will try to show the relationship that underlies the methodology used for its definition, the sustainable model inherited from the international documents, and the permanence of the unsustainable tendencies in the urban systems.

* Miriam Alonso Naveiro es Doctora en el programa de doctorado Las Ciudades del Arco Atlántico. Patrimonio Cultural y Desarrollo Urbano, por la Universidad de Historia del Arte y Musicología de Oviedo; Máster en Las Ciudades del Arco Atlántico. Patrimonio Cultural y Desarrollo Urbano, por la Universidad de Oviedo y Arquitecta por la Escuela Técnica Superior de Arquitectura de La Coruña, ETSAC. alonso.naveiro.m@gmail.com

\section{CONSULTA DE NÚMEROS ANTERIORES/ACCESS TO PREVIOUS WORKS:}

La presente publicación se puede consultar en color en formato pdf en la dirección:

This document is available in pdfformat and full colour in the following web page:

http://www2.aq.upm.es/Departamentos/Urbanismo/institucional/publicaciones/ciur/ 


\section{ÍNDICE}

1 DE LA SOSTENIBILIDAD AL DESARROLLO SOSTENIBLE EN SU PROYECCIÓN EN LAS

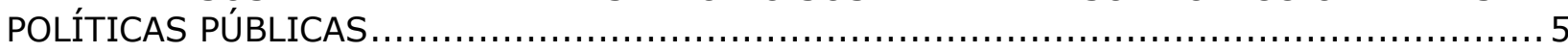

1.1 La huella económica en el proceso de incorporación de la dimensión ambiental ...... 5

1.2 El conflicto con la dimensión económica en la toma de conciencia de la dimensión

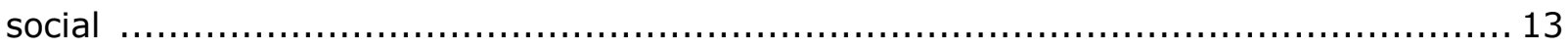

2 CONSECUENCIAS DEL DESARROLLO SOSTENIBLE EN LA DIMENSIÓN URBANA......... 17

2.1 La regeneración urbana integrada como marco de común entendimiento ........... 27

2.2 El modelo urbano sostenible en la legislación española ........................... 33

3 EL DESARROLLO SOSTENIBLE EN LOS INSTRUMENTOS DE ORIENTACIÓN CON

INFLUENCIA EN LAS POLÍTICAS URBANAS: ESTRATEGIAS Y AGENDAS ...................... 38

3.1 La Economía como dimensión vertebradora de la sostenibilidad en las estrategias de

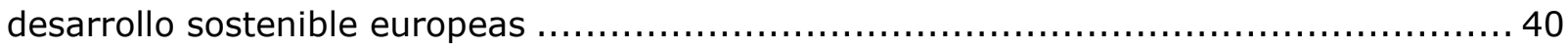

3.1.1 Estrategia de Lisboa 2000: economía basada en la competencia global................40

3.1.2 Estrategia de la Unión Europea para un Desarrollo Sostenible 2001: tímida apuesta hacia la incorporación de la dimensión ambiental .............................................................43

3.1.3 Revisión de la Estrategia de Desarrollo Sostenible 2005: falsas esperanzas de mundialización del desarrollo sostenible.

3.1.4 Estrategia Europa 2020: Economía oculta tras la objetividad de la cuantificación .49

3.2 La incorporación de la base territorial en el proceso de recepción del desarrollo

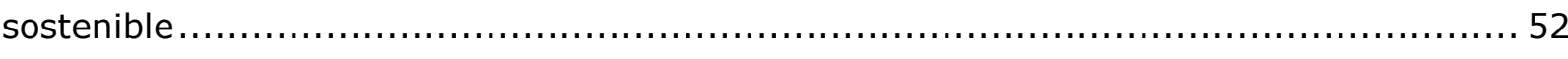

3.2.1 Estrategia Territorial Europea 1999: el policentrismo europeo como prioridad para

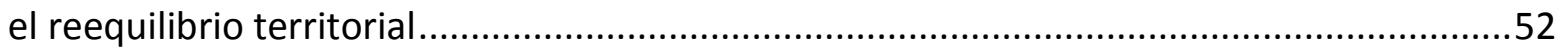

3.2.2 Agenda Territorial Europea 2007: Reforzando la dimensión territorial de la

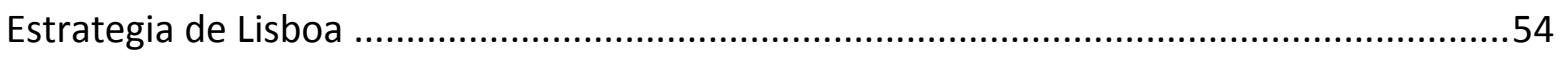

3.2.3 Agenda Territorial Europea 2020: un nuevo refuerzo de la dimensión territorial 57 3.3 Estrategias españolas de desarrollo sostenible: Influencias del proceso de incorporación europea del desarrollo sostenible en el ámbito nacional ..................... 59

3.3.1 Estrategia Española de Desarrollo Sostenible (2007): primeros pasos hacia la REDS2005

3.3.2 Estrategia Española de Sostenibilidad Urbana y Local 2009: avanzando a la escala local

3.3.3 Estrategia Española de Sostenibilidad Urbana y Local 2011: reiteración en la importancia de la dimensión urbana ..........................................................................63

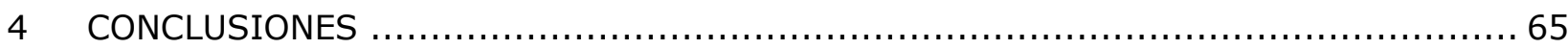

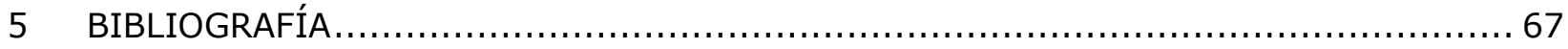


"Toda forma de la materia tiene una historia, o mejor dicho, no es más que historia"(CASTELLS, 1976: 13)

\section{DE LA SOSTENIBILIDAD AL DESARROLLO SOSTENIBLE EN SU PROYECCIÓN EN LAS POLÍTICAS PÚBLICAS}

El proceso de incorporación de la sostenibilidad ya tiene un recorrido tal que ha llegado a influir en los documentos internacionales, europeos y nacionales, y por tanto en las políticas públicas ${ }^{1}$. Esta incorporación del concepto de sostenibilidad se ha producido hasta el punto de que un análisis en la actualidad permitiría esclarecer cual fue la interpretación de este término que finalmente albergó cada uno de los documentos internacionales y europeos ${ }^{2}$.

Desentrañar cual es el modelo de sostenibilidad que hemos heredado de las políticas públicas es uno de los eslabones clave de la presente investigación. Para ello en el presente artículo haremos un recorrido desde el momento en que se toma conciencia de las necesidades de cambio, hasta llegar a la constitución de la política urbana de la Unión Europea. Transición que aún sigue luchando por consolidarse con el desarrollo de nuevos documentos del Acervo Urbano Europeo ${ }^{3}$.

El reto de alcanzar la sostenibilidad, que aún hoy continúa activo, pasaba por la recuperación de la visión multidisciplinar perdida. Esta recuperación de las diferentes disciplinas comenzó con la incorporación de la dimensión ambiental, pasando luego a la social, y finalmente a la urbana. Y a pesar de las intenciones integradoras, y de que hoy todas las dimensiones aparecen en los textos internacionales y en las herramientas de análisis y evaluación, los resultados no parecen acercarse a la equidistribucción deseada.

\subsection{La huella económica en el proceso de incorporación de la dimensión ambiental}

Las diferentes interpretaciones a que dio lugar el término de sostenibilidad, derivadas del proceso de incorporación de la dimensión ambiental, fueron las responsables de que finalmente se produjera una desviación de los objetivos iniciales de reequilibrio. $Y$ es que entre el enfoque económico ambiental, y el enfoque económico ecológico, existió, y aún perdura, dispar conceptualización de cómo administrar de manera responsable la relación hombre-medio.

\footnotetext{
1 Con políticas públicas haremos referencia al conjunto de documentos vinculantes, y no vinculantes que encaminaron hacia la sostenibilidad.

${ }^{2}$ El desarrollo de documentos que denominaremos soft law ${ }^{2}$, y que comprenden resoluciones no vinculantes de organizaciones internacionales, instrumentos de actores no estatales, acuerdos no normativos, etc., llevaron a establecer unos principios y objetivos que a pesar de no ser obligatorios promovieron las prácticas estatales en una determinada dirección ética hacia la que se pretendió también encaminar el derecho internacional (MAZUELOS BELLIDO, 2004:3). Las normas jurídicas o también hard law, influidas por esa ética internacional, comenzaron a tratar de incorporar los objetivos y principios de consenso internacional para de esta forma avanzar hacia el modelo acordado.

${ }^{3}$ Más información del Acervo Urbano Europeo en el documento "La europeización urbana a través de la política de cohesión". (GONZALEZ MEDINA 2013)
} 
De este modo, mientras que para la economía ambiental el medio ambiente se considera desde la perspectiva de este como proveedor de servicios para la sociedad, y por tanto como riqueza material economizando el medio ambiente, el enfoque económico ecológico incorpora la perspectiva ecosistémica, entendiendo que es necesario reformular el sistema económico juzgando que existe una limitación física impuesta por el medio ambiente (ERIAS REY \& ÁLVAREZ-CAMPANA GALLO, 2007:83).

Estas lecturas de la dimensión ambiental se corresponden con las interpretaciones del concepto sostenibilidad, coexistiendo la "sostenibilidad débil", que deriva del sistema económico ambiental, y la "sostenibilidad fuerte", que deriva de la economía ecológica. Esto implica que la sostenibilidad débil se da por tanto sin una conservación de todo el stock de capital medioambiental, y se considera la posibilidad de paliar un daño en una zona realizando inversiones en otra. Por el contrario, la sostenibilidad fuerte puede llegar a convenir que no es posible reducir más el stock medioambiental, poniendo en primer plano la salud de los ecosistemas si el daño producido por el desarrollo se considerara irreparable (ERIAS REY \& ÁLVAREZ-CAMPANA GALLO, 2007:378).

La necesidad de decantarse hacia alguna de las interpretaciones de la sostenibilidad para ponerla en práctica a escala internacional llego de la mano del desarrollo de informes que, como el informe de Malthus de 1798 titulado "Ensayo sobre la población" ${ }^{4}$, comenzaron a reflejar muestras de este agotamiento a corto y largo plazo del modelo de desarrollo basado en el consumo de recursos.

Esta dualidad presente en la definición del concepto sostenibilidad, entre establecer fuertes límites o apostar por la confianza en el desarrollo, se observa también en los informes posteriores. Existían defensores de crecimiento cero o estacionario, que apuntaban a la necesidad de suspender el desarrollo en aras del equilibrio, y desarrollistas, que buscaban la conciliación del desarrollo con el sector ambiental y social. De este conflicto se derivan el Modelo Meadows y el Modelo Bariloche, ambos elaborados a finales del S.XX, y que reflexionan sobre posibles escenarios futuros.

En el informe de Donella y Dennis Meadows, del año 1972 titulado "Los límites del crecimiento" 5(MLC), ya se advertía que "si el actual incremento de la población mundial, la industrialización, la contaminación, la producción de alimentos y la

\footnotetext{
4 En el "Ensayo sobre la población" Malthus critica las visiones filosóficas existentes por aquel entonces que contrapuestas, buscaban con mayor intensidad desacreditarse las unas a las otras, que ejercer una crítica constructiva. Los unos criticaban el afán especulador de aquellos que promovían el cambio, los otros criticaban el afán de querer seguir aprovechándose de aquellos en situación desfavorable. Malthus en el desarrollo de su ensayo pretende dar argumentos basados en hechos observables y mesurables y para ellos parte de dos premisas "el alimento es necesario a la existencia del hombre" y "la pasión entre los sexos es necesaria y se mantendrá prácticamente en su estado actual. Tomando como ciertos sus argumentos afirma que "la capacidad de crecimiento de la población es infinitamente mayor que la capacidad de la tierra para producir alimentos para el hombre. MALTHUS, Thomas, "Primer ensayo sobre la población", Altaya, p.50-53. (MALTHUS 1846)

${ }^{5}$ Encargado por el Club de Roma al MIT (Instituto Tecnológico de Massachussets) y desarrollado por un grupo de analistas encabezados por Dennis Meadows, el informe de Meadows es uno de los documentos, que entre otros, afirman de la insostenibilidad del modelo, llegando a establecer la fecha de caducidad del mismo. Informe Meadows 1972.(MEADOWS et al. 1972)
} 
explotación de los recursos naturales se mantenía sin variación, alcanzaría los límites absolutos de crecimiento en la Tierra durante los próximos cien años". El informe realizado a través del programa World3 mostraba una clara extralimitación en el uso de los recursos naturales entendiendo que debía ser modificada esa tendencia. Propone que "el estado de equilibrio global debía ser diseñado de forma que se satisfagan las necesidades de cada persona sobre la tierra, y que todas tuvieran las mismas oportunidades de desarrollar su propio potencial humano".

Sin embargo, a pesar de esta voluntad de satisfacer las necesidades de todos, los países en vías de desarrollo vieron amenazada su capacidad de desarrollo con el posible establecimiento de límites universales, y por tanto, elaboraron un documento con un planteamiento alternativo. En oposición al documento de Meadows, las ciudades latinoamericanas elaboran el "Modelo Mundial Latinoamericano" (MMLA), como alternativa con un carácter más social que técnico (FOY, 1998:23). El MMLA o "Modelo Bariloche" de la Fundación Bariloche, fue desarrollado entre 1972 y 1975 con la intención de mostrar un camino para la evolución mundial más equitativo.

El libro "¿Catástrofe o Nueva Sociedad?" muestra el resultado del Modelo Mundial Latinoamericano $y$, aunque su publicación es relativamente reciente, nos ayuda a comprender la confrontación de visiones existente por aquel entonces. El MMLA realiza una crítica al MLC, ya que Meadows, basándose en variables de crecimiento exponencial, indudablemente hacía que la extensión del crecimiento económico, tal y como venía siendo desarrollado en los países centrales, en los países en desarrollo derivara en la "no sustentabilidad de cualquier propuesta relativamente igualitaria a nivel mundial" basado en el agotamiento de recursos naturales (HERRERA, SCOLNICK, CHICHILINSKY, GALLOPÍN, \& HARDOY, 2004:9). Ante esta perspectiva centraron por tanto el MMLA en la factibilidad de lograr un objetivo mínimo de bienestar global que pudiera ser extensible a los países en vías de desarrollo.

Esta controversia también llegó a tener repercusión en las conferencias internacionales que abordaban la incorporación de la sostenibilidad a los acuerdos internacionales. Las Naciones Unidas consolidaron la intención manifestada en 1968 de considerar por primera vez la necesidad de integrar los asuntos del medio ambiente a sus objetivos internacionales ${ }^{6}$. La Asamblea General decidió finalmente convocar la "Conferencia de las Naciones Unidas sobre el Medio Humano" (NACIONES UNIDAS 1968b) ${ }^{7}$ en Estocolmo 1972. Esta reunión se desarrolló en Estocolmo del 5 al 16 de junio de 1972, y no estuvo exenta de polémica entre las dos visiones a las que hacíamos referencia con anterioridad. El trabajo de René Dubos, redactado por Barbara Ward $y$ en que se apoyaron las conferencias denominado "Una sola Tierra. El cuidado y conservación de un pequeño planeta", dio lugar a voces que pretendían la inclusión en el eslogan de "Un solo pueblo",

\footnotetext{
6 "Convencido de la urgente necesidad de intensificar los esfuerzos, en el plano nacional e internacional, para limitar y, de ser posible, eliminar la deterioración del medio humano, y con objeto de proteger y mejorar el ambiente natural, en interés del hombre," Naciones Unidas. Resolución 1346 (XLV)(NACIONES UNIDAS 1968a)

7 En su $23^{\circ}$ período de sesiones, la Asamblea General aprobó la resolución 2398 (XXIII), de 3 de diciembre de 1968.(NACIONES UNIDAS 1968b)
} 
como llamada de atención a la necesidad de inclusión de los problemas de los países en vías de desarrollo.

Queda patente que la indeterminación que presentaba el término sostenibilidad8 no favoreció la definición de unas metas claras, efecto que se tradujo en una falta de puesta en práctica de acciones eficaces (NAREDO, 1996). La Conferencia de Naciones unidas, a pesar de llevarse a cabo en este clima de controversia representó el primer escalón en la incorporación al marco jurídico internacional de la protección ambiental, y llevó a la creación de la "Declaración de Estocolmo sobre el ambiente humano" ${ }^{\prime \prime}$, responsabilizando a cada estado de controlar que no se produjeran daños dentro de su jurisdicción. Esta declaración constituyó el primer documento legislativo internacional sobre medio ambiente y llevó a la creación del "Programa de las Naciones Unidas para el Medio Ambiente"10 que marcó el inicio del camino hacia el modelo sostenible como compromiso internacional.

Siguiendo la apuesta por la incorporación de la sostenibilidad, y tratando de establecer un consenso internacional, la definición de "desarrollo sostenible" correspondiente al informe "Nuestro futuro común" o también conocido como "Informe Brundtland 1984" actuales sin poner en peligro la capacidad de las generaciones futuras de satisfacer sus propias necesidades ${ }^{\prime 12}$, fue tomada como referencia en la implantación del nuevo modelo. Esta interpretación de la sostenibilidad dejó su huella en todos los documentos posteriores, y por tanto de ella se deriva el modelo sostenible heredado tanto en el ámbito internacional como comunitario europeo.

La interpretación de la definición del Informe Brundtland representó finalmente un viraje hacia la visión desarrollista entendiendo los países que ésta apoyaba el mantenimiento del crecimiento. De esta forma, se atendía a la petición de los países en vías de desarrollo de permitir crecimiento para incorporar su disfunción social. El inconveniente fue que esta demanda se universalizó también para los países desarrollados, consolidándose con esta definición del informe Brundtland la

\footnotetext{
${ }^{8}$ Conceptos como racionalidad, eficacia o competitividad, se plantean como conceptos más cercanos al ciudadano que el concepto sostenibilidad. Algunos artículos plantean esta "ciudad en clave racional", para evitar las malinterpretaciones que se derivan de un término que comienza a "vaciarse de contenido". (FARIÑ̃A TOJO 2004)

9 "Declaración de Estocolmo 1972". Este documento está constituido por 106 "recomendaciones" y 24 "principios" que abogan por el derecho al desarrollo sostenible y a la protección y conservación del medio ambiente. (NACIONES UNIDAS 1972)

10 La Conferencia de Estocolmo recomendó la creación de un secretariado en la Naciones Unidas para la acción y coordinación de las cuestiones del medio ambiente. Adquirió el nombre de "Programa de las Naciones Unidas para el Medio Ambiente" (PNUMA) y constituye el principal programa de las Naciones Unidas a cargo de los asuntos del medio ambiente. (NACIONES UNIDAS 1972)

${ }^{11}$ El Informe Brundtland presentó una nueva mirada al desarrollo sostenible. Elaborado por la Comisión Mundial sobre el Medio Ambiente y Desarrollo con el objetivo de establecer una agenda global para el cambio, se partió de la convicción de que es posible un futuro "más próspero, más justo y más seguro. Planteaba la posibilidad de un crecimiento económico basado en políticas de sostenibilidad y expansión de los recursos naturales. Tres fueron los objetivos fundamentales: examinar los temas críticos, promover formas de cooperación internacional y promover la comprensión y compromiso de los individuos, empresas, gobiernos, institutos y organizaciones (COMISIÓN MUNDIAL SOBRE MEDIO AMBIENTE Y DESARROLLO 1987)

12 Definición de desarrollo sostenible según fue enunciado en el Informe Brundtland, Informe que centraba su atención en los siguientes aspectos: población y recursos humanos, especies y ecosistemas, energía, industria, el reto urbano. (COMISIÓN MUNDIAL SOBRE MEDIO AMBIENTE Y DESARROLLO 1987)
} 
asociación entre desarrollo y bienestar, y bienestar con crecimiento económico. La petición de los países en vías de desarrollo de no establecer límites quedo cumplida, pero también para la perspectiva insostenible de los países desarrollados de continuar apostando por el crecimiento.

Consolidado este consenso, el desarrollo sostenible desde entonces ha marcado la senda de implementación de la sostenibilidad hasta nuestros días. Y es que en la "Conferencia de las Naciones Unidas sobre Medio Ambiente y Desarrollo", conocida popularmente como Cumbre de Río de Janeiro celebrada en $1992^{13}$, queda manifiesta esta apuesta por el desarrollo aún en mayor medida, mostrando los análisis de la Conferencia de Río el retroceso que se experimenta en ésta respecto a la Conferencia de Estocolmo de 1972.

La Unión Europea también realizó, y aún continúa, este progresivo avance hacia una lectura multidimensional que venía siendo demandada desde la escala internacional. Formando parte del grupo de países desarrollados que, dando de lado a las voces que proponen el crecimiento estacionario continuaron con el enfoque de crecimiento económico sostenible, comenzó la elaboración de diversos documentos para adaptarse y cumplir con el avance hacia el desarrollo sostenible propuesto en las cumbres internacionales.

La dimensión ambiental comenzó a adquirir relevancia. El mayor impulso a los temas medio ambientales a nivel Europeo se produce principalmente en la Conferencia europea de Paris de 1972 en la que se expone que "la expansión económica no es un fin en sí mismo," y que por tanto "se dará particular atención a los valores intangibles y a la protección del medio ambiente" (CUADRADO RUIZ 2010). Esta conferencia indica que los recursos constituyen la base, y los límites del crecimiento, sin embargo como veremos a continuación el enfoque europeo se alinea con la perspectiva económico-ambiental a la que hicimos referencia anteriormente.

Como consecuencia de ésta conferencia, se aprueba un año después en 1973 el "I Programa de Acción Comunitaria en Materia de Medio Ambiente (PACMA)" que marca el marco de la política medioambiental comunitaria para el periodo 1973 a 1976. Las críticas más fuertes hacia este programa, y que ponen de manifiesto la pérdida de visión ecosistémica comunitaria europea, son las que tienen que ver con el excesivo peso que el programa concedió a solventar los problemas ambientales una vez se han hecho presentes más que a la prevención de que estos lleguen a producirse. No será hasta el "III Programa de Acción Comunitaria en Materia de Medio Ambiente" del año 1982 que comiencen a hacerse énfasis en las medidas preventivas (GOMEZ PIÑERO 1989). Sin embargo, siguen siendo sectoriales, y por

\footnotetext{
13 La Cumbre de Río de 1992 forma parte de las conferencias de las Naciones Unidas sobre medioambiente y desarrollo llevada a cabo entre el 3 y el 14 de junio de 1992. En esta los países participantes acordaron adoptar un enfoque de desarrollo que protegiera el medio ambiente asegurando el desarrollo, a través de una alianza mundial y la cooperación de los estados. En la cumbre fueron aprobados algunos documentos por los gobiernos participantes en la misma, entre ellos la Declaración de río sobre el medioambiente y el desarrollo. (NACIONES UNIDAS 1992a)
} 
esta independencia de la política económica su repercusión no fue tan efectiva como se esperaba.

La entrada en vigor del "Acta Única Europea"14 en 1987 supone una de las mayores reformas en el ámbito medioambiental con la introducción de un Título específico en el "Tratado constitutivo de la Comunidad Europea". Se incluyen objetivos medioambientales como la conservación, la protección y la mejora de la calidad del medio ambiente, y el uso prudente y racional de los recursos, la protección de la salud de las personas; y la introducción en el ordenamiento comunitario de la acción preventiva, corrección de los atentados y el quién contamina paga. La inclusión de este título suponía necesariamente la incorporación de los temas medio ambientales al resto de políticas comunitarias ya que gracias a este se antepuso al medioambiente ante cualquier agresión de otra política económica, agrícola, ganadera, pesquera, etc. Sin embargo, continúa con los castigos económicos hacia el incumplimiento de la legislación ambiental a pesar de que la clave hacia el éxito era precisamente evitar que este llegara a producirse. Muy criticado fue este sistema en el que el daño medioambiental tenía un precio, muchas veces asequible.

Los posteriores tratados europeos siguieron persiguiendo la incorporación de esta visión apoyada en un crecimiento económico medioambientalmente asumible. Al mismo tiempo que se llevaba a cabo a nivel internacional la Cumbre de Río de 1992, el Tratado de Maastricht de 1992 (UNIÓN EUROPEA 1992), siguió avanzando en los temas ambientales. Con la firma de este tratado, los temas ambientales pasaron a ser considerados políticas y quedaron constituidos como un fin de la comunidad europea ${ }^{15}$. Igualmente continuaron también los programas en materia de medio ambiente, el VI PACMA que se correspondió con la etapa 2001-2010, pretendió incidir en la utilización sostenible de los recursos y gestión de residuos entendiendo que de esta forma el problema era atacado desde los hábitos que podían dañar el medio ambiente. Sin embargo no se dieron los resultados deseados. A pesar de los esfuerzos por incorporar la problemática del medio ambiente, los documentos europeos siguieron evidenciando que las pérdidas de patrimonio natural y biodiversidad eran cada vez mayores.

La Unión Europea, que podría haber liderado la corriente más potente de incorporación de la política ambiental, realizaba avances muy lentos y graduales. Si las organizaciones supranacionales no lideraban el proceso de cambio con contundencia de forma que en su avance arrastraran al resto de organizaciones

\footnotetext{
14 El Acta Única Europea es un Tratado internacional firmado en Luxemburgo y La Haya el 17 de Febrero por 9 estados miembros y 28 de febrero de 1986 por Italia, Dinamarca y Grecia. Entra en vigor el 1 de Julio de 1987. Su objetivo principal es reactivar el proceso de construcción europea para pasar del Mercado único al Mercado interior. Información obtenida de la web de la Unión Europea, sección legislación: http://europa.eu/legislation_summaries/institutional_affairs/treaties/treaties_singleact_es.htm [5-09-2014]. (COMUNIDAD EUROPEA 1986)

15 "La Unión definirá y ejecutará políticas comunes y acciones y se esforzará por lograr un alto grado de cooperación en todos los ámbitos de las relaciones internacionales con el fin de: f) contribuir a elaborar medidas internacionales de protección y mejora de la calidad del medio ambiente y de la gestión sostenible de los recursos naturales mundiales, para lograr el desarrollo sostenible." DOCUMENTO DE LA UNIÓN EUROPEA: Versión consolidada del Tratado de la Unión. 30- 03-2010. (UNIÓN EUROPEA 2010)
} 
nacionales, y si las organizaciones nacionales tampoco desarrollaban el compromiso para orientarse en la dirección del desarrollo sostenible, el proteccionismo de la situación existente no revertirá en mejoras de las disfunciones existentes sino en su agravamiento. $Y$ es que la falta de compromiso ha sido el factor decisivo en el mantenimiento de conductas insostenibles (ERIAS REY \& ÁLVAREZ-CAMPANA GALLO, 2007:395). Ninguno de los países desarrollados quiso liderar el avance hacia un modelo sostenible que pasaba por abandonar el sistema de consumo que por aquel entonces era la base del crecimiento.

A pesar de todas las iniciativas que hemos descrito en este epígrafe la realidad muestra que el recrudecimiento de los problemas sociales como la pobreza sigue agravándose cada día más y la persistencia de muchos de los problemas medioambientales. Tal y como podemos ver en la siguiente tabla correspondiente al informe "El medioambiente europeo: estado y perspectivas" de 2015 (AGENCIA EUROPEA DEL MEDIO AMBIENTE 2015) tanto los problemas de cambio climático, como los de biodiversidad marina, consumo de agua, entre otros siguen creciendo.

La inclusión de la dimensión ambiental no supuso por tanto grandes mejoras a nivel global aunque no debemos negarle su capacidad de poner sobre la mesa ciertos temas en los que tarde o temprano debería llegarse a un consenso internacional. Este empeoramiento de escala global, perceptible en todos los informes desarrollados por la Agencia Europea de Medio Ambiente, será el que finalmente haga que se modifique este sistema bidimensional para incorporar de manera firme nuevos desafíos. Tratarán de afrontarse gradualmente con la inclusión de la dimensión social en la apuesta por la sostenibilidad. Inclusión que desarrollaremos en el siguiente epígrafe con mayor detenimiento. 


\begin{tabular}{|c|c|c|c|c|}
\hline & $\begin{array}{l}\text { Tenden- } \\
\text { cias a 5-10 } \\
\text { años vista }\end{array}$ & $\begin{array}{l}\text { Perspec- } \\
\text { tivas a } \\
\text { más de } 20 \\
\text { años vista }\end{array}$ & $\begin{array}{c}\text { Avance } \\
\text { hacia los } \\
\text { objetivos } \\
\text { de las } \\
\text { políticas }\end{array}$ & $\begin{array}{c}\text { Más } \\
\text { informa- } \\
\text { ción en la } \\
\text { sección... }\end{array}$ \\
\hline \multicolumn{5}{|l|}{ Protección, conservación y fomento del capital natural } \\
\hline Biodiversidad de especies terrestres y de agua dulce & & & $\square$ & 3.3 \\
\hline Uso y funciones del suelo & & & $\begin{array}{c}\text { Sin } \\
\text { objetivo }\end{array}$ & 3.4 \\
\hline Estado ecológico de las masas de agua dulce & & & 国 & 3.5 \\
\hline Calidad y carga de nutrientes del agua & & & $\square$ & 3.6 \\
\hline $\begin{array}{l}\text { Contaminación atmosférica y sus efectos en los } \\
\text { ecosistemas }\end{array}$ & & & $\square$ & 3.7 \\
\hline Biodiversidad marina y costera & & & 国 & 3.8 \\
\hline Impactos del cambio climático en los ecosistemas & & & $\begin{array}{c}\text { Sin } \\
\text { objetivo }\end{array}$ & 3.9 \\
\hline \multicolumn{5}{|c|}{ El uso eficiente de los recursos y la economía con bajas emisiones de carbono } \\
\hline $\begin{array}{l}\text { Uso y aprovechamiento eficiente de los recursos } \\
\text { materiales }\end{array}$ & & & $\begin{array}{c}\text { Sin } \\
\text { objetivo }\end{array}$ & 4.3 \\
\hline Gestión de residuos & & & $\square$ & 4.4 \\
\hline $\begin{array}{l}\text { Emisiones de gases de efecto invernadero y } \\
\text { mitigación del cambio climático }\end{array}$ & & & 可/圆 & 4.5 \\
\hline Consumo de energía y uso de combustibles fósiles & & & $\underline{\square}$ & 4.6 \\
\hline $\begin{array}{l}\text { Demanda de transporte e impactos } \\
\text { medioambientales asociados }\end{array}$ & & & $\square$ & 4.7 \\
\hline Contaminación industrial del aire, el suelo y las aguas & & & $\square$ & 4.8 \\
\hline $\begin{array}{l}\text { Uso del agua y estrés hídrico (por escasez del } \\
\text { recurso) }\end{array}$ & & & 圂 & 4.9 \\
\hline \multicolumn{5}{|c|}{ Protección de la salud contra los riesgos medioambientales } \\
\hline $\begin{array}{l}\text { Contaminación del agua y riesgos para la salud de } \\
\text { carácter medioambiental }\end{array}$ & & & $\nabla / \square$ & 5.4 \\
\hline $\begin{array}{l}\text { Contaminación del aire y riesgos para la salud de } \\
\text { carácter medioambiental }\end{array}$ & & & $\square$ & 5.5 \\
\hline $\begin{array}{l}\text { Contaminación acústica (especialmente en zonas } \\
\text { urbanas) }\end{array}$ & & n/a. & $\square$ & 5.6 \\
\hline Sistemas urbanos e infraestructura "gris" & & & $\begin{array}{c}\text { Sin } \\
\text { objetivo }\end{array}$ & 5.7 \\
\hline $\begin{array}{l}\text { Cambio climático y riesgos para la salud de carácter } \\
\text { medioambiental }\end{array}$ & & & $\begin{array}{c}\text { Sin } \\
\text { objetivo }\end{array}$ & 5.8 \\
\hline $\begin{array}{l}\text { Productos químicos y riesgos para la salud de } \\
\text { carácter medioambiental }\end{array}$ & & & $\square /$ 圆 & 5.9 \\
\hline
\end{tabular}

\begin{tabular}{|c|c|c|c|}
\hline \multicolumn{2}{|c|}{$\begin{array}{l}\text { Evaluación de los indicios de tendencias y } \\
\text { perspectivas }\end{array}$} & \multicolumn{2}{|c|}{$\begin{array}{l}\text { Evaluación de los indicios del avance hacia } \\
\text { los objetivos de las políticas: }\end{array}$} \\
\hline & Dominan las tendencias negativas & 四 & $\begin{array}{l}\text { En términos generales, no se avanza } \\
\text { adecuadamente hacia los principales } \\
\text { objetivos de las políticas }\end{array}$ \\
\hline & Las tendencias son desiguales & $\square$ & $\begin{array}{l}\text { En algunos casos, se avanza } \\
\text { adecuadamente hacia los principales } \\
\text { objetivos de las políticas }\end{array}$ \\
\hline & Dominan las tendencias positivas & $\square$ & $\begin{array}{l}\text { En la mayoría de los casos, se avanza } \\
\text { adecuadamente hacia los principales } \\
\text { objetivos de las políticas }\end{array}$ \\
\hline ota: & \multicolumn{3}{|c|}{$\begin{array}{l}\text { La evaluación de indicios incluida en este cuadro se basa en indicadores clave (utilizados } \\
\text { y recogidos en las notas informativas temáticas de SOER), así como en la valoración de } \\
\text { expertos. Los recuadros de «Tendencias y perspectivas» de las distintas secciones ofrecen } \\
\text { información adicional. }\end{array}$} \\
\hline
\end{tabular}

Figura 1. Tabla correspondiente al informe medioambiental 2015

Fuente: Agencia Europea del Medio Ambiente 2015 


\subsection{El conflicto con la dimensión económica en la toma de conciencia de la dimensión social}

El avance hacia la sostenibilidad, y por ende la recuperación de la visión multidimensional, necesariamente pasaba por la inclusión del ámbito social como dimensión independiente de la medioambiental. Hasta que Naciones Unidas no imprimió énfasis en los problemas sociales a los que se enfrentaba la humanidad, los temas sociales habían estado asociados a los temas ambientales basados en el límite de los recursos.

Es cierto que no era la primera vez que las tentativas para hacer de los temas sociales un compromiso político se llevaba a cabo, y es que ya desde el inicio, venimos haciendo referencia a este conflicto. Sin embargo, no será hasta 1990 cuando se perciba una de las apuestas más significativas en el camino hacia el establecimiento de objetivos sociales internacionales. Este año un documento elaborado por el Comité de Ayuda al Desarrollo de la OECD, denominado "Modelando el siglo XXI: contribución a la cooperación para el desarrollo", describió los siete Objetivos Internacionales para el Desarrollo que por aquel entonces se consideraban como primordiales (Development Assistance Committee - OECD 1996).

Cuando el clima en el ámbito internacional fue propicio para retomar los temas sociales, Naciones Unidas, en su afán por seguir los principios que habían quedado establecidos en la "Carta de las Naciones Unidas"16, de 1945, comenzó su andadura hacia el desarrolló, con objeto del nuevo milenio, de una cumbre con la que pretendió fortalecer el avance hacia la paz, la igualdad, y la justicia. "We the people"(NACIONES UNIDAS 2000b) es uno de los primeros documentos que reflejan el acercamientos de la ONU a los objetivos globales, y aunque no fueron considerados tan eficaces como los "Objetivos Internacionales para el Desarrollo" por ser menos compatibles con el sistema de gestión por resultados, fue la forma de comenzar a incorporar objetivos internacionales sin desencantar a los países menos favorables al documento (HULME 2007), países que se corresponden con los más desarrollados que veían amenazadas sus expectativas de crecimiento.

La "Cumbre del Milenio" celebrada en Nueva York en el 2000 y de la que deriva la "Declaración del Milenio"17 incorporó metas de dimensión social como uno de los principales desafíos del nuevo milenio. A partir de entonces quedaron establecidos una serie de compromisos a nivel internacional llamados "Objetivos del Milenio"

\footnotetext{
16 La Carta de las Naciones Unidas se firma en 1945, posteriormente revisada y con la consiguiente revisión de alguno de sus artículos, centra su propósito en "preservar la paz, reafirmar los derechos fundamentales del hombre y la igualdad, a crear un marco que mantenga la justicia y el respeto, y a promover el progreso social", con este objetivo formula una serie de principios que fueron la basa para el desarrollo de los Objetivos del Milenio. NNUU, "Carta de las Naciones Unidas", p. 2. (NACIONES UNIDAS 1945)

${ }^{17}$ La Declaración del Milenio constituye el documento clave de la Cumbre del Milenio celebrada en Nueva York el 6-8 de Septiembre del 2000, "La Declaración reafirma la fe de los Estados Miembros en las Naciones Unidas y en su Carta como elementos indispensables para construir un mundo más pacífico, próspero y justo. El reconocimiento de la responsabilidad colectiva de los gobiernos del mundo para lograr la dignidad humana, la igualdad y la equidad; así como la responsabilidad de los líderes del mundo hacia sus ciudadanos, en especial los niños y los más vulnerables." (NACIONES UNIDAS 2000a)
} 
(MDG's), objetivos que fueron desarrollados posteriormente en el documento "Un concepto más amplio de la libertad: desarrollo, seguridad y derechos humanos para todos" (NACIONES UNIDAS 2005) elaborado por Kofi Annan y que formaron parte de la "Cumbre Mundial del 2005".
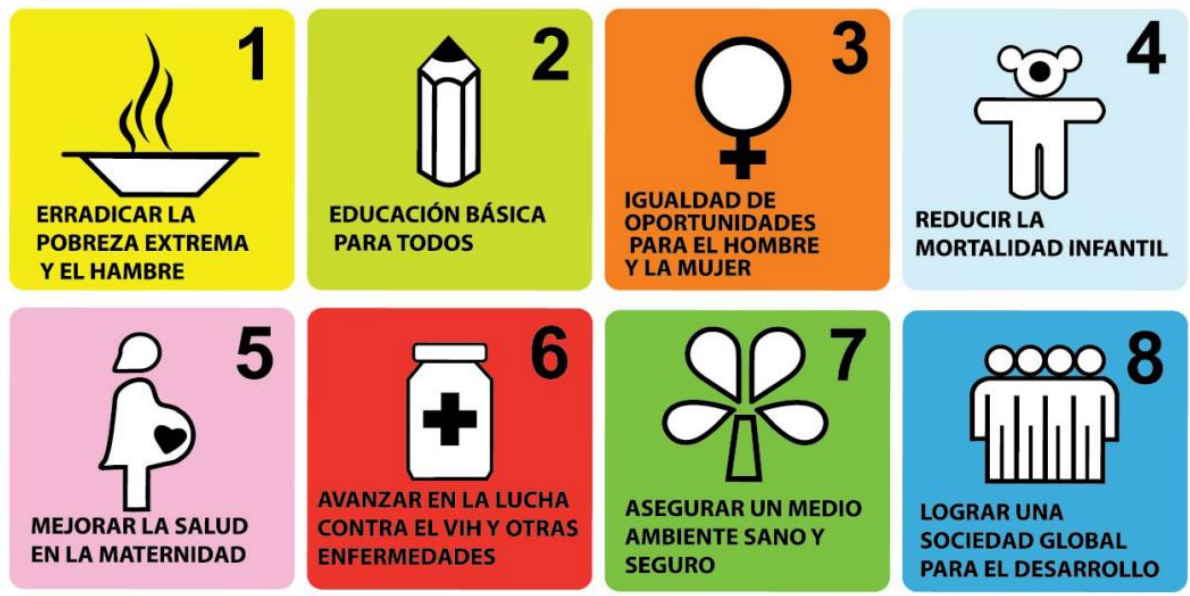

Figura 2. Objetivos del milenio.

Fuente: http://www.onu.org.mx/agenda-2030/objetivos-de-desarrollo-del-milenio/

Los MDG's se consolidaron finalmente como ocho hacia los cuales existió diferente grado de compromiso:

1. Erradicar la pobreza extrema y el hambre,

2. Lograr la enseñanza primaria universal,

3. Promover la igualdad de género y empoderar a la mujer,

4. Reducir la mortalidad infantil,

5. Mejorar la salud materna,

6. Combatir el vih/sida paludismo y otras enfermedades,

7. Garantizar la sostenibilidad del medio ambiente,

8. Fomentar una alianza mundial para el desarrollo.

Los objetivos 1 a 6 quedaron definidos con unas metas claras, incluso el objetivo 7 en parte se correspondía con el sistema de gestión por resultados, sin embargo, el objetivo 8 se mostró más difícil de clarificar y es que las críticas a los objetivos destacaban las altas y claras metas para los objetivos de países en desarrollo, y la ambigüedad que rodeaba aquellos que entrañaban implicación de los países desarrollados.

En estas críticas a los MDG's ya se advierte esta oposición hacia unas metas de consenso internacional que se alejaban de una sostenibilidad ecosistémica. Si se analiza con detenimiento la interpretación de la sostenibilidad que subyace en los objetivos llegamos a ver la brecha que estos establecen entre los países en vías de desarrollo y los desarrollados en cuanto a implicación en el proceso de cambio. Un 
ejemplo de esta visión sesgada es la definición de pobreza, en lugar de inequidad, término que incide en los países en vías de desarrollo pero que deja fuera muchas otras desigualdades sociales también presentes en países desarrollados(PARNEL 2016), y también la definición en el objetivo 6 de enfermedades concretas, dejando fuera muchas otras que en algunos países llegan a tener mayor repercusión ${ }^{18}$.

Esta interpretación realizada por las Naciones Unidas, que influyó a todas las naciones, tuvo gran trascendencia respecto a lo que posteriormente se llevó a cabo, y es que la simplificación en las metas a la que hacíamos referencia anteriormente ya dio pie a la consolidación de posturas que finalmente se tornaron ineficaces en la aproximación hacia la sostenibilidad. A pesar de todos los inconvenientes, debemos destacar igualmente el avance que suponen los Objetivos del Milenio en la apertura a la participación. La incorporación de otros actores, como el Banco Mundial, el Fondo Monetario Internacional (FMI), y otras agencias de la OECD, pretendía demostrar la voluntad de coordinación mundial contra la pobreza con los grandes actores económicos.

Debemos señalar que fue clave la interpretación que estos organismos internacionales efectuaron del desarrollo sostenible por ser estos la referencia internacional del discurso económico. La Organización Mundial del Comercio en su internacionalización del comercio olvidó incorporar en la valoración de las mercancías el coste medioambiental y social, el Fondo Monetario Internacional basándose en los principios del Consenso de Washington, fomentó el libre comercio, la inversión y el sector financiero, la desregulación, y la privatización, sin tener en cuenta otra clase de principios que atendieran a los problemas de países menos desarrollados (VILLAFÁÑEZ SAGARDOY 2015). Y es que al igual que Naciones Unidas orientaba en la escala internacional, otras agencias también ejercían su influencia discrepando a veces las interpretaciones entre éstas ${ }^{19}$.

Por tanto, a pesar de esta voluntad de coordinación internacional, el crecimiento económico siguió siendo el sistema aceptado y en que se confiaba para alcanzar un equilibrio que, sin embargo, se veía cada vez más lejano. La coherencia interinstitucional mundial aún no parecía conseguida, no existía tal y como hemos visto consenso en las orientaciones desarrolladas.

Respecto a la Unión Europea, en el ámbito comunitario el alcance de la dimensión social también estuvo sometido a debate. Podía considerarse que el equilibrio social iba a producirse de forma espontánea con el devenir del progreso, o

\footnotetext{
${ }^{18} \mathrm{En}$ el artículo de Smith y Taylor queda patente la disfunción entre el Objetivo 6 de los Millenium Development Goal, y las necesidades derivadas de las enfermedades tropicales. El NTP, o Neglected Tropical Diseases hace referencia a esta discrepancia entre las enfermedades descritas por las Naciones Unidas y aquellas que consideran están afectando gravemente en algunos países. Estas disfunciones son las que provocarán el cambio de nomenclatura de los objetivos tras su revisión. Smith, J., \& Taylor, E. M. (2013). MDGs and NTDs: Reshaping the global health agenda. PLOS Neglected Tropical Diseases, 7(12), e2529. En la web: http://dx.doi.org/10.1371/journal.pntd.0002529. (SMITH and TAYLOR 2013).

19 La apuesta por proyectos que se centraban más la preocupación en préstamos de alto presupuesto que en mejoras de infraestructuras que en la voluntad de cambiar la estructura urbana, la economía, o el modo de funcionamiento de la ciudad. PARNEL, Susan, Defining a Global Urban Development Agenda, World Development Vol. 78, pp. 529-540, 2016. (PARNEL 2016).
} 
que era necesaria una homogeneización previa que mantuviera las cuestiones sociales dentro de unos márgenes de equilibrio. La Unión Europea pasó por varios escenarios, el inicio tiene que ver con el Tratado Constitutivo de la Comunidad Económica Europea, firmado en Roma el 25 de marzo de $1957^{20}$ correspondiéndose con la confianza en el progreso y por tanto con el que algunos denominaron el periodo del olvido (PEDROSA SANZ 2009).

Posteriormente, al igual que el panorama internacional Europa también se vio abocada a la inclusión de la dimensión social, y en la Cumbre de Paris de 1972, se encarga a la Comisión Europea la elaboración de un programa social. En 1974 se adopta el primer "Programa de Acción Social"(QUESADA DÍEZ 2010), y a partir de ahí, la dimensión social continuó, lenta pero progresivamente consolidándose en Europa de forma que la unión que nació inicialmente como económica, pasaba a ser socioeconómica. Esta incorporación no estuvo exenta de dificultades, pues tanto el cambiante contexto político de los estados miembros, como las crisis económicas y la competencia internacional hicieron que la incorporación de lo social no experimentara un crecimiento continuo sino con altibajos, y grandes problemas de implementación.

El Tratado de Ámsterdam de octubre de 1997 supuso la aceptación por parte de todos los estados miembros de la integración del Acuerdo sobre política social en el texto del Tratado. Posteriormente, el Consejo europeo de Helsinki de $1999^{21}$ asume la Declaración del Milenio consolidando la necesidad de preparar nuevas propuestas para avanzar hacia una política de desarrollo sostenible multidisciplinar, que integrara el punto de vista económico, social y ecológico. A pesar de que la visión multidimensional adquirió cada vez mayor énfasis a escala comunitaria, desde el ámbito internacional la Cumbre de Johannesburgo de 2002 representó un fracaso en la incorporación de la dimensión social, acusándola todos los balances de ser mera declaración retórica respecto a las anteriores, por la falta de compromisos y nuevos fondos en los documentos de acuerdo.

La Unión Europea no representó un gran avance respecto de la visión internacional y, al igual que ésta, planteó una dimensión social sesgada y con una marcada orientación hacia el crecimiento económico. El Tratado de Lisboa de $2007^{22}$

\footnotetext{
${ }^{20}$ El Tratado de Roma en "el Título III de su Tercera Parte está dedicado íntegramente a ella (artículos 117 a 128). Hace referencia a la necesidad de promover la mejora de las condiciones vitales y laborales de los trabajadores (art. 117) y una colaboración estrecha entre los Estados nacionales en el ámbito social, particularmente en las materias relacionadas con el empleo, el derecho del trabajo y las condiciones de trabajo, la formación y el perfeccionamiento profesionales, la seguridad social, la protección contra los accidentes de trabajo y las enfermedades profesionales, la higiene del trabajo, el derecho de sindicación y las negociaciones colectivas entre empresarios y trabajadores (art. 118). Además, crea un Fondo Social Europeo para fomentar, dentro de la Comunidad, tanto las oportunidades de empleo como la movilidad geográfica y profesional de los trabajadores y contribuir a la elevación del nivel de vida (art. 123)". (PEDROSA SANZ 2009)

21 En las conclusiones de la presidencia de la reunión del Consejo Europeo de Helsinki, en el apartado III correspondiente a Una economía competitiva, generadora de empleo y sostenible, encontramos en el punto 50 la alusión al llamamiento de la elaboración de estrategias por parte de la comisión. Reunión del Consejo Europeo de Helsinki de diciembre de 1999. (CONSEJO EUROPEO 1999) Oficina de Publicaciones Oficiales de las Comunidades Europeas, (1999). "Conclusiones de la presidencia de la reunión del Consejo Europeo de Helsinki", Luxemburgo, Europarl.

22 "El Tratado de Lisboa de 13 de diciembre de 2007, tras confirmar en su Preámbulo su adhesión a los derechos sociales fundamentales definidos tanto en la Carta Social Europea de 1961 como en la Carta comunitaria de los
} 
será el que en última instancia refuerce la dimensión social en la Unión Europea, aunque como veremos más adelante no fue suficientemente efectiva como para revertir las tendencias negativas. Y es que la política social se convirtió en un factor de productividad que ayudaba a la competitividad económica más que a la igualdad y equidistribución.

Podemos afirmar que finalmente la Unión Europea apostó por la interpretación de Brundtland de desarrollo sostenible como objetivo fundamental y a largo plazo. Lejos quedaban las voces que clamaban por el eslogan "Un solo pueblo" y los principios de igualdad que demandaban las Naciones Unidas. Y es que al igual que los MDG's fueron poco definitivos en los temas que conciernen a los países desarrollados, los temas sociales europeos en su aplicación a los estados miembros dependieron más de la voluntad de implicación nacional en ámbitos sociales que de la imposición de unos principios europeos de igualdad, y por tanto presentaron una implementación desigual.

Teniendo en cuenta la existencia de estos desequilibrios descritos, no cabe duda de que el territorio, contenedor que de algún modo refleja estas tendencias internacionales y europeas también iba a verse influido por este recorrido hacia el desarrollo sostenible. Y por tanto, tras la incorporación de las dimensiones medioambiental y social se dio paso a la dimensión territorial de la sostenibilidad. Las ciudades con su crecimiento y concentración poblacional se afianzaron como elementos clave en el devenir de la sostenibilidad global. Y por tanto, el territorio y como los sistemas urbanos influían en la escala global, se convirtió en tema recurrente en los documentos, y la interpretación de esta interacción, en la clave de la lectura en términos sostenibles de la dimensión territorial. En el siguiente apartado se desarrolla en profundidad como esta visión multidimensional de la sostenibilidad influyó en el ámbito territorial.

\section{CONSECUENCIAS DEL DESARROLLO SOSTENIBLE EN LA DIMENSIÓN URBANA}

La importancia que comenzaban a adquirir los temas urbanos en el avance hacia el desarrollo sostenible impulsó la incorporación de la dimensión territorial ${ }^{23}$ en la lectura multidimensional. Debido al grado de concentración poblacional y de consumo de recursos en los sistemas urbanos estos fueron considerados como uno de los principales retos en la conquista de los objetivos sostenibles, y por tanto, las ciudades comenzaron a atraer todas las miradas como motores de cambio.

\footnotetext{
Derechos Sociales Fundamentales de los Trabajadores de 1989, y sustituir en el TUE a la Comunidad Europea por la Unión Europea (art. 1), refuerza la dimensión social europea." (PEDROSA SANZ 2009)

23 "Las ciudades y los pueblos han sido motores de crecimiento y focos de civilización, y han favorecido la evolución del saber, la cultura y la tradición, así como de la industria y el comercio. Los asentamientos urbanos bien planificados y administrados encierran la promesa del desarrollo humano y de la protección de los recursos naturales del mundo por su capacidad de sustentar a gran número de personas limitando al mismo tiempo sus efectos en el medio ambiente. Para superar los problemas actuales y velar por que no se detenga la mejora de las condiciones económicas, sociales y ambientales de los asentamientos humanos, debemos comenzar por reconocer las dificultades a que se enfrentan las ciudades y los pueblos." (NACIONES UNIDAS 1996)
} 
En el ámbito internacional, a pesar de que durante los años 70 aún se mantenía un elevado porcentaje de población rural, desde la ONU ya se venía haciendo hincapié en la necesidad de mejorar los asentamientos humanos como elemento clave hacia la sostenibilidad. La "Declaración de Vancouver sobre asentamientos urbanos", entendiendo que el desarrollo económico y social era indisociable de los problemas asociados a los sistemas urbanos, puso de manifiesto la importancia de estos para alcanzar el desafío global ${ }^{24}$.

Continuando la incorporación de la dimensión urbana, en 1975 se estableció la Fundación de las Naciones Unidas para el Habitat y los Asentamientos Humanos, primer órgano dedicado a los temas de urbanización. Sin embargo, en este primer estadio fue escasa la financiación, y muy orientada a los países en vías de desarrollo. $Y$ es que al igual que en la dimensión social parecían empeñarse en mantener una brecha entre los países en vías de desarrollo y los países desarrollados, en los aspectos territoriales también parecían establecer metas claras para unos y difusas para otros, como si los problemas territoriales dependieran del ajuste de solo algunos países en vez de depender de un cambio de escala global. Si la sostenibilidad trataba de modificar un sistema que se basaba en el consumo de recursos por encontrarse este llegando a su obsolescencia. Si esa era la premisa inicial, es obvio que los asentamientos de los países desarrollados tienen que decir casi más que los asentamientos en países en vías de desarrollo a la hora de alcanzar el nuevo equilibrio por ser los principales consumidores de recursos.

Poco a poco, con la "Agenda Habitat" y la "Declaración del Milenio", la dimensión urbana fue adquiriendo más peso, hasta llegar a consolidarse en 2002 como programa dentro de la ONU dando lugar al "Programa de las Naciones Unidas para los Asentamientos Humanos". Los problemas de asentamiento en países en vías de desarrollo se consolidaron como eje central. Sin embargo, el creciente interés en los temas urbanos contrastó nuevamente con los resultados obtenidos. Y es que a pesar de que el resto de organismos especializados Banco Mundial, Fondo Monetario Internacional firmaron acuerdos en 1947 con la ONU para coordinar su actividad, la "posibilidad" y no la "obligatoriedad" de coordinación hizo que en cierto modo coexistieran la visión sostenible con una realidad que se basó fundamentalmente en el crecimiento económico. El Banco Mundial fue ampliamente criticado por la financiación a través de la Corporación Financiera Internacional de operaciones inmobiliarias con dudoso valor para la recuperación de los países en vías de

\footnotetext{
24 "Adopción de políticas y estrategias de asentamientos humanos que sean audaces, significativas y eficaces, y que se ajusten en forma realista a las condiciones locales; la creación de asentamientos más habitables, atractivos y eficientes erigidos a escala humana y que brinden justicia social a cada persona; la creación de posibilidades para la participación efectiva de todos los habitantes en la planificación, construcción y administración de los asentamientos humanos; la elaboración de criterios nuevos para la formulación y aplicación de programas de asentamientos en que se empleen más adecuadamente la ciencia y la tecnología; la utilización de medios de comunicación sin precedentes para el intercambio de conocimientos y experiencia en la esfera de los asentamientos humanos; la consolidación de vínculos de cooperación internacional, tanto a escala regional como mundial" Documento de las Naciones Unidas Habitat, "Declaración de Vancouver sobre asentamientos humanos", de la Conferencia de las Naciones Unidas sobre asentamientos humanos, 31-05-1976.(NACIONES UNIDAS 1976)
} 
desarrollo ${ }^{25}$, que nuevamente reflejaban intenciones de concentración económica más que de equidistribución. $Y$ es que las intervenciones sirvieron más a la consolidación de entes económicos globales, que a la mejora global de la sostenibilidad.

Conscientes de estas incoherencias en los años 80 se desarrollan las Políticas de Salvaguardia (IEG WORLDBANK 2010) que, en continua revisión, pretendieron defender el medio ambiente y los derechos sociales para evitar que las inversiones del Banco Mundial fomentaran la pobreza, la exclusión, y los problemas medioambientales. Sin embargo, la oposición a los proyectos desarrollados por éste continuó por, tal y como describen sus críticos, en muchas ocasiones no responder estos a las necesidades propias del país receptor (BRETTON WOODS PROJECT 2009). Y es que los organismos especializados y los estados miembros incorporaron una visión sostenible que pretendió aumentar el crecimiento económico y desarrollo, nuevamente sin tener en cuenta que estas premisas eran fundamentales solo en los países en vías en desarrollo y no tanto como clave universal (PRADO LALLANDE 2006), y que por encima de esto se encontraban las necesidades sociales.

Para acallar las críticas estos hicieron creer que tímidamente se producía un viraje hacia la sostenibilidad social. El enfoque desarrollado por UNICEF y denominado "Ajuste de rostro humano", a través del cual se denunciaban las graves consecuencias a que podía dar lugar la reforma estructural propuesta por el FMI y el Banco Mundial, proponía un crecimiento que no dañara a los grupos vulnerables. Se les pidió que tuvieran en cuenta la pobreza como parte de las reformas estructurales, a la vez que mayor compromiso a los estados miembros hasta entonces con una colaboración poco intensa. Sin embargo, las reformas en las instituciones fueron a tratar de paliar los daños ocasionados en lugar de evitar que estos se produjeran.

Este conflicto refleja nuevamente la persistencia de las tensiones entre sostenibilidad y desarrollo sostenible también en la dimensión urbana. Esta división de objetivos entre países en desarrollo y desarrollados trata de afrontarse en la revisión de los MDG's. Estos entran en juego nuevamente en tanto su revisión implicó la toma de conciencia internacional de la importancia de las ciudades a escala global en el avance hacia el desarrollo sostenible.

La revisión de los MDG's, en la "Conferencia de las Naciones Unidas sobre el Desarrollo Sostenible" de Río de Janeiro 2010, dio lugar a los "Objetivos de

25 VILLAFAÑEZ SAGARDOY, Diego, "Voces críticas con el Fondo Monetario Internacional y el Banco Mundial", Derecho y Cambio social, ISSN 2224-4131, p. 1-15. La ONG Turismo Equitativo Hindú ha publicado en 2012 un informe (Las instituciones financieras internacionales y el turismo) en el que se destacan las preocupaciones sobre los proyectos turísticos del Banco, pues "visten su apoyo para el turismo y los proyectos de infraestructura con el lenguaje del desarrollo sostenible, del medio ambiente y de la preservación de la cultura, la creación de empleo y el desarrollo económico local, pero tienen un nefasto historial de modelos de desarrollo turístico a gran escala en los países en desarrollo, los cuales han producido impactos negativos visibles". (VILLAFÁÑEZ SAGARDOY 2015). 
desarrollo sostenible"(NACIONES UNIDAS 2018). Lo más reseñable de esta revisión fue la incorporación de un nuevo objetivo referente a "Ciudades y comunidades sostenibles". Este SDG que se corresponde con el número 11, viene a ser el resultado de las continuas investigaciones científicas y documentos que han venido haciendo referencia de la importancia de las ciudades en la consecución de los objetivos de sostenibilidad.

Este nuevo objetivo incorporaba el "derecho a la ciudad" o "Right to the city" (REVI and ROSENZWEIG 2013) y la ciudad como oportunidad. El "Right to the city" entendido como el derecho a cambiar nuestras vidas cambiando las ciudades, se concibe como una respuesta colectiva a la necesidad de reorganizar el proceso de urbanización. Por otro lado, la concentración poblacional en las ciudades se entiende como la oportunidad de poder solucionar las conductas insostenibles a través de la actuación en estos polos de concentración económica, social, cultural, medioambiental que a su vez son los que ejercen influencia en el resto de territorios. Por tanto podemos decir que en cierto modo se evoluciona en esta revisión de la tradicional asociación de los problemas de hábitat con los países menos desarrollados a una visión más global. Para ello se pretende que veamos las ciudades como Socio-Ecological Systems, o también llamados SES's, entendiendo que estas son un sistema en sí mismas, pero que a su vez funcionan junto con otras ciudades y territorios como sistemas de escala superior que han de ser tenidos en cuenta.

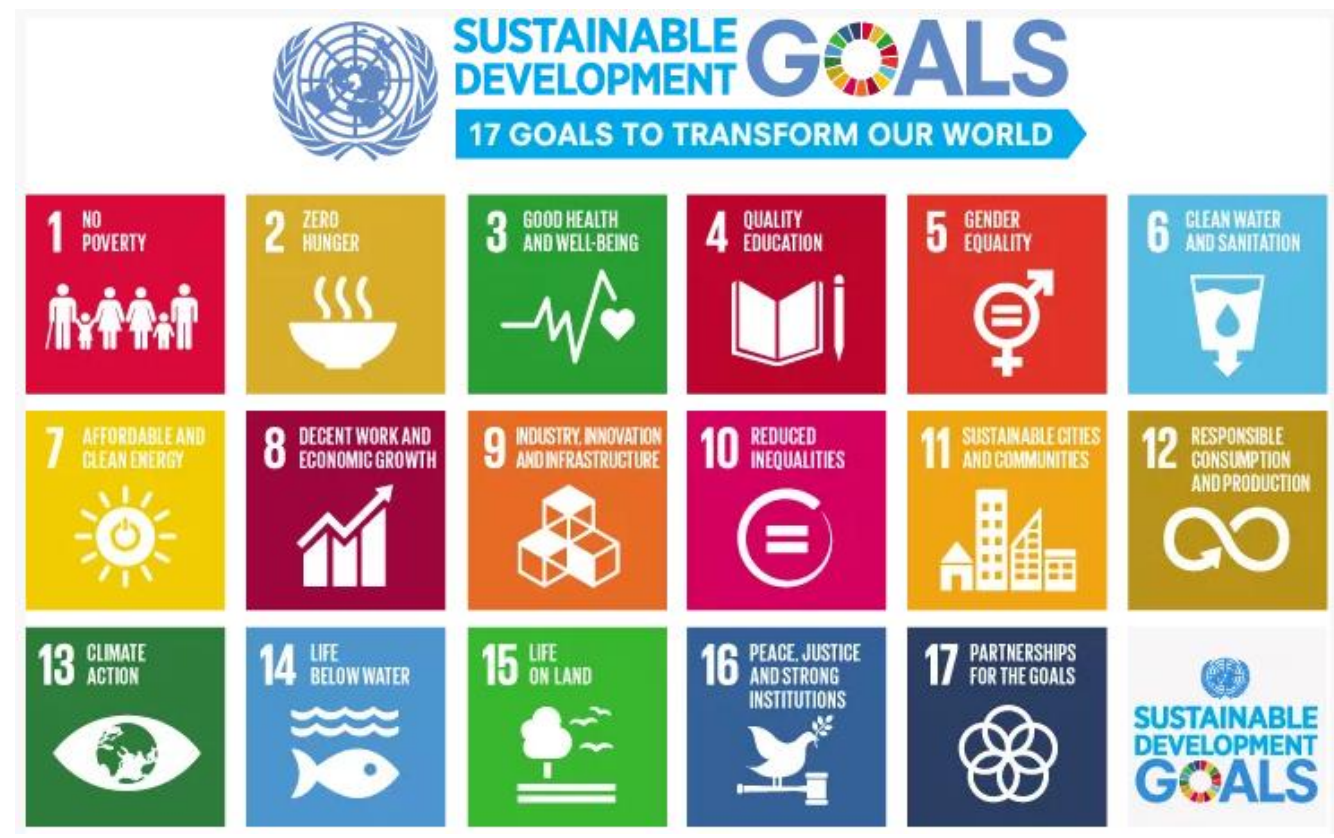

Figura 3. Objetivos de Desarrollo Sostenible.

Fuente: https://www.un.org/sustainabledevelopment/sustainable-development-goals/

Sin embargo, al igual que con la definición de desarrollo sostenible, nuevamente nos encontramos con el problema de la abstracción que cada individuo realice del planteamiento propuesto por las Naciones Unidas en este SDG 11. Si bien es cierto 
que se le concede mayor peso a las ciudades esto no implica que debamos olvidar el resto del territorio (URBAN AGE CITA). Esta apuesta por la sostenibilidad de las ciudades puede derivar en la malinterpretación de que éstas son el fin último, cuando realmente se pretende que sean el motor para alcanzar esa sostenibilidad global $^{26}$. Es por tanto de gran importancia ver de qué forma los objetivos definen con exactitud lo que plantean a para el ámbito internacional como ciudad sostenible.

El reto propuesto era de gran envergadura pues al igual que en otras ocasiones existen diferentes intereses respecto a lo que cada país pretende conseguir con la aplicación de los SDG's. Estos intereses afloran con mayor virulencia cuanto más precisa pretenda ser la definición del objetivo, y del consenso dependía la definición que finalmente influirá en todas las escalas. Ya desde el inicio del planteamiento de la sostenibilidad se percibe que existen intereses contradictorios, y la falta de concreción del objetivo onceavo deja abierta la posibilidad de que cada estado en la elaboración de futuros documentos interprete la sostenibilidad urbana de forma diferente.

Estas disfunciones entre la sostenibilidad urbana y la interpretación del desarrollo urbano sostenible que se consolidó finalmente ya quedan de manifiesto en la Agenda Urbana Habitat III, celebrada en Quito en 2016. Centrada en los temas urbanos y territoriales ya hace referencia a que: "4. Las acciones emprendidas hasta el momento distan mucho de ser una respuesta a estos y otros desafíos existentes y nuevos,...". Sin embargo, y a pesar de la necesidad de que se produjera el desacoplamiento entre bienestar y crecimiento las referencias en la agenda a esta vinculación son aún frecuentes refiriéndose a que "4...es necesario aprovechar las oportunidades que presenta la urbanización como motor impulsor del crecimiento económico, social y cultural sostenido e inclusivo, y de la protección del medio ambiente, así como de sus posibles contribuciones al logro de un desarrollo transformador y sostenible." (NACIONES UNIDAS 2016).

Buscando "5...reorientar la manera en que se planifican, se diseñan, se financian, se desarrollan, se administran y gestionan las ciudades y los asentamientos humanos," (NACIONES UNIDAS 2016) la Nueva Agenda Urbana buscaba "poner fin a la pobreza y al hambre en todas sus formas y dimensiones, a reducir las desigualdades, promover un crecimiento económico, sostenible, inclusivo y sostenido, lograr la igualdad de género y el empoderamiento de todas las mujeres y las niñas a fin de aprovechar plenamente su contribución vital al desarrollo sostenible, mejorar la salud humana y el bienestar, fomentar la resiliencia, y proteger el medio ambiente" (NACIONES UNIDAS 2016), la perspectiva urbana sigue haciendo referencias continuas al crecimiento, sin embargo contrasta con las

\footnotetext{
26 Debido a que lo que sucede dentro de las ciudades impacta a las naciones de manera económica, social y ecológica, Hábitat III tiene que posicionar las ciudades como el centro de todo desarrollo. Esta posición de las "ciudades como impulsoras del desarrollo" ya es evidente en la Agenda Urbana Nueva Africana y es ampliamente promovida por la Alianza de Ciudades, pero es poco probable que sea asumida por muchas de las ONG y será resistida por los gobiernos nacionales que continúan Para promover una visión de desarrollo sostenible rural o espacialmente neutral. PARNEL, Susan, Defining a Global Urban Development Agenda, World Development Vol. 78, pp. 529-540, 2016. (PARNEL 2016)
} 
perspectivas de reequilibrio y por lo tanto se la describe como una agenda con visiones contrapuestas (TIRADO 2016).

La Unión Europea no permanece ajena a esta apertura a las cuestiones territoriales. Esta tendencia internacional a la incorporación de la dimensión urbana en su afán por extender el alcance más allá de los temas medioambientales ayudó a que finalmente los temas urbanos adquirieran mayor peso, llegando también a tener repercusión en los documentos elaborados por la Unión Europea.

El creciente interés por la superación de las dificultades que presentan los asentamientos apreciada en los escritos internacionales es la causa de que a nivel europeo se produzca el desarrollo de los documentos que conforman el acervo urbano o "urban acquis"27. Y es que a pesar de la ausencia de competencias de la UE en cuestiones urbanas, competencia formal de las autoridades nacionales, regionales y locales, la necesidad de tratar estos aspectos desde una perspectiva comunitaria se hizo evidente.

La europeización ${ }^{28}$ llevó a la integración de los temas económicos de todos los estados miembros, y las grandes repercusiones que esta unión generó a otros niveles, derivó en la necesidad de estudiar las cuestiones medioambientales, sociales como ya hemos visto, y también las de índole territorial a escala comunitaria como veremos a continuación ${ }^{29}$.

La creciente influencia de las ciudades llevó a la creación del "Urban Development Group ${ }^{\prime 30}$ para promover el desarrollo sostenible en las ciudades de la Unión Europea a través de este grupo de trabajo permanente. Además, comienzan a llevarse a cabo Reuniones Informales de Ministros responsables de la Ordenación Territorial y Políticas Urbanas, de las cuales la primera tuvo lugar en Nantes en 1989. Sin embargo, no será hasta 1990, momento en que la Comisión Europea publicó el "Green Paper on the Urban Environment" (COMISIÓN EUROPEA 1990), cuando a escala comunitaria comenzó a hablarse de la problemática común de todas las ciudades europeas y se intenta superar los enfoques sectoriales para solventar los problemas del medioambiente examinando no solo el problema

\footnotetext{
27 "Urban Acquis" hace referencia a toda la serie de documentos europeos que representan el enfoque común. Más información en los documentos: (URBAN-Future 2005)(GONZALEZ MEDINA 2013)

28 Entendemos europeización como: Procesos de a) construcción, b) difusión y c) institucionalización de reglas, procedimientos, paradigmas de políticas, estilos, "modos de hacer las cosas" formales e informales y creencias y normas compartidas que primero son definidos y consolidados en la elaboración de las políticas y el juego político de la UE y luego incorporados en la lógica del discurso, identidades, estructuras políticas y políticas públicas domésticas. RADAELLI, C.M., «The Europeanization of Public Policy», en MARISCAL, Nicolás, "Repensando la europeización", Cuadernos Europeos de Deusto, ISSN: 1130 - 8354, Núm. 49/2013, Bilbao, págs. $19-46$. (RADAELLI 2003)

${ }^{29}$ La presión sobre el territorio fomento la implicación europea. El $80 \%$ de la población europea se encontraba ya en 1997 viviendo en ciudades, característica que hacía de Europa por aquel entonces el continente más urbanizado del mundo. CICRED.

${ }^{30}$ El Urban Development Group era un grupo de trabajo permanente en el que estaban representados además de los 27 Estados Miembros, la Comisión, el Parlamento Europeo y otras instituciones con relevancia en temas urbanos EIB, EEA, CoR, EESC, CEMR,EUROCITIES, EFAP, ACE, ECTP-CEU, EUKN, URBACT, etc. Información de la web:
} 
medioambiental sino su raíz social y económica, y su especial concentración en los entornos urbanos.

Unos años más tarde, "La Carta de Aalborg" o "Carta de las Ciudades Europeas hacia la Sostenibilidad" (HERNANDEZ AJA 2003) ${ }^{31}$ firmada en 1994 por 80 autoridades locales viene a consolidar el compromiso con la Agenda 21 Local internacional (NACIONES UNIDAS 1992b), y por tanto la consolidación de la sostenibilidad al ámbito urbano local, dando lugar posteriormente a la "Campaña Europea de Ciudades Sostenibles" de 1996. Este documento de consenso viene a significar que las ciudades reconocían su influencia en el deterioro medioambiental. Entendiendo que los recursos eran el tope al crecimiento económico, creyeron necesario un enfoque en el que la ciudad como ecosistema urbano alcanzara el equilibrio. Era necesario abandonar el sistema económico-sistemático para caminar hacia el ecológico-sistemático de la gestión urbana ${ }^{32}$.

El Programa 21(NACIONES UNIDAS 1992b), elaborado con objeto de la Conferencia de Río de Janeiro en 1992, puso de manifiesto la necesidad de trascender el ámbito local, y es que las interacciones entre ciudades alcanzaban la escala mundial y una reestructuración exclusivamente local no sería capaz de influir estas dinámicas de la globalización que fortalecían y debilitaban a las ciudades con procesos que iban más allá de las posibilidades del control local. A pesar de esta visión global, la incorporación de la sostenibilidad a los sistemas urbanos siguió un recorrido muy ligado al ámbito local pero con poca incidencia respecto a las externalidades negativas más allá del propio sistema, influencias de las que ya por aquel entonces se conocía su existencia.

Esta urgencia de control en escalas superiores no era desconocida para la Unión Europea, las ciudades ya eran consideradas por aquel entonces las principales fuentes de riqueza por ser estas la principal contribución al PIB y de ahí su importancia estratégica, sin embargo esta capacidad de ser motor de desarrollo económico era proporcional también a la capacidad de éstas para dinamitar el equilibrio medioambiental y social si este no tenía en cuenta el precio del desarrollo (COMISIÓN EUROPEA 1997). Y es que los retos a los que se enfrentaban tanto por la tendencia demográfica como por la economía global suponían un difícil desafío para el equilibrio. No debemos olvidar que la dualidad entre crecimiento cero y desarrollo, y entre crecimiento económico o bienestar social había sido constante en

\footnotetext{
31 La Carta de Aalborg o Carta de las Ciudades Europeas hacia la Sostenibilidad, fue un documento firmado en Aalborg, Dinamarca en la Conferencia europea sobre ciudades sostenibles celebrada entre los días 24 y 27 de mayo de 1994 bajo el patrocinio de la Comisión Europea y la ciudad de Aalborg, y organizada por el Consejo Internacional de Iniciativas Ambientales Locales. Con la firma de la Carta, las ciudades, poblaciones menores, y unidades territoriales de Europa se comprometían a participar en las iniciativas locales del Programa 21 , y a desarrollar programas a largo plazo hacia un desarrollo sostenible, a la vez que iniciaron la Campaña de ciudades europeas sostenibles. HERNANDEZ AJA, Agustín, Carta de las ciudades europeas hacia la sostenibilidad. La carta de Aalborg, Madrid, noviembre de 2003, en la web: http://habitat.aq.upm.es/doc.html [06/12/2016]. (HERNANDEZ AJA 2003) ${ }^{31}$

32 Con económico-sistemático y ecológico-sistemático hacemos referencia a la toma de posición respecto de la visión económico-ambiental y la ecológico-ambiental respectivamente. Visiones contrapuestas que desarrollamos con mayor profundidad en el capítulo: 1. De la sostenibilidad al desarrollo sostenible en su proyección a las políticas públicas, subcapítulo: 1.1 La huella económica en el proceso de incorporación de la dimensión ambiental. Y cuya información se puede ampliar en la publicación: (ERIAS REY \& ÁLVAREZ-CAMPANA GALLO, 2007:83).
} 
la internacionalización de la dimensión ambiental, y de igual modo comenzaba a cobrar importancia en la dimensión urbana.

Continuando con la inclusión de la dimensión urbana, en mayo de 1997, la Comisión Europea publicó la comunicación "Hacia una política urbana para la Unión Europea" ${ }^{33}$ aproximándose a una interpretación europea de la dimensión urbana de la sostenibilidad. Existen, y son visibles en los documentos europeos, las influencias del viraje del que el desarrollo sostenible había sido objeto tras su definición consensuada en Brundtland. Influyendo a las tendencias europeas, la prosperidad económica se instauró así como una de las dimensiones con más peso en la incorporación de la sostenibilidad urbana argumentando que el crecimiento económico de las pequeñas y grandes ciudades era fundamental para el desarrollo urbano sostenible.

A raíz de esta interpretación quedó asociado el auge económico al bienestar en las ciudades, asociación que aun hoy en día es ampliamente utilizada y discutida. Debemos hacer hincapié en que también se perseveró en la necesidad de que esta fortaleza económica sirviera para fomentar el reequilibrio y la cohesión territorial, social y medioambiental, equilibrio que la lectura territorial de la Unión Europea cada vez manifiesta más irreal. Tenemos por tanto una visión multidimensional con claros referentes al crecimiento económico que la Unión Europea trató de implantar a escala comunitaria. A ese propósito contribuyeron el resto de documentos que consolidaron finalmente la política urbana como algo explícito en la Unión.

Aumentar la sensibilidad de todas las políticas europeas a lo urbano con este carácter multidimensional fue la misión del "Marco de Actuación para el Desarrollo Urbano Sostenible en la Unión Europea"34 de 1998 (MADUS). Para ello analizó las políticas a través de su repercusión en las ciudades velando por que facilitaran un desarrollo urbano integral ${ }^{35}$. Desde esta perspectiva de colaboración, el MADUS en cierto modo aposto por ciudades cabezas visibles capaces de obtener beneficios que mediante la redistribución permitieran consolidar el sistema policéntrico a la vez que mantener la capacidad competitiva mundial. El tiempo reveló que las técnicas de reequilibrio no fueron capaces de reajustar las grandes brechas entre territorios que

\footnotetext{
33 "La Comisión Europea recogiendo diversas iniciativas tanto de asociaciones de municipios como del propio Parlamento Europeo y el Comité de Regiones, ha preparado una comunicación, denominada "Hacia una política urbana para la Unión Europea" en la que examina diversas posibilidades de mejorar la habitabilidad de las ciudades así como incrementar la eficacia de las intervenciones comunitarias que afectan a las zonas urbanas.", MORATILLA, Fernando Esteban, Las políticas europeas para el desarrollo de las ciudades, Documentación oficial del comité Hábitat II España, Hoja informativa, Junio 1999, en la web: http://habitat.aq.upm.es/ch/g014_3.html [/12/2016]. (MORATILLA 1999)

${ }^{34}$ Documento elaborado por la Comisión Europea trató de influir en las políticas para hacerlas más "sensibles hacia lo urbano". No intentó especificar una solución urbana a nivel europeo, sino dar dimensión urbana a las políticas para solucionar las disfunciones económicas, sociales y medioambientales perceptibles por aquel entonces. COMUNICACIÓN DE LA COMISIÓN: "Marco de actuación de la Unión Europea para un desarrollo urbano sostenible", 1998. (COMISIÓN EUROPEA 1998)

${ }^{35} \mathrm{El}$ "Marco de actuación de la Unión Europea para un desarrollo urbano sostenible" constituye un primer paso para responder al compromiso que se expone en la comunicación en cuanto a "una mejor integración de las políticas comunitarias en materia de desarrollo urbano" a fin de "consolidar o recuperar el papel de las ciudades europeas como puntos de integración social y cultural, fuentes de prosperidad económica y desarrollo sostenible y cimientos de la democracia", COMUNICACIÓN DE LA COMISIÓN: "Marco de actuación de la Unión Europea para un desarrollo urbano sostenible", 1998. (COMISIÓN EUROPEA 1998)
} 
se estaban produciendo en la Unión Europea. En el territorio comunitario así como a nivel internacional al igual que la concentración económica la tendencia a la concentración territorial ha sido creciente a pesar de la visión policéntrica que pretendía mantener Europa.

La incorporación de los temas urbanos continuó siendo la tendencia. El "Tratado de Lisboa" de 2007(EUROPEA 2007) supuso la consolidación de la dimensión urbana en la política de cohesión de la Unión Europea. Entendiendo que los principios de cohesión que defiende la unión se veían comprometidos si no se incluía el ámbito territorial además del medioambiental y social a las políticas comunitarias, esta necesaria anexión de la dimensión urbana comenzó a hacer explicita la existencia de una política urbana europea.

Los Ministros responsables de Desarrollo Urbano de los Estados Miembros continuaron con la elaboración de documentos orientativos, consolidándose en 2007 el desarrollo urbano integrado, que ya había sido mencionado en el documento "Hacia una política urbana para la Unión Europea"36, como principio rector del camino hacia la planificación y puesta en marcha de estrategias sostenibles, y por tanto, como rector de las políticas urbanas europeas ${ }^{37}$. Este concepto que aglutinaba los factores medioambiental, social, cultural y económico en el desarrollo de los sistemas urbanos quedó documentado en la "Carta de Leipzig" de $2007^{38}$ que viene a representar junto con el "Tratado de Lisboa" la consolidación del proceso de europeización urbana (GONZALEZ MEDINA 2013).

La "Carta de Leipzig" encarnó el acuerdo y el compromiso de los estados miembros "a iniciar un debate político en sus países", "a utilizar la herramienta de desarrollo urbano integrado y la gobernanza asociada a su puesta en marcha", y a "fomentar la puesta en práctica de una organización territorial equilibrada" (COMISIÓN EUROPEA 2007a). Este acuerdo ministerial dejó asociada la política urbana a las políticas integradas de desarrollo urbano39, consolidando la

\footnotetext{
${ }^{36}$ Estas acciones contribuirán a concentrar más atención sobre: el desarrollo urbano integrado y sostenible que combine soluciones multisectoriales y suponga una inversión en capital humano y físico. Documento de la Unión Europea: Hacia una política urbana para la Unión Europea, p. 4. (COMISIÓN EUROPEA 1997)

37 Con la consolidación de la cohesión territorial en el Tratado de Lisboa se considera que se explicita la Política Urbana, por entenderse que los problemas de cohesión territoriales en cierto modo validan a la Unión Europea para establecer un marco urbano comunitario. Europea GONZALEZ MEDINA, Moneyba, "La europeización urbana a través de la política de cohesión", Revista CIDOB d’Afers Internacionals, nº104, p.133-154, 2013. (GONZALEZ MEDINA 2013)

${ }^{38}$ Documento en el que se recogieron los acuerdos de la Reunión de Ministros responsables de Desarrollo Urbano de los Estados Miembros, Documento de los Estados Miembros (2007). "Carta de Leipzig sobre ciudades europeas sostenibles" (COMISIÓN EUROPEA 2007a)

39 Entendidas como aquellas que tiene en cuenta todos los aspectos relevantes para el desarrollo urbano, coordinando los aspectos espaciales, sectoriales y temporales de las áreas clave de la política urbana, y con la esencial implicación de los agentes económicos, partes interesadas y el público en general, a escala nacional, regional y local, es decir, debían ser globales, coordinar a todas las personas e instituciones involucradas. En el documento además de acuñarse el termino de política integrada de desarrollo urbano, y su alcance, se recomienda a todas las ciudades europeas que comiencen a elaborar programas en esta línea: "Para nosotros, las políticas integradas de desarrollo urbano suponen la consideración justa y simultánea de todas las preocupaciones e intereses que puedan ser relevantes en materia de desarrollo urbano." "Recomendamos que las ciudades europeas elaboren programas integrados de desarrollo urbano para el conjunto de la ciudad." Documento de los Estados Miembros (2007). "Carta de Leipzig sobre ciudades europeas sostenibles", p.2. (COMISIÓN EUROPEA 2007a)
} 
interpretación multidimensional del proceso de incorporación de la sostenibilidad, la múltiple escala y la necesidad de coordinación. Con esto se pretendió intensificar la interacción entre la arquitectura y la planificación urbana y de infraestructuras, y la creación de espacios públicos atractivos y humanos, y lograr altos estándares en relación al medioambiente y la calidad de vida ${ }^{40}$.

Por otro lado, el "Tratado de Lisboa" representó la asunción de competencias territoriales para la cohesión por parte de la Unión Europea, y por tanto la explicitación de las políticas urbanas europeas. De este modo mientras que los primeros Proyectos URBAN ${ }^{41}$ encaminados a la regeneración urbana eran canalizados a través de la política de cohesión social y económica, a partir del Tratado de Lisboa, los fondos quedaron asociados a la cohesión territorial, entendiendo que ésta era tan necesaria como la social y la económica para alcanzar un desarrollo verdaderamente sostenible.

Consolidada ya la necesidad de definir con más rigurosidad un acercamiento común a la dimensión urbana europea se creó en la Dirección General Regional ${ }^{42}$ una unidad específica denominada Desarrollo Urbano y Cohesión Territorial para responder a las exigencias de alineación de las tendencias urbanas y territoriales. Por otro lado, la "Declaración de Toledo" del año $2010^{43}$ fue la encargada de concretar de forma más precisa los compromisos que los estados miembros habían adquirido con la "Carta de Leipzig". Y reafirmándose en la necesidad de enfrentarse a estos retos urbanos, los Ministros consideraron necesario establecer un marco para un entendimiento común, avanzando hacia un desarrollo urbano más inteligente, sostenible, y socialmente inclusivo, dando lugar a la Regeneración Urbana Integrada de la que nos ocuparemos a continuación.

\footnotetext{
40 Esta humanización de la ciudad partió de la necesidad de combatir la crisis que, después de amenazar a diferentes factores, llegó a afectar al ámbito social. De ahí que en la Cumbre de Río se estableciera en el primero de los principios la humanización como eje fundamental del desarrollo "Los seres humanos constituyen el centro de las preocupaciones relacionadas con el desarrollo sostenible. Tienen derecho a una vida saludable y productiva en armonía con la naturaleza." Naciones Unidas (1992). "Declaración de río sobre el medioambiente y el desarrollo.": 1-5 (NACIONES UNIDAS 1992a)

${ }^{41}$ Los proyectos URBAN eran proyectos financiados por la Unión Europea para favorecer el desarrollo sostenible de las ciudades y barrios en crisis.(DE GREGORIO HURTADO 2012)

42 Existía ausencia competencial en cuestiones urbanas dio lugar a conflictos entre los distintos ministerios tanto en los estados miembros como en el ámbito comunitario resultando finalmente la Dirección General Regional la encargada del control de la temática urbana.

${ }^{43}$ La declaración de Toledo es un documento que surge de la Reunión Informal de Ministros de Desarrollo Urbano de los países miembros de la UE, cuyo tema central fue la regeneración urbana integrada análisis de las ciudades europeas desde la múltiple dimensión de la sostenibilidad, entendiendo esta como una oportunidad para mantener un rumbo firme basado en los principios del desarrollo urbano integrado, inteligente, cohesivo, e inclusivo, como el único modo de conseguir una mayor competitividad económica, ecoeficiencia, cohesión social y progreso cívico en las ciudades europeas, así como de garantizar la calidad de vida y el bienestar de los ciudadanos en el presente y en el futuro. Documento de los Estados Miembros (2010). "Declaración de Toledo", p.11, (COMISIÓN EUROPEA 2010a)
} 


\subsection{La regeneración urbana integrada como marco de común entendimiento}

El reto al que se enfrentaban los países de la Unión Europea era la definición de los enunciados del desarrollo sostenible con la eficacia suficiente para marcar un rumbo firme para el conjunto de los países miembros. El "Documento de Referencia de Toledo sobre la regeneración urbana integrada y su potencial estratégico para un desarrollo urbano más inteligente, sostenible y socialmente inclusivo en Europa" ${ }^{\prime 4}$ del año 2010, documento asociado a la "Declaración de Toledo", pretendió llenar este vacío. Este documento incorporó una descripción de las características del enfoque integrado bajo el concepto de Regeneración Urbana Integrada (RUI), y por tanto se proclamó como la base comunitaria para el desarrollo de políticas urbanas integradas comprometiéndose las autoridades nacionales y comunitarias a promoverlo.

La RUI se planteó como la oportunidad para revalorizar, optimizar y preservar el capital urbano existente desde una perspectiva multidimensional. Apoyada por el Comité de las Regiones y el Consejo Económico y Social Europeo a través de los Dictámenes "El papel de la regeneración urbana integrada en el futuro del desarrollo urbano en Europa", y "La necesidad de aplicar un enfoque integrado a la regeneración urbana", ambos documentos aprobados en mayo de 2010 (ALONSO IBAÑEZ 2012), pretendieron generar respuestas a los problemas de los sistemas urbanos de manera convergente e igual eficiencia en todas las dimensiones cultural, medioambiental, social y económica.

Este enfoque se planteó como la base para la elaboración de estrategias encaminadas a "logar un modelo urbano más inteligente, más sostenible y socialmente más inclusivo, y en particular hacer frente a los retos urbanos actuales..." (COMISIÓN EUROPEA 2010c). Para tal fin, la RUI además de especificar el conjunto de dimensiones que intervienen en el modelo de desarrollo sostenible "...desde la clásica perspectiva de la múltiple dimensión de la sostenibilidad económica, social, ambiental, cultural y gobernanza ${ }^{45}$ desarrolló los factores sociales, económicos, medioambientales y culturales en profundidad ${ }^{46}$. Acometió la definición de qué entendía por cada una de estas dimensiones (medioambiental,

\footnotetext{
44 "Documento de Referencia de Toledo sobre la regeneración urbana integrada y su potencial estratégico para un desarrollo urbano más inteligente, sostenible y socialmente inclusivo en Europa", (COMISIÓN EUROPEA 2010c).

${ }^{45}$ Dimensión medioambiental: asociada al consumo de recursos, producción de recursos y emisiones. Dimensión social: asociada a la cohesión social y la integración, el desempleo, la pobreza. Dimensión económica: asociada a la competitividad global. Dimensión cultural: asociada a la identidad cultural y a la conservación y aumento del patrimonio. Documento de Referencia de Toledo sobre la regeneración urbana integrada y su potencial estratégico para un desarrollo urbano más inteligente, sostenible y socialmente inclusivo, Documento de los Estados Miembros (2010). "Documento de Referencia de Toledo sobre la regeneración urbana integrada y su potencial estratégico para un desarrollo urbano más inteligente, sostenible y socialmente inclusivo" p. 1-10. (COMISIÓN EUROPEA 2010c)

46 "A largo plazo, las ciudades no pueden satisfacer su función de motor de progreso social y crecimiento económico, tal y como se describe en la Estrategia de Lisboa, a menos que seamos capaces de mantener el equilibrio social, tanto intra como interurbano, de proteger su diversidad cultural y de establecer una elevada calidad en lo que al diseño, la arquitectura y el medio ambiente se refiere." Documento de los Estados Miembros (2007). "Carta de Leipzig sobre ciudades europeas sostenibles", p.2, (COMISIÓN EUROPEA $2007 a$ ).
} 
social, cultural y económica) que intervienen en el sistema urbano, acotando el significado de las mismas. Sin embargo, y a pesar de que apuesta por la integración de todas ellas para el desarrollo de futuras estrategias, en su definición deja fuera algunos aspectos importantes para una lectura sostenible.

Esta regresión se produjo en cierto modo debido a que la interpretación de las dimensiones era ya por aquel entonces dependiente de la aproximación a la regeneración urbana integrada realizada por la "Estrategia 2020"47, que estudiaremos a continuación. La estrategia definía unas líneas de acción concretas que se apoyaban en objetivos específicos para cada dimensión urbana lo que hizo ganar en concreción pero también perder en amplitud de miras.

No dejando de ser una aproximación incompleta a la sostenibilidad, lastró la "Declaración de Toledo" en su acercamiento al modelo integrado. El análisis de la definición de las dimensiones hace posible una lectura bastante clarificadora sobre el modelo que proponía por aquel entonces la Unión Europea a través de la RUI.

Desde el punto de vista medioambiental (COMISIÓN EUROPEA 2010c) se incidió en la necesidad de tener en cuenta "el consumo de recursos y la producción de residuos y emisiones, haciendo su apuesta por la reducción de emisiones de $\mathrm{CO}^{2}$, el aumento de las fuentes de energía renovables y los ecobarrios". Tal y como se pretendió en la "Estrategia 2020", trataba de equilibrar la balanza de recursos y emisiones apostando por la disminución de utilización de productos contaminantes o el cambio a recursos renovables. Los problemas urbanos se centran en aquellos aspectos que lastran el crecimiento de las ciudades europeas o que podrían hacerlo en un futuro por las limitaciones de recursos, y parecen dejar en un segundo plano la sostenibilidad global o como estas acciones podrían repercutir a nivel mundial.

Perdió en cierto modo la visión espacial de conjunto que los SDG's denominaban Socio-Ecologycal Systems o SES. La meta de "coordinación vertical" (COMISIÓN EUROPEA 2010c) entre todos los niveles, UE-nacional-regional-intermedia-local, pareció perder peso en favor de una visión medioambiental ligada al entorno urbano próximo. Esta tendencia europea, y que se repite en todos los países desarrollados, provocó que como vimos en la tabla correspondiente a la Agencia Europea de Medio Ambiente muchos de los valores medioambientales siguieran empeorando a nivel mundial a pesar de la aplicación de los principios sostenibles a las ciudades.

Desde el punto de vista social, también en la línea de la estrategia, la RUI apostó por "el impulso del empleo, la reducción del abandono escolar, y la reducción del riesgo de pobreza, haciendo gran hincapié en la renovación y rehabilitación y en desarrollar políticas de vivienda adecuadas como uno de los principales pilares para la consecución de estos objetivos". Esta interpretación que realiza el "Documento de Toledo" no proporcionaba una visión tan amplia del marco social como la planteada por la sostenibilidad, y aún aparece muy ligado a los temas de vivienda que fueron el inicio de la reflexión sobre asentamientos.

\footnotetext{
47 Documentos de orientación de las políticas que estudiaremos en el siguiente capítulo correspondiente a "El desarrollo sostenible en los instrumentos de orientación con influencia en las políticas urbanas".
} 
El papel del ciudadano como mero espectador, como objeto de análisis, difiere del papel activo del ciudadano concebido inicialmente. No será hasta más avanzados en el documento con "la definición de los elementos clave del enfoque integrado" cuando llegue a clarificarse esta necesidad de "coordinación horizontal" entre todos los actores que intervienen en el sistema urbano, haciendo hincapié en la necesaria implicación y participación del ciudadano. Por lo tanto, si nos ceñimos exclusivamente a la definición de la dimensión social, el ciudadano quedaba nuevamente apartado de la gestión urbana. Ésta será la dinámica que más se repitió en el proceso de transición a la sostenibilidad urbana. Veremos que la elaboración de documentos y herramientas de análisis y evaluación continuó siendo poco permeable a la participación. Reto que aún hoy continúa existiendo pues se muestran aún las dificultades para canalizar la participación ciudadana, y coordinar las decisiones de la participación con las que se derivan de documentos no vinculantes estratégicos, o vinculantes normativos(SUBIRATS HUMET 2017).

Desde el punto de vista económico es necesario destacar la importancia que el documento concedió a la competitividad global a través de la preservación de las características del modelo europeo de ciudad (COMISIÓN EUROPEA 2010c), en las que destaca "la cultura de la ciudad y al mantenimiento de la memoria colectiva". La RUI no dejó en ningún momento de ser una manera común de afrontar la crisis económica y financiera de la Unión Europea (ALONSO IBAÑEZ 2011). A pesar de que pretendía mantener el equilibrio y complementariedad que había permitido que todas las ciudades europeas subsistieran como una red de sistemas urbanos, la competitividad económica desintegró las interacciones.

La apuesta por el desacoplamiento del progreso económico y los recursos pasaba por la búsqueda de nuevas vías que permitieran mantener las condiciones de competitividad. Esta presión por mantener la posición en la escala mundial condicionó enormemente la transición hacia sistemas menos centrados en el crecimiento económico, y en cierto modo perpetúo la asociación entre bienestar y crecimiento. $Y$ es que si la competitividad se establece como fin en el desarrollo del I+D, empleo, formación, etc., no es de extrañar que el sistema territorial que hayamos obtenido se aleje de la voluntad de reequilibrio de la sostenibilidad ecológica.

Además de estos factores, la "Declaración de Toledo" también hacía referencia a la dimensión cultural. En ésta, la rehabilitación de edificios y la puesta en valor de espacios degradados cobraba especial importancia aludiendo a la estrecha relación entre la imagen de la ciudad y los valores de democracia, progreso cívico. Este factor quedó asociado a procesos de renovación de la ciudad existente, que dieron lugar finalmente a la renovación de áreas determinadas de la ciudad, visión considerada como veremos fragmentaria. Vemos por tanto que no existen grandes avances respecto al estudio de la ciudad existente y de las preexistencias urbanas centrándose el documento más en la ecoeficiencia que en aspectos de identidad cultural. 
La rehabilitación de viviendas se convirtió en uno de los pilares fundamentales en que derivó la aplicación del desarrollo sostenible en las ciudades ${ }^{48}$. El análisis de estas intervenciones pone de manifiesto que igualmente no se tuvo en cuenta en su redacción la "escala temporal" y "escala espacial", factores clave en la conquista de la visión integral que se pretendía alcanzar, repercutiendo muchas veces en que las intervenciones aparentemente sostenibles se mostraran finalmente contrarias a la finalidad buscada. A pesar de que aparece definido con detalle en el epígrafe "Hacia un entendimiento común del enfoque integrado en la regeneración urbana en particular y en el desarrollo urbano en general" (COMISIÓN EUROPEA 2010c), la repercusión en el largo plazo era un factor que aún no se analizaba con suficiente detenimiento.

Podemos decir viendo esta evolución que la lectura multidimensional a través de la RUI, aunque ya con matices que lastraban el proceso de aplicación a los sistemas urbanos, se encontraba consolidada en la Unión Europea. A pesar de las variaciones que a lo largo de los años fueron experimentando las definiciones de las dimensiones del desarrollo sostenible, la visión territorial multidimensional ya había sido incorporada a los documentos europeos con éxito a través de la Regeneración Urbana Integrada.

Jan Vranken, en la "Conferencia de Alto Nivel sobre Sostenibilidad Urbana y Regeneración Urbana Integrada en Europa" (BOUAZZA, TROVATO, and MATA 2010) señaló nuevamente como estrategia fundamental para la regeneración integrada "la apuesta por una mejora duradera de las condiciones de un área desde el punto de vista económico, físico, social y ambiental", es decir, la incorporación de todas las dimensiones en el estudio de un área concreta. Sin embargo, destacó la dificultad de encontrar los aspectos estratégicos clave para lograr los objetivos, reto clave que requiere de una buena gobernanza, último de los factores con dimensión urbana que aparecen mencionados en el "Documento de Referencia de Toledo".

Esta dimensión era en último término la encargada de controlar que las dimensiones medioambiental, económica, social y cultural se desarrollasen de forma adecuada asegurando la coordinación vertical, horizontal y transversal, teniendo en cuenta las escalas temporales y espaciales adecuadas en cada punto del territorio. La implicación gubernamental en la incorporación del desarrollo sostenible no fue destacable. Se puede afirmar que uno de los lastres de la sostenibilidad tuvo que ver con la falta de compromiso de los estados miembros y con la falta de estructuras administrativas capaces de tramitar los procesos que conlleva la incorporación de la sostenibilidad en todos los ámbitos de forma transversal. Hacer operativo el principio de sostenibilidad se convirtió en uno de los mayores retos (ALONSO IBAÑEZ 2012). Y es que un notable apoyo gubernamental y el desarrollo

\footnotetext{
${ }^{48}$ Este documento hace referencia a la puesta en marcha de iniciativas de rehabilitación del patrimonio edificado en aras de conseguir los estándares de eficiencia energética demandados por el desarrollo sostenible. MARTÍNCONSUEGRA, F., ALONSO, C., FRUTOS, B., La regeneración urbana integrada y la declaración de Toledo, Informes de la construcción, ISSN 0020-0883, Vol. 67, No. Extra 1 (marzo 2015), 2015. (MARTÍN-CONSUEGRA, ALONSO, and FRUTOS 2015)
} 
de los recursos institucionales necesarios a largo plazo habrían dado mayor impacto al cambio propuesto (PARKINSON 2014).

Sin embargo, es visible la falta de compromiso en la incorporación a las políticas nacionales y a la planificación local. Influyó en ello la dificultad de la aplicación por la magnitud de la intervención y el alto grado de colaboración que requiere difícilmente asumible por los instrumentos y estructuras administrativas tradicionales (ALONSO IBAÑEZ 2012) ${ }^{49}$.

A pesar de que la RUI apostó por una lectura transversal de la ciudad y no sectorial como venía realizándose hasta la actualidad. Y olvidando que la única manera de avanzar en la dirección señalada por la "Estrategia Europa 2020" era a través de una herramienta que proporcionara un enfoque verdaderamente integrado. La Regeneración Urbana Integrada finalmente se aplicó desde una perspectiva reduccionista de mejora urbana competitiva perdiendo ese enfoque de proceso planificado que había de trascender los ámbitos y enfoques parciales hasta ahora habituales, para abordar la ciudad como totalidad funcional, y sus partes, como componentes del organismo urbano (COMISIÓN EUROPEA 2010c).

Aún en la actualidad se está sufriendo esta desorientación en la aplicación de la Regeneración Urbana Integrada en la escala urbana europea. Y es que, a pesar de la existencia de ese enfoque teórico comúnmente admitido, no se ha llegado a un enfoque práctico, es decir a un entendimiento de cómo gestionar, planificar, y evaluar el desarrollo sostenible integrado aplicable al conjunto de los estados miembros. El informe de evaluación de la Regeneración Urbana Integrada de 2010 (INSTITUTO UNIVERSITARIO DE URBANÍSTICA DE LA UNIVERSIDAD DE VALLADOLID 2010), daba a entender la falta de carácter integrado de las actuaciones por aquel entonces, y por tanto la ineficacia de éstas para hacer evolucionar a las ciudades europeas hacia una gestión sostenible.

Los documentos sobre análisis del desarrollo espacial de la Unión Europea realizados durante el proceso de europeización urbana revelan ya el escaso impacto de las políticas urbanas de desarrollo sostenible. Así, claramente en el año 1999 (COMISIÓN EUROPEA 1999b) ya se hacía referencia a los desequilibrios entre ciudades, territorios, e incluso estados miembros, que se estaban produciendo paralelamente a la unificación ${ }^{50}$. Desequilibrios que se reiteraban en el informe "Territorial Scenarios for Europe" elaborado en 2015 donde se mencionaba el aumento de las disparidades entre regiones en Europa y la necesidad de reflexionar acerca del escenario hacia el que quería caminar la Unión Europea, pues no es lo

\footnotetext{
49 En su artículo "De la política urbanística a la política urbana: los retos actuales del derecho urbanístico" Ma Rosario Alonso Ibáñez hace referencia a la manifiesta dificultad en el ámbito jurídico de hacer operativo el desarrollo urbano sostenible. ALONSO IBAÑEZ, Ma Rosario, p. 25

50 Este desequilibrio ha sido descrito en el territorio gallego, haciéndose mención a las disparidades entre el crecimiento de núcleos que responden a estas necesidades derivadas de las economías de concentración (comunicaciones, TIC, etc.), mientras que otros núcleos a pesar de su integración con el medio desaparecen por no ser capaces incorporar estas demandas. $Y$ es que la estructura se describe como "una estructura territorial que funciona más o menos a nivel de los grandes intereses actuales de comunicación pero que soporta, por un lado, el desmembramiento de los núcleos mejor conectados y, por otro, desperdicia y abandona como reliquias o agujeros negros del pasado asentamientos ejemplares de integración con el medio."(CREUS ANDRADE 1995)
} 
mismo un policentrismo de lo que denominó MEGA's (megacuidades) ${ }^{51}$, que un policentrismo regional (ESPON 2015).

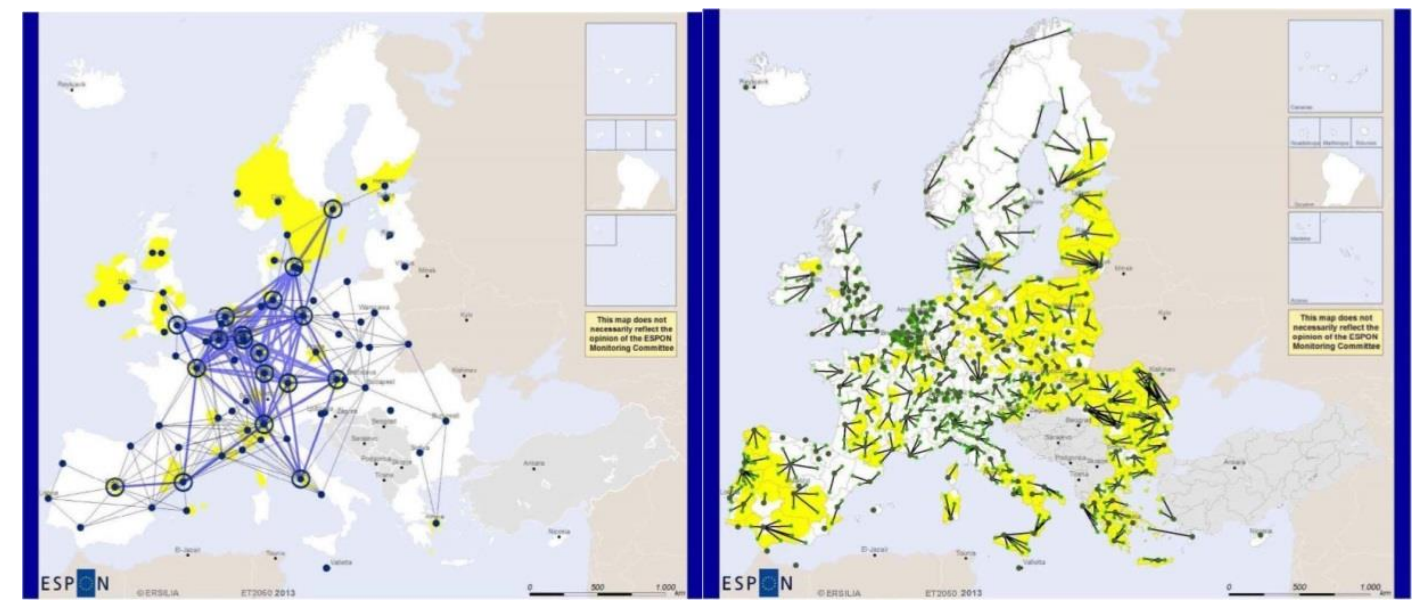

Figura 4. En la figura vemos los diferentes escenarios territoriales entre un policentrismo basado en megaciudades a nivel mundial, o un policentrismo regional que tenga en cuenta las ciudades de pequeña y mediana entidad. Esquemas de modelos territoriales. ESPON.

Fuente: ESPON 2015

La "Declaración de Riga"52 de 2015 llegó para reafirmar la importancia de las ciudades europeas pequeñas y medianas en la consecución de los objetivos de sostenibilidad y de equilibrio, y por tanto apoyar un escenario regional que cesara en el refuerzo de las MEGA's como modelo espacial. Finalmente, la falta de un enfoque práctico común favoreció el desarrollo de multitud de aproximaciones urbanas que trataron de acercarse al desarrollo sostenible desde diferentes prismas. Todas las aproximaciones buscaban conciliar los sistemas urbanos con desarrollo sostenible. Sin embargo, al igual que las diferentes perspectivas espaciales que configuraba ESPON (ESPON 2015), las diferentes aproximaciones configuraban diferentes escenarios en el que el equilibrio era alcanzado de forma muy diversa produciendo desarrollos con consecuencias opuestas en las dimensiones ambiental, social, económica, y en diferentes escalas.

Y es que la sostenibilidad podía justificarse a través de potenciar la escala local, o a través de mejorar la eficiencia de las megaciudades. Una y otra visión eran posibles en el marco europeo, y las múltiples alternativas dieron lugar a aproximaciones urbanas contrapuestas. A continuación analizaremos las consecuencias de este enfoque comunitario en el ámbito estatal.

\footnotetext{
${ }^{51}$ Con MEGA's se hace referencia a las megaciudades que se establecieron como cabezas visibles de en la escala mundial y que adquirían cada vez más peso como motores económicos, símbolos de poder, pero también atractores de las disfunciones entre las dimensiones de la sostenibilidad.(ESPON 2015)

52 UNIÓN EUROPEA: La Reunión Informal de Ministros Responsables de Cohesión territorial y urbana, da lugar a la Declaración de Riga que pretende reforzar el papel de las ciudades en la consecución de los principios de desarrollo sostenible. Declaración de Riga, junio 2015. (NACIONES UNIDAS 2006)
} 


\subsection{El modelo urbano sostenible en la legislación española}

Influir en las políticas nacionales a través del enfoque común propuesto por la Unión Europea era el siguiente paso para la consolidación de la sostenibilidad. La Regeneración Urbana Integrada debía "actuar para que funcione de manera integrada el entero sistema urbano, donde todo se relaciona con todo" y para conseguir este propósito "sin actuar difícil será hablar de cambios en la buena dirección" (ALONSO IBAÑEZ 2012).

Tanto en la normativa estatal como en la autonómica el principio de sostenibilidad ya había dejado su impronta de manera que, este concepto, aparece en la definición de objetivos como principio fundamental de las nuevas políticas. Sin embargo, en su incorporación a las políticas públicas nacionales y autonómicas, al igual que en la escala comunitaria, encontramos diferentes interpretaciones del principio de desarrollo sostenible internacional. $Y$ es que cada uno de estos documentos tiene su particular visión del desarrollo sostenible y de los cauces a través los cuales ha de encaminarse hacia él, variando el peso que se dio a cada una de las dimensiones económica, social, medioambiental, cultural según la interpretación recogida.

Sin lugar a dudas, el excesivo peso en la economía española del sector de la construcción, que quedó patente en todos los análisis comparativos a nivel europeo (MINISTERIO DE LA VIVIENDA ESPAÑA 2010), marcó en gran medida la búsqueda de la sostenibilidad de las políticas. Siendo España con un 12,7\% el país de Europa con mayor porcentaje de población activa dedicada al sector de la construcción (muy por debajo aparecen Francia y Alemania con un 5,7\% y 5,4\% respectivamente). Y posicionándose en cabeza en el 2006 en número de viviendas construidas, el control de la ocupación del suelo y el cambio en el sistema económico fueron objetivos clave en el camino hacia un desarrollo sostenible (IUUUVA, 2010:12). Esta visión sostenible comenzó a incorporarse como objetivo fundamental en los desarrollos normativos posteriores, y así queda patente en la evolución de la legislación desde la formulación de la "Carta de Leipzig" 2007.

Entendiendo que cuando el Derecho Urbanístico abandona su papel regulador se producen situaciones insostenibles de desequilibrio medioambiental, social, cultural, económico, era fundamental que éste se adaptara a las nuevas políticas para alcanzar los objetivos propuestos. Ya en la Ley de Suelo del año $2007^{53}$ se establecía en los artículos 1 y 2 como principal objetivo el fijar las bases para un uso racional del suelo según los principios del desarrollo territorial y urbano sostenible. Asumía así la necesidad de actuar conforme al interés general, y de considerar las dimensiones medioambientales y sociales armonizándolas con la

53 Como señalaba el artículo 1 de esta ley: Objeto de esta Ley. Esta Ley regula las condiciones básicas que garantizan la igualdad en el ejercicio de los derechos y en el cumplimiento de los deberes constitucionales relacionados con el suelo en todo el territorio estatal. Asimismo, establece las bases económicas y medioambientales de su régimen jurídico, su valoración y la responsabilidad patrimonial de las Administraciones Públicas en la materia. RD 2/2008 (MINISTERIO DE LA VIVIENDA ESPAÑA 2008) 
dimensión económica ${ }^{54}$ reforzando la eficacia de la conservación del patrimonio natural y cultural, y del medio rural y urbano de cada punto del territorio. Para ello la ley apostó por la desvinculación del concepto de igualdad con las condiciones básicas de propiedad de los terrenos, para caminar hacia una lectura más amplia del término, que atendiera a los derechos de participación ciudadana, al derecho a un medio ambiente adecuado, a la vivienda digna, en definitiva, a la igualdad en términos globales tal y como se define en la Constitución. Sin embargo, a pesar de que los enunciados acerca del desarrollo sostenible se encuentran tanto en el prólogo como en algunos artículos, podemos decir que en el núcleo fundamental permanece invariable apostando nuevamente por el crecimiento como sustento de la economía (MATESANZ PARELLADA 2009).

Siguiendo esta paulatina incorporación del concepto de sostenibilidad al marco jurídico español, en el ámbito económico se elabora la Ley 2/2011 de Economía sostenible (en adelante LES). Concebida para introducir en el ordenamiento jurídico las reformas necesarias para un desarrollo económico que conciliara las dimensiones social y medioambiental ${ }^{55}$ y debido a las conexiones existentes entre desarrollo urbano y el crecimiento económico, la dimensión urbana aparece tratada en varias de las "acciones de competencia pública" que se exponen en el artículo 3 de la ley ${ }^{56}$. En éste se especifican las condiciones que marca la ley para las intervenciones de

\footnotetext{
54 Como señalaba el artículo 2: "de ordenación, ocupación, transformación y uso del suelo conforme al interés general y según el principio de desarrollo sostenible, propiciando así el uso racional del suelo, y para ello armonizando los factores medioambientales y sociales y su protección, con los requerimientos económicos" "el uso racional de los recursos naturales armonizando los requerimientos de la economía, el empleo, la cohesión social, la igualdad de trato y de oportunidades entre mujeres y hombres, la salud y la seguridad de las personas y la protección del medio ambiente, contribuyendo a la prevención y reducción de la contaminación, y procurando en particular: RD 2/2008 (MINISTERIO DE LA VIVIENDA ESPAÑA 2008)

a) La eficacia de las medidas de conservación y mejora de la naturaleza, la flora y la fauna y de la protección del patrimonio cultural y del paisaje.

b) La protección, adecuada a su carácter, del medio rural y la preservación de los valores del suelo innecesario o inidóneo para atender las necesidades de transformación urbanística.

c) Un medio urbano en el que la ocupación del suelo sea eficiente, que esté suficientemente dotado por las infraestructuras y los servicios que le son propios y en el que los usos se combinen de forma funcional y se implanten efectivamente, cuando cumplan una función social. RD 2/2008 (MINISTERIO DE LA VIVIENDA ESPAÑA 2008)

${ }^{55}$ Como establece el artículo 2: "A los efectos de la presente Ley, se entiende por economía sostenible un patrón de crecimiento que concilie el desarrollo económico, social y ambiental en una economía productiva y competitiva, que favorezca el empleo de calidad, la igualdad de oportunidades y la cohesión social, y que garantice el respeto ambiental y el uso racional de los recursos naturales, de forma que permita satisfacer las necesidades de las generaciones presentes sin comprometer las posibilidades de las generaciones futuras para atender sus propias necesidades." Ley 2/2011, de 4 de marzo, de Economía Sostenible. (JEFATURA DEL ESTADO 2011)

56 Se encuentran numerosos artículos de aplicación al sistema urbano con el objetivo de avanzar hacia actividades más estables y de reducir la dependencia con el sector de la construcción Tanto en la línea encaminada a la "sostenibilidad energética y tratamiento de residuos", como en la línea sobre "racionalización de la construcción", queda evidenciada esta estrecha relación entre el sistema urbano y territorial, y los modelos energéticos, las emisiones, el transporte y la movilidad sostenible, y rehabilitación y vivienda. "1.mejora de la competitividad, 2.estabilidad de las finanzas públicas, 3.racionalización de las Administraciones Públicas, 4.fomento de la capacidad innovadora de las empresas, 5.ahorro y eficiencia energética, 6.promoción de las energías limpias, reducción de emisiones y eficaz tratamiento de residuos, 7.racionalización de la construcción residencial, 8.extensión y mejora de la calidad de la educación e impulso de la formación continua, 9.fortalecimiento y garantía del Estado social." Ley 2/2011, de 4 de marzo, de Economía Sostenible, p.17
} 
renovación y rehabilitación en el entorno urbano ${ }^{57}$. Éstas nos dan pistas de en qué punto se encuentra la asimilación del concepto de regeneración urbana integrada que por aquel entonces ya había quedado establecido a nivel europeo en la "Declaración de Toledo".

El énfasis mostrado en que las intervenciones se articulen a través de programas y planes que tengan en cuenta en su redacción las dimensiones medioambiental, económica y social, manifiesta esa voluntad de acercamiento a las interpretaciones europeas de desarrollo sostenible. Así mismo, el hincapié en la necesidad de elaborar herramientas de análisis y evaluación para la incorporación de estas propuestas de intervención integradas ${ }^{58}$ muestra las intenciones de que esta interpretación trascienda la mera definición de principios.

Se observa por tanto como la Ley de Economía Sostenible apuesta por la inclusión ${ }^{59}$ de los principios de la Regeneración Urbana Integrada en los procesos de rehabilitación y renovación. La LES confiaba en estos como único modo de alcanzar el desarrollo sostenible ${ }^{60}$ apostando por sistema de desarrollo basado en la

57 El artículo 109 sobre "Rehabilitación y renovación para la sostenibilidad del medio urbano" especifica las cualidades que exigidas a las intervenciones. Ley $2 / 2011$, de 4 de marzo, de Economía Sostenible.

58 Lo articula a través de la formación y actualización de un sistema informativo general e integrado de censos de edificación, mapas de ámbitos urbanos obsoletos de información sobre suelo y urbanismo. Ley 2/2011, de 4 de marzo, de Economía Sostenible.

59 Las actuaciones de renovación y rehabilitación urbana tienen la consideración de actuaciones de transformación urbanística, de conformidad con lo previsto en el artículo 14.1 del texto refundido de la Ley de Suelo, aprobado por el Real Decreto Legislativo 2/2008, de 20 de julio, siéndoles de aplicación el régimen legal establecido en dicho texto a las actuaciones de urbanización o de dotación, según sea su objeto. 1. A efectos de esta Ley, se entiende por actuaciones de transformación urbanística:

a) Las actuaciones de urbanización, que incluyen:

1) Las de nueva urbanización, que suponen el paso de un ámbito de suelo de la situación de suelo rural a la de urbanizado para crear, junto con las correspondientes infraestructuras y dotaciones públicas, una o más parcelas aptas para la edificación o uso independiente y conectadas funcionalmente con la red de los servicios exigidos por la ordenación territorial y urbanística.

2) Las que tengan por objeto reformar o renovar la urbanización de un ámbito de suelo urbanizado, en los mismos términos establecidos en el párrafo anterior.

b) Las actuaciones de dotación, considerando como tales las que tengan por objeto incrementar las dotaciones públicas de un ámbito de suelo urbanizado para reajustar su proporción con la mayor edificabilidad o densidad o con los nuevos usos asignados en la ordenación urbanística a una o más parcelas del ámbito y no requieran la reforma o renovación de la urbanización de éste. RD 2/2008.

60 "Las intervenciones deben tener por objetivo la cualificación, revitalización y, en general, puesta en valor de las tramas y los tejidos correspondientes así como de su periferia inmediata, considerándose además la necesidad de articular estos mediante planes, programas e instrumentos integrales que hayan tenido en cuenta en su redacción todas las dimensiones de naturaleza medioambiental, económica y social. "Tengan por objetivo la cualificación, revitalización y, en general, puesta en valor de las tramas y los tejidos correspondientes, así como, en su caso y complementariamente, de la extensión razonable de los mismos en el ámbito de su periferia inmediata, de acuerdo con criterios de compacidad y proximidad física y funcional y aprovechamiento racional de infraestructuras, dotaciones y servicios y garantizando en todo caso un marco urbano coherente.

b) Se articulen preferentemente en planes, programas o instrumentos integrales que, considerando las pertinentes variables de naturaleza, ambiental, económica y social en ámbitos urbanos obsoletos, desfavorecidos, degradados o que padezcan problemas de naturaleza análoga determinados al efecto, combinen las medidas de creación o mejora del espacio urbano con las de reequipamiento en dotaciones y servicios y garanticen su coherencia y eficacia.

c) Contribuyan, cuando tengan carácter aislado, al objetivo a que se refiere la letra anterior y a un marco urbano coherente, en el que se aborde la mejora y refuerzo de dotaciones y servicios y se consideren cuantas variables de naturaleza socioeconómica son inherentes al proceso rehabilitador. Ley $2 / 2011$, de 4 de marzo, de Economía Sostenible. (JEFATURA DEL ESTADO 2011) 
mejora y modificación de la ciudad existente en lugar de promover la creación de nueva. A pesar de esta aparente permeabilidad al desarrollo sostenible, los análisis de la LES hacen hincapié en la apuesta de ésta por la obtención de resultados macroeconómicos positivos en lo que se refiere al aumento del PIB, y la productividad (CUERPO and KESSLER 2011). Debido a esta apuesta por el crecimiento esta ley ha sido muy criticada por entender que seguiría fomentando tendencias insostenibles como las obras de infraestructuras que fomentan el vehículo privado, y la internacionalización de mercancías aumentando la huella de carbono (ECOLOGISTAS EN ACCIÓN 2009).

Otro texto normativo estatal que vamos a tener en cuenta es la Ley 8/2013, de 26 de junio, de rehabilitación, regeneración y renovación urbanas, en la actualidad incorporada al texto refundido 201561. En el preámbulo de la ley, procurando un cambio con la tradición urbanística española, que había estado enfocada fundamentalmente a la producción de nueva ciudad descompensando el necesario equilibrio entre dichas actuaciones y aquellas otras orientadas hacia los tejidos urbanos existentes, se hace hincapié en esta necesidad de caminar hacia un modelo sostenible e integrador mediante la rehabilitación, regeneración y renovación urbanas, buscando por tanto promover la intervención en las ciudades, con la intención de generar bienestar económico y social y garantizar la calidad de vida a sus habitantes ${ }^{62}$.

La rehabilitación y renovación de los sistemas urbanos a que hacía referencia la sostenibilidad no tenía ya la dimensión de los centros históricos o la ciudad tradicional, sino que por el contrario tenía que ver con la recomposición de la fragmentación derivada de la explosión del proceso de urbanización. Esto implicaba la renovación de barrios, de viviendas, de entornos urbanos con implicación ciudadana, y con compromiso por el gestor y el técnico, y no solo como operaciones de construcción (FARIÑA TOJO 2013). Sin embargo, desde la ley, el camino hacia la recuperación, se fundamentó nuevamente en la dimensión económica, apareciendo de nuevo muy enfocado al sector de la construcción pero volcado esta vez en las intervenciones de rehabilitación edificatoria y renovación urbana ${ }^{63}$.

\footnotetext{
61 Nos referimos al Real Decreto Legislativo 7/2015, de 30 de octubre, por el que se aprueba el texto refundido de la Ley de Suelo y Rehabilitación Urbana, publicado en el BOE 261 de fecha 31 de octubre de 2015.

${ }^{62}$ Esta Ley tiene por objeto regular las condiciones básicas que garanticen un desarrollo sostenible, competitivo y eficiente del medio urbano, mediante el impulso y el fomento de las actuaciones que conduzcan a la rehabilitación de los edificios y a la regeneración y renovación de los tejidos urbanos existentes, cuando sean necesarias para asegurar a los ciudadanos una adecuada calidad de vida y la efectividad de su derecho a disfrutar de una vivienda digna y adecuada. Ley 8/2013, de 26 de junio, de rehabilitación, regeneración y renovación urbanas.

63 Ley $8 / 2013$, de 26 de junio, de rehabilitación, regeneración y renovación urbanas. El camino de la recuperación económica, mediante la reconversión del sector inmobiliario y de la construcción y también la garantía de un modelo sostenible e integrador, tanto ambiental, como social y económico, requieren volcar todos los esfuerzos en aquellas actuaciones, es decir, las de rehabilitación y de regeneración y renovación urbanas, que constituyen el objeto esencial de esta Ley. La regulación que contiene esta norma se enmarca en un contexto de crisis económica, cuya salida depende en gran medida -dado el peso del sector inmobiliario en dicha crisis-, de la recuperación y reactivación -de cara sobre todo al empleo- del sector de la construcción. Dicha salida, en un contexto de improcedencia de políticas de expansión, tales como la generación de nueva ciudad y nuevas viviendas, sólo es posible actuando sobre el patrimonio inmobiliario y la edificación existente.
} 
Apoyándose en la Directiva Europea 2010/31/UE, que busca la renovación del parque edificatorio para el cumplimiento de los objetivos marcados en la Estrategia Europea 2020, planteó la creación oportunidades de crecimiento y empleo a través del sector de la construcción, al mismo tiempo que contribuir a la sostenibilidad ambiental, a la cohesión social y a la mejora de la calidad de vida de todos los ciudadanos $^{64}$. Por tanto, a pesar de que en el Artículo $3^{65}$ se defienden los principios de sostenibilidad integrada como fines comunes de las políticas públicas para un medio urbano más sostenible, eficiente y competitivo, en el Preámbulo de la ley queda claramente manifiesta esta voluntad de apostar nuevamente por la unión del sector económico y la construcción de la ciudad, queda así expuesto en sus objetivos:

"En primer lugar, potenciar la rehabilitación edificatoria y la regeneración y renovación urbanas, eliminando trabas actualmente existentes y creando mecanismos específicos que la hagan viable y posible. En segundo lugar, ofrecer un marco normativo idóneo para permitir la reconversión y reactivación del sector de la construcción, encontrando nuevos ámbitos de actuación, en concreto, en la rehabilitación edificatoria y en la regeneración y renovación urbanas. En tercer lugar, fomentar la calidad, la sostenibilidad y la competitividad, tanto en la edificación, como en el suelo, acercando nuestro marco normativo al marco europeo, sobre todo en relación con los objetivos de eficiencia, ahorro energético y lucha contra la pobreza energética."

Esto hizo que finalmente los sistemas de evaluación se centraran en el aspecto económico, apareciendo en el Capítulo II correspondiente a "Ordenación y gestión", como documento esencial en el control de las intervenciones una "Memoria de viabilidad económica", quedando evaluada únicamente la repercusión financiera de la intervención y viéndose disminuida la interpretación integradora de las políticas de regeneración urbana tal y como habían sido definidas en el ámbito europeo.

Como ya hemos visto en el presente capítulo la evolución desde la insostenibilidad hacia el desarrollo sostenible reavivó las intenciones de recuperación de nuevas dimensiones de la relación del hombre con el medio más allá de la estrictamente económica. Sin embargo, tanto en el ámbito internacional

\footnotetext{
${ }^{64}$ No parece admitir dudas el dato de que el parque edificado español necesita intervenciones de rehabilitación y de regeneración y renovación urbanas. distancia que separa nuestro parque edificado de las exigencias europeas relativas a la eficiencia energética de los edificios y, a través de ellos, de las ciudades.

A través de esta estrategia de renovaciones exhaustivas y rentables que reduzcan el consumo de energía de los edificios, en porcentajes significativos con respecto a los niveles anteriores a la renovación, se crearán además oportunidades de crecimiento y de empleo en el sector de la construcción.

Esta actividad, globalmente entendida, no sólo es susceptible de atender los objetivos de eficiencia energética y de recuperación económica ya expresados, sino también de contribuir activamente a la sostenibilidad ambiental, a la cohesión social y a la mejora de la calidad de vida de todos los ciudadanos, tanto en las viviendas y en los edificios, como en los espacios urbanos. Ley 8/2013, de 26 de junio, de rehabilitación, regeneración y renovación urbanas. (JEFATURA DEL ESTADO 2013)

${ }^{65}$ Artículo 3. Fines comunes de las políticas públicas para un medio urbano más sostenible, eficiente y competitivo, en el que se enumeran las funciones para las que se desarrollan las políticas de acuerdo con los principios de sostenibilidad económica, social y medioambiental, cohesión territorial, eficiencia energética y complejidad funcional.
} 
como en el nacional, finalmente los documentos orientativos y los vinculantes se desvían de la sostenibilidad global y continúan apoyando la supremacía económica. A pesar de ello veremos a continuación como la elaboración de documentos es continua y afecta también a los de carácter estratégico.

\section{EL DESARROLLO SOSTENIBLE EN LOS INSTRUMENTOS DE ORIENTACIÓN CON INFLUENCIA EN LAS POLÍTICAS URBANAS: ESTRATEGIAS Y AGENDAS}

Esta toma de conciencia internacional, y comunitaria europea, produjo transformaciones que, además de como vimos en el capítulo anterior llegar a calar en las políticas públicas, desencadenó la producción de documentos de orientación ${ }^{66}$ de corto, medio y largo plazo. La necesidad de contextualizar para la Unión Europea este acercamiento multidimensional compartido, que se corresponde con la interpretación del desarrollo sostenible según Brundtland, hizo necesaria la definición de unos objetivos comunes para la comunidad en los ámbitos económico, medioambiental, social, de manera que todos los estados miembros bajo ese prisma común caminaran progresivamente hacia esa Europa social y medioambientalmente amigable.

Con esa intención se elaboraron una serie de documentos no vinculantes que recogían la visión común sobre desarrollo sostenible para todos los estados miembros, invitando a todos los países a incorporar esa nueva orientación en sus políticas públicas. Esta compilación de objetivos de la visión multidimensional quedó asociada al desarrollo de estrategias ${ }^{67}$, que al igual que en su día ayudaron en el ámbito militar del que proceden, y en el ámbito empresarial, orientaran a los países en los desafíos que planteaba la globalización. Por tanto, las estrategias fueron las encargadas de "definir el alcance, lo que se quiere ser y establecer, para cumplir con lo que se espera" (CONTRERAS SIERRA 2013). Es decir, concretar los principios y objetivos del desarrollo sostenible.

El éxito de una estrategia dependía de la correcta interpretación de los objetivos por parte del estratega, y por tanto en este caso, de la correcta interpretación de la sostenibilidad, o más concretamente del desarrollo sostenible tal y como había sido definido por consenso para el ámbito internacional. Ya hemos hecho referencia en el capítulo anterior a la desviación que la interpretación del desarrollo sostenible había sufrido respecto del concepto de sostenibilidad. Esta desviación no es indiferente al desarrollo de las estrategias europeas y dejará como veremos su huella en estas.

En su redacción final estos documentos se caracterizaron por dar pie a múltiples alternativas en el avance hacia la sostenibilidad, ambigüedad que dio lugar a resultados poco uniformes. Bajo el mismo prisma, y auspiciadas por los objetivos de

\footnotetext{
66 Con documentos de orientación nos referimos a todos aquellos que una vez establecida la interpretación comúnmente aceptada de la sostenibilidad en la soft law, tienen como misión orientar las normas jurídicas, planes y programas estableciendo unos objetivos comunes como base y representación de la visión común.

67 La palabra estrategia deriva del latín "strategia", que a su vez procede del griego "stratos" o ejército, y "agein" conductor o guía, lo que significa que la palabra estrategia significa el arte de dirigir las operaciones militares.
} 
la estrategia, se podían englobar percepciones muy diferentes de la misma realidad, pudiendo en ocasiones producirse que éstas nos alejaran más de los objetivos iniciales por su erróneo planteamiento que acercarnos a tendencias sostenibles. Esta imprecisión, tal y como afirman los estudios sobre estrategias, es la causante de que la competencia en lugar de la colaboración, lograra permear en la estructura de estos documentos de manera que finalmente éstos se desvían de la sostenibilidad ecológica, y por tanto de la equidad y equilibrio dimensional (CONTRERAS SIERRA 2013).

A pesar de estas consideraciones el desarrollo de estos documentos fue muy prolífico. En la Cumbre de Río de Janeiro celebrada en 1992 se hizo un llamamiento a la creación de estas estrategias, que adquirieron la denominación de "estrategias de desarrollo sostenible" y cuya finalidad específica quedo definida como "instrumentos de alta participación que garantizaran el desarrollo económico socialmente responsable a la vez que proteger los recursos y el medio ambiente para las generaciones futuras (ORGANISATION FOR ECONOMIC CO-OPERATION AND DEVELOPMENT 2001). Podemos decir que se consolidaron como los instrumentos no vinculantes capaces de responder a necesidades como la adaptación a las influencias externas con un logro de efectividad positivo en el corto, medio y largo plazo, y a su vez permitiendo definir la misión, los objetivos y las tácticas involucrando a todo el personal.

El matiz desarrollista que incorporaron todas las estrategias, tal y como veremos a continuación, vino ya inducido desde los inicios. Entendiendo éste como la principal finalidad de su existencia siguen la línea marcada por la interpretación del desarrollo sostenible asociada al crecimiento. Esto unido a que las estrategias de desarrollo se consolidaron como promotoras del desarrollo sostenible, hizo de éstas las responsables del nuevo rumbo que habría de tomar la política internacional y nacional para responder a las amenazas actuales y futuras. Esto implica por tanto, que a partir del estudio de las estrategias podemos descubrir las repercusiones económicas, sociales y ambientales que éstas están ejerciendo sobre las políticas, planes y programas para finalmente comprender a qué aproximación de la sostenibilidad estaban induciendo, y comprobar si estaban acogiendo el carácter trasversal propuesto para paliar las deficiencias en las interacciones entre las dimensiones económica, social, medioambiental, cultural.

El empeño en que los principios de desarrollo sostenible que quedaron establecidos a nivel internacional y europeo llegaran a consolidarse, en la práctica, formalizó a nivel europeo las peticiones de elaboración de estrategias que, desde la Cumbre de Lisboa celebrada en el año 2000 hasta la actualidad, no han dejado de sucederse.

Las estrategias de desarrollo, llegaron a influir en muchos ámbitos de las políticas públicas. Y por tanto, en su avance a la visión multidimensional integrada, al igual que en la dimensión medioambiental, social y cultural, las estrategias llegaron a incorporar también la dimensión territorial. La "Carta de Leipzig", como documento que representó esta simbiosis entre desarrollo sostenible y la dimensión territorial, no permaneció ajena a esta apuesta por el desarrollo de documentación 
estratégica. Afirmando los Ministros Responsables de Desarrollo Urbano de los Estados Miembros que "la Carta de Leipzig necesita llegar a ser más que un conjunto de principios, y aspirar a convertirse en un documento vivo sobre la base del cual se puedan elaborar estrategias concretas con el fin de poner en práctica todas sus recomendaciones" (COMISIÓN EUROPEA 2007a), consolidaron las estrategias de desarrollo como instrumento para alcanzar los objetivos en la escala territorial.

Así, las estrategias de desarrollo urbano sostenible y las agendas territoriales quedaron aseguradas como el documento para fomentar la aplicación de los principios de desarrollo sostenible teniendo en cuenta la dimensión territorial. Por tanto, esa indagación nos da a conocer la visión territorial para la Unión Europea, visión cuya implementación como hemos visto en la actualidad aún continua generando multitud de problemas sociales, medioambientales, culturales y económicos.

Su desarrollo, al igual que las estrategias desarrolladas en otras campos, se corresponde con una serie de etapas entre las que se encuentran: la de plantear objetivos en la que incluían la participación como principio fundamental, la de organizar para implantar los nuevos objetivos, la de definir unas líneas para llegar a los objetivos, y por último la de fase de evaluación del cumplimiento de lo esperado. Por esta razón, el análisis de las estrategias y su enfoque es tan representativo, ya que inciden tanto en el aspecto propositivo como en el desarrollo de instrumentos de validación.

En su definición están aproximando a todos los estados miembros a la visión comúnmente aceptada, no solo a través de unos objetivos, sino también a través de la creación de un marco de referencia para los instrumentos de la regeneración urbana integrada. Pero, ¿Cuál fue esa visión de desarrollo sostenible propuesta desde la Unión Europea? A continuación haremos un análisis de las principales estrategia de referencia de la Unión Europea.

\subsection{La Economía como dimensión vertebradora de la sostenibilidad en las estrategias de desarrollo sostenible europeas}

\subsubsection{Estrategia de Lisboa 2000: economía basada en la competencia global}

El primer acercamiento estratégico al desarrollo sostenible lo encontramos en el año 2000 con el proceso que dio lugar a la "Estrategia de Lisboa"68 (ELisboa2000). El 23 y 24 de marzo del 2000 el Consejo Europeo celebró una sesión especial en Lisboa para acordar los nuevos objetivos estratégicos de la Unión. Cabe destacar que nos encontramos en un periodo de contradicción, en el que a pesar de ser notables los buenos resultados macroeconómicos de la Unión obtenidos con la política monetaria existe una profunda insatisfacción derivada de la comparativa con los grandes

\footnotetext{
${ }^{68}$ Documento que recoge el acuerdo de principios estratégicos de desarrollo sostenible en el año 2000. (COMISIÓN EUROPEA 2000)
} 
avances realizados por EEUU, mucho mayores que los europeos (MATÍAS CLAVERO 2005).

Esta dualidad acompañó durante todo el proceso de acomodo a las estrategias de desarrollo, que trataron de hacer frente a la sostenibilidad, pero en ningún momento pudieron desembarazarse del peso que represento la necesidad de mantener las posiciones de cabeza en el panorama mundial. De este modo, la sostenibilidad interpretada desde el punto de vista del mantenimiento del desarrollo será la que forme parte de los objetivos de los documentos estratégicos desde sus inicios.

Para mantener este constante crecimiento sin dejar de lado la sostenibilidad se plantea un cambio del sistema económico respecto del tradicional ligado a la producción y consumo de recursos. Con el fin de reforzar el empleo, el crecimiento económico y la cohesión social la UE apuesta por una "economía basada en el conocimiento" ${ }^{69}$. Entendían que el dinamismo y la competitividad en conocimiento les proporcionarían la capacidad de crecer económicamente y de forma más sostenible, generando empleo y favoreciendo la cohesión social y la igualdad de oportunidades. Por aquel entonces el declive de la capacidad productiva, el descenso del número de patentes europeas, la deslocalización de empresas y laboratorios, y el éxodo de jóvenes cualificados daban a conocer la urgente necesidad de impulsar la investigación y el desarrollo (MAYOR ZARAGOZA 2004).

Las aspiraciones eran complejas y requerían de un enfoque novedoso, una actuación que integrara aspectos económicos, sociales con un objetivo estratégico claro y unos plazos para alcanzarlos. Las conclusiones del Consejo fueron recogidas en un documento dando lugar a la "Estrategia de Lisboa" en el año 2000. En este documento la UE acordó un programa ambicioso que pretendía hacer de Europa una potencia mundial en economía del conocimiento para el año 2010. La mejora de las políticas relativas a la sociedad de la información, el fomento del I+D, la reforma estructural a favor de la competitividad y la innovación, la culminación del mercado interior, la inversión en capital humano y la lucha contra la exclusión manteniendo el crecimiento eran los objetivos globales de la estrategia. Para su cumplimiento pretendió establecer objetivos a corto, medio y largo plazo, desarrollar unos indicadores cualitativos y cuantitativos, y organizar controles y evaluaciones.

A pesar de que no solo crecimiento competitividad y empleo son mencionados en la ELisboa2000, sino que también hace referencia a la calidad de vida de los ciudadanos y al medio ambiente, y a la necesidad de que estos se conviertan en el centro de las políticas de la Unión, la estrategia fue ampliamente criticada por entenderse que esta visión humanística hacía más referencia al ciudadano como activo económico que como individuo al que satisfacer con las nuevas políticas. Y es que el desempleo y el envejecimiento poblacional eran analizados como costes

\footnotetext{
69 El Consejo Europeo fijó como objetivo de la Estrategia que en 2010 la UE se convirtiese "en la economía basada en el conocimiento más competitiva y dinámica del mundo, capaz de crecer económicamente de manera sostenible con más y mejores empleos y con mayor cohesión social" DOCUMENTO DE TRABAJO DE LOS SERVICIOS DE LA COMISIÓN. Documento de evaluación de la estrategia de Lisboa, Bruselas, 2010, p. 2.(COMISIÓN EUROPEA 2010b)
} 
económicos a combatir con cohesión y generación de empleo para hacer frente a los retos que planteaba la competencia mundial.

La necesidad de la Unión Europea de alcanzar los niveles de productividad de los $E_{E U U}{ }^{70}$, que por aquel entonces superaba al cómputo de los países miembros, y de no perder posiciones de poder en el ámbito internacional en el que comenzaban a posicionarse también otros países como China o la India ${ }^{71}$ hizo del PIB uno de los indicadores de mayor repercusión. Varios informes de la Comisión realizados con intención de evaluar los objetivos conseguidos centran las buenas perspectivas en el aumento del PIB de la Unión, reduciendo finalmente el éxito a la dimensión económica (MATÍAS CLAVERO, 2005:2).

Las iniciativas europeas entre las que se encontraban la e-Europe, el mercado interior, los servicios financieros, la empresa, la creación del espacio europeo de investigación y el re-examen de los instrumentos financieros sirvieron finalmente como líneas de actuación encaminadas a reactivar la productividad y con ella la economía. La dimensión económica, al igual que ocurrió con la interpretación de la sostenibilidad, aparecía en las estrategias nuevamente subordinando a las otras dimensiones de la sostenibilidad, apareciendo la social tal y como se describe en las evaluaciones como una de las grandes damnificada en el proceso de renovación del sistema económico.

El resultado, fuera intención implícita de la estrategia o derivada del declive productivo, fue el aumento del desempleo y el aumento de las deficiencias y la calidad de los puestos de trabajo tal y como aparece descrito en el informe de evaluación realizado en 2003 acerca de los logros de la ELisboa2000 (COMITÉ CONSULTIVO DEL ESPACIO ECONÓMICO EUROPEO 2003). En el informe de evaluación de 2010 (COMISIÓN EUROPEA, 2010b:2) se subraya una vez más este fracaso en las metas que pretendían haber sido alcanzadas a través de la ELisboa2000. Destaca el fallo en temas sociales como el empleo y la educación que a pesar de la crisis se mantuvieron presentes e invariables en los sectores más desfavorecidos, además del bajo nivel de inversión en I+D, que no alcanzó los valores esperados.

\footnotetext{
70 "Los mayores avances de los EE UU, patentes en los informes de diversas consultoras internacionales que se conocen a finales de los años noventa, como Morgan Stanley y Booz, Allen y Hamilton, aconsejaban nuevos impulsos y perspectivas. El de la primera decía que la inversión acumulada por la UE en tecnologías de la información estaba en 1998 casi al mismo nivel que la de EE UU en 1990. Incluso Booz, Allen y Hamilton sugería que en algunas áreas la distancia con América había crecido desde mediados de los años noventa como consecuencia del mejor aprovechamiento de la revolución digital realizado por los Estados Unidos." MATÍAS CLAVERO, Gustavo, "La Estrategia de Lisboa sobre la sociedad del conocimiento: la nueva economía", ICE, n 820, enero-febrero 2005, p.172. (MATÍAS CLAVERO 2005)

71 La globalización ha supuesto cambios importantes en nuestras sociedades que han ido acompañados muchas veces de incertidumbre. El resurgir económico de China y otros países en desarrollo ha traído consigo presiones en los mercados que han generado una inevitable quietud...Los beneficios potenciales de la globalización sólo se pueden materializar para aquellos países que pueden reaccionar rápidamente. Así, la economía de la Unión necesita ser lo suficientemente flexible para hacer frente a la fuerte competencia de las economías de bajo coste como China o India y de las economías innovadoras como EEUU." COMUNIDAD DE MADRID. Dirección General de Asuntos Europeos y Cooperación con el Estado "Guía de la Estrategia de Lisboa", 2008, p. 185. (BURRIEL DEVESA and GARCÍA-POSADA GÓMEZ 2008)
} 
Las evaluaciones llevadas a cabo tras el periodo de implantación de la ELisboa2000 apuntan como causa del fracaso la falta de control de los mercados financieros, del consumo inducido por el crédito y la excesiva importancia concedida a los resultados en el ámbito macroeconómico en detrimento de los microeconómicos, y de algunas políticas concretas generando más avance en unas áreas que en otras, en definitiva, falta de éxito en la voluntad de desarrollar una política integradora. $Y$ es que la propia estrategia favoreció que coexistieran políticas afines a los organismos mundiales como el FMI o el Banco Mundial, más propias de la supremacía de la dimensión económica, choque que nos recuerda a las tensiones entre las voluntad de la ONU y la de estos otros organismos internacionales.

La falta de concreción en los objetivos fijados fue una de las causas a la que achacan el fracaso de la estrategia. Esta indefinición dio lugar a que los estados llegaran a interpretar de manera contradictoria los objetivos de sostenibilidad, fijándose en algunos estados agendas nacionales más ambiciosas, y limitándose en otros a agendas meramente descriptivas o con límites poco realistas imposibles de alcanzar (COMISIÓN EUROPEA, 2010b:7). Y es que el compromiso de cada estado para con el desarrollo sostenible fue variable. La implantación de la estrategia en los diferentes estados miembros fue desigual y con grandes diferencias temporales, revirtiendo negativamente en la progresión. La ELisboa2000 fue sufriendo revisiones a lo largo de todo el periodo de implantación. Sin embargo, a pesar de las modificaciones encaminadas a paliar la abstracción de la estrategia estas no acabaron por consolidar un cambio real en el equilibrio dimensional, manteniéndose la supremacía económica hasta el 2010, año en que se describen los balances negativos.

\subsubsection{Estrategia de la Unión Europea para un Desarrollo Sostenible 2001: tímida apuesta hacia la incorporación de la dimensión ambiental}

La intención de seguir incorporando el concepto de desarrollo sostenible permanecía invariable en el ámbito estratégico de la Unión Europea. Es por ello que después de haber sido completada la ELisboa2000 se desarrollaron documentos de revisión para eliminar las posibles disfunciones de la redacción previa.

La "Estrategia de la Unión Europea para un Desarrollo Sostenible 2001", en adelante EDS2001, nació como resultado de la reunión celebrada en Helsinki en 1999 en la que el Consejo Europeo invitó a la Comisión a elaborar una propuesta de desarrollo sostenible desde el punto de vista social, económico y ecológico, que además sirviera de aportación comunitaria a la revisión de la Cumbre de Río en $2002^{72}$. La Comisión presentó frente al Consejo Europeo de Gotemburgo la EDS en 2001.

\footnotetext{
72 Comunicación de la Comisión Desarrollo sostenible en Europa para un mundo mejor: Estrategia de la Unión Europea para un desarrollo sostenible 2001. (Propuesta de la Comisión ante el Consejo Europeo de Gotemburgo). "El Consejo Europeo invitó a la Comisión Europea a elaborar una propuesta de estrategia a largo plazo que integre políticas de desarrollo sostenible desde el punto de vista económico, social y ecológico. En la Comunicación de la comisión "Desarrollo sostenible en Europa para un mundo mejor" aparece desarrollada la Estrategia de la Unión Europea para un desarrollo sostenible.(COMISIÓN EUROPEA 2001)
} 
La estrategia nació con la intención de ser un complemento del compromiso político adoptado en la ELisboa2000, un "catalizador para los responsables políticos y la opinión pública en los próximos años, así como una fuerza motriz para la reforma institucional y los cambios en el comportamiento de las empresas y de los consumidores" (COMISIÓN EUROPEA, 2001b:3). Como mejora al compromiso político que había sido adquirido en el año 2000, la EDS2001 incluyó entre los aspectos a tener en cuenta en la redacción la dimensión ambiental. De esta forma quedaba reconocida la vinculación existente entre el crecimiento económico, la cohesión social y la protección del medioambiente a largo plazo.

Pese a todos los esfuerzos realizados por desarrollar una estrategia eficaz, ya en el 2002 aparecen referencias al valor conceptual, más que al valor en la implementación real, que habían albergado las propuestas de desarrollo sostenible de la ELisboa2000. Y es que lejos de haber contribuido a la disolución de las políticas insostenibles, la primacía de la dimensión económica, o la desigualdad social, los informes de evaluación como "Medio Ambiente en la UE en el umbral del siglo XXI" (MINISTERIO DE MEDIO AMBIENTE UE 2001) demostraban las tendencias inesperadas y el aumento del deterioro medioambiental en que se había derivado. La ineficacia de las políticas de protección ambiental, que eran anuladas por los desarrollos inadecuados en otros ámbitos sectoriales como las políticas económicas, transporte, turismo, planificación territorial, usos del suelo, desarrollo urbano e infraestructuras, etc. (JIMÉNEZ BELTRÁN 2002), quedaba así manifiestas.

La intención de la EDS2001 fue reforzar los objetivos marcados por la ELisboa2000, donde ya se hacía mención a "un medio ambiente más limpio, seguro y sano", apostando por las políticas ambientales como camino para el equilibrio entre el crecimiento económico y el consumo de recursos que había sido hasta entonces motor de la dimensión económica y social (Europea, 2001:2). Esto significó que debían ser coherentes con los objetivos específicos de rentabilidad, fomento de empleo y cohesión social. Esta vinculación supeditó la visión medioambiental a la situación de competencia mundial.

Así, con la intención de aumentar su eficacia respecto a la anterior, y de evitar las dificultades derivadas de la falta de concreción, definió los problemas que debían ser atajados y en los que se debía focalizar la atención en la escala nacional, así como las líneas de actuación futuras llegando a establecer "principales amenazas al desarrollo sostenible"73. Estas quedaron definidas en un cuadro en las que ya aparecen referencias a temas medioambientales como la biodiversidad, los residuos, la fertilidad rural, etc. Del mismo modo, entre las medidas a tener en cuenta por los estados miembros hizo hincapié en aspectos medioambientales paliando las deficiencias ELisboa2000 en la que no se hacía referencia a tendencias sostenibles como son "limitar el cambio climático e incrementar el uso de energías limpias", la "respuesta a las amenazas de salud pública" y la "gestión responsable de recursos naturales".

\footnotetext{
73 Comunicación de la Comisión Desarrollo sostenible en Europa para un mundo mejor: Estrategia de la Unión Europea para un desarrollo sostenible. (Propuesta de la Comisión ante el Consejo Europeo de Gotemburgo), p. 2.
} 
En definitiva el Consejo Europeo de Gotemburgo pone en valor la relación estrecha que existe entre la estructura y el desarrollo económico y los problemas medioambientales, como el cambio climático, el agotamiento de los recursos naturales, la utilización del suelo, etc. Relaciones que tienen que ver con los problemas de los territorios desarrollados y que en definitiva tratan de paliar las deficiencias que podrían lastrar su posición de cabeza en la escala global.

Principales amenazas al desarrollo sostenible

- Las emisiones de gases de efecto invernadero producidas por la actividad humana están provocando un calentamiento global. Es probable que el cambio climático genere más episodios meteorológicos extremos (huracanes, inundaciones), con serias implicaciones para las infraestructuras, los bienes raíces, la salud y la naturaleza.

- Existe un grave peligro para la salud pública debido a nuevas cepas resistentes a los antibióticos en algunas enfermedades y la posibilidad de que los miles de productos químicos que se utilizan en la actualidad tengan efectos a más largo plazo; las amenazas a la seguridad alimentaria crecen de forma preocupante.

- Uno de cada seis europeos vive en situación de pobreza. La pobreza y la exclusión social tienen efectos directos gravísimos para las personas, que pueden reflejarse en mala salud, suicidios o desempleo persistente. La carga de la pobreza recae de forma desproporcionada en las madres solas y en las mujeres mayores que viven sin compañía. Se observa asimismo en la pobreza una tendencia marcada a la repetición: el problema suele permanecer en una familia durante varias generaciones.

- Aunque no cabe sino alegrarse por la mayor esperanza de vida, si ésta se combina con un índice de natalidad bajo, el envejecimiento de la población consiguiente amenaza el ritmo del crecimiento económico, así como la calidad y la sostenibilidad financiera de los regímenes de pensiones y de sanidad pública. En muchos Estados miembros, en el período 2000-2040, los gastos podrían aumentar hasta alcanzar un 8\% del PIB.

- La pérdida de biodiversidad en Europa se ha acelerado de forma drástica en las últimas décadas. Las poblaciones de peces en aguas europeas están al borde del colapso. Los volúmenes de residuos crecen de forma constante a mayor ritmo que el PIB. La erosión y el declive de la fertilidad afectan a la viabilidad de algunas regiones rurales.

- La congestión en el transporte ha aumentado rápidamente y está llegando a la paralización total. Esto afecta ante todo a las zonas urbanas, que también se ven afectadas por problemas de degradación de los barrios céntricos, expansión del extrarradio y concentración de bolsas de pobreza y exclusión social. Los desequilibrios regionales en la Unión Europea siguen siendo un problema preocupante.

Figura 5. Amenazas del desarrollo sostenible. EDS 2001.

Fuente: COMISIÓN EUROPEA 2001 
Además de reforzar la ELisboa2000 en lo que se refiere al equilibrio dimensional, debemos destacar la aportación de la EDS2001 en la búsqueda de un mayor compromiso. En su insistencia en la necesidad de "actuación urgente", que no hace referencia a otra cosa que a la obligación de afrontar los retos de la sostenibilidad cuanto antes.

Entre ellos se encuentra el "liderazgo político" voluntad política de comunicación y apuesta por el cambio, también un "nuevo enfoque en la formulación de políticas" entendiendo la necesidad de integración entre todas ellas, la necesidad de "amplia participación" atendiendo a la necesidad de que la estrategia abarque la escala comunitaria y a todos los actores que intervienen en el proceso, y la "responsabilidad internacional" como respuesta a escala mundial ya que el impacto del consumo de los países desarrollados en la actualidad va más allá de sus fronteras. Estos conflictos suponían introducir nuevas perspectivas a las dimensiones social, económica, medioambiental. Todas estas aproximaciones hacen referencia a intenciones inherentes al concepto de sostenibilidad que habían sido perdidas en favor de la consecución de los objetivos de crecimiento.

En esta revisión llevada a cabo en 2001 solo el conflicto referente a responsabilidad internacional llegó a incluirse aunque con poca profundidad. Cumpliendo el compromiso de completar la estrategia EDS2001, en febrero 2002 la Comisión presentó otra comunicación sobre la dimensión externa del desarrollo sostenible "Hacia una asociación global a favor del desarrollo sostenible"74. El incremento del comercio mundial multiplicado por quince y el aumento de la renta mundial per cápita duplicado, hizo necesario abordar los problemas desde una perspectiva mundial.

Entendiendo que el mundo es cada vez más interdependiente y los problemas cada vez más complejos, se siente cada vez más la necesidad de una mejor gobernanza mundial capaz de hacer frente a los problemas de desigualdad entre los países derivados de la mundialización. Con la intención de caminar hacia un "pacto global" en la "Cumbre Mundial sobre Desarrollo Sostenible" de 2002, se elaboró este documento de reflexión a escala planetaria.

Este documento completó la EDS2001, añadiendo a la ELisboa2000, además del factor medioambiental la dimensión externa (JIMÉNEZ BELTRÁN 2002). A pesar de ello esta dimensión no aparecerá integrada completamente en una estrategia hasta la posterior revisión del 2005. Revisión que trataremos a continuación y donde desarrollaremos más en profundidad cual ha sido la posición europea respecto a las necesidades de mundialización.

\footnotetext{
${ }^{74}$ La comisión propone medidas en pro de un desarrollo sostenible y un mundo más justo: Realización del programa de Doha, lucha contra la pobreza, administrar de manera duradera los recursos naturales y el medio ambiente, la financiación del desarrollo, integración del término en las políticas de la unión, mejorar la gobernanza mundial, mejorar el marco institucional internacional. Comunicación de la Comisión "Hacia una asociación global a favor del desarrollo sostenible", 13-02-2002, Bruselas.(COMISIÓN EUROPEA 2002)
} 


\subsubsection{Revisión de la Estrategia de Desarrollo Sostenible 2005: falsas esperanzas de mundialización del desarrollo sostenible}

Los malos resultados de trasposición de la ELisboa2000 y la urgencia por que ésta se produjera propiciaron que la Comisión se comprometiera a la revisión de las estrategias al inicio de cada mandato para así poder actualizar y paliar las deficiencias.

Al igual que en el año 2000, en 2005 continuaban siendo amenazas para la Unión Europea la competencia mundial creciente, el envejecimiento de la población, y la reducción del crecimiento que, al $1 \%$ anual, dejaba a la Unión Europea en ámbitos muy alejados de sus competidores. Al igual que habían quedado definidas en la ELisboa2000, estas fueron las principales preocupaciones durante el desarrollo de la "Revisión de la Estrategia de la Unión Europea para un desarrollo sostenible" de 2005 (en adelante REDS2005), que volvió a centrarse en producir crecimiento duradero y compatible con el respeto medioambiental y social. Nuevamente la preocupación europea se centra en la insuficiencia de las medidas para hacer que Europa se mantenga en los puestos de cabeza, siendo el crecimiento el pilar fundamental.

A pesar de la dificultad de acometer una estrategia capaz de abordar todas las deficiencias, la REDS2005 trató de mermar algunas carencias de sus predecesoras aunque con poca incidencia en los resultados finales. La revisión pretendía complementar y no sustituir a la EDS2001, y las pequeñas modificaciones no fueron suficientes para cambiar el curso que llevaba la implementación de la ELisboa2000. En junio de 2005 el Consejo Europeo aceptaba los principios y objetivos del desarrollo sostenible basados en la dimensión económica, social y medioambiental que ya habían sido objeto de la EDS2001 ${ }^{75}$ incorporando también la dimensión de internacionalización, que hasta aquel momento aparecía como documento independiente elaborado en 2002, tal y como señalamos en el capítulo anterior.

Al igual que en el ámbito internacional, la internacionalización de la estrategia lejos de hacer a los países desarrollados responsables de los problemas de escala global los convierte en rescatadores de los países en vías de desarrollo afectados por la deriva mundial. Centra nuevamente la sostenibilidad global en los problemas de unos pocos estados, en lugar de atender al problema desde una perspectiva mundial en el que los estados conectados generan externalidades más allá de sus fronteras. La internacionalización no llega por tanto a adquirir el éxito esperado del mismo modo que no lo harán las modificaciones en el resto de los campos.

Habiéndose avanzado en iniciativas sociales y medioambientales, estas se mostraban aún insuficientes en el avance hacia la inversión de las tendencias insostenibles (COMISIÓN EUROPEA, 2005a:3). La REDS2005, además de ponderar los avances que se habían llevado a cabo desde la ELisboa 2000, también puso de manifiesto las debilidades que estaban lastrando su éxito y que trataron de paliar en

\footnotetext{
${ }^{75}$ Estos aspectos se reafirman y en ellos se centraron asimismo los debates de la reunión de Jefes de Estado y de Gobierno europeos en Hampton Court en octubre de 2005. COMUNICACIÓN DE LA COMISIÓN AL CONSEJO Y AL PARLAMENTO. "Revisión de la Estrategia para un desarrollo sostenible"(COMISIÓN EUROPEA 2005)
} 
esta nueva redacción. Para ello, además de la reafirmación de lo promovido por sus predecesoras, en el primer documento REDS2005 se hizo hincapié en la necesidad de afianzar el carácter tridimensional (económico, medioambiental, social) de la estrategia, reforzar la coherencia entre las políticas realizando evaluaciones de impacto tridimensionales, estudio exhaustivo de las tendencias insostenibles y su repercusión en las tres dimensiones, establecer unos objetivos y plazos más concretos y eficaces, garantizar un seguimiento eficaz, y la participación de actores públicos y privados a todos los niveles (COMISIÓN EUROPEA 2005).

De las consultas realizadas ${ }^{76}$ se resumió igualmente la necesidad de avanzar hacia una mayor especificidad en la nueva estrategia revisada, por tanto, el informe final de la REDS2005 establecía una serie de temas transversales, cambio climático y energía limpia, salud pública, exclusión social - demografía - flujos migratorios, gestión de los recursos naturales, trasportes sostenibles, y pobreza en el mundoretos en materia de desarrollo (COMISIÓN EUROPEA 2006), más concretos que en ocasiones anteriores. Pretendió acotar los ámbitos en los que hacer hincapié para así aumentar la eficacia de la estrategia quedando definidas unas iniciativas principales relativas a cada uno de los temas. Sin embargo, con esta renovación en lugar de la sostenibilidad como meta, trataban de definir unas pautas que además de impulsar la productividad, el crecimiento y el empleo, hicieran de Europa un lugar atractivo para las inversiones, con mayor inversión en I+D, con empleos de mayor calidad, y promocionando la dimensión externa.

Esto indica que a pesar de las intenciones iniciales de ahondar en los temas sociales y medioambientales la revisión finalmente continuó insistiendo en el crecimiento. Por tanto dio continuidad a las deficiencias que ya aparecían en la EDS2001, sin profundizar en aspectos como la gobernanza y la participación que ya habían sido reconocidos como un lastre en el avance hacia la implementación de la sostenibilidad en los informes sobre balances y orientaciones futuras de las anteriores estrategias ${ }^{77}$.

La revisión de la EDS2001, resultante en la REDS2005 se desarrolló en un contexto de voluntad de impulso del crecimiento y el empleo, y de elaboración integrada de todas las políticas públicas, pero que, a pesar de ello, siguió amparando el aumento de las tendencias insostenibles, los deficientes resultados económicos de Europa, la baja intensidad en los compromisos internacionales, y la aparición de nuevas amenazas. En el Consejo de 2004 de Bruselas ya se mencionaba la amenaza que la insuficiente aplicación de las estrategias supondría a nivel europeo en términos de crecimiento, empleo, I+D, etc., llegando a hacer un

\footnotetext{
76 "En el contexto de la elaboración de este conjunto de medidas, la Comisión organizó una amplia consulta y solicitó la opinión del Consejo, el Parlamento, los Estados miembros, las ONG, los ciudadanos y las partes interesadas" "La Comisión recibió más de 1.100 contribuciones en el marco de estas consultas". (COMISIÓN EUROPEA 2005)

77 A pesar de que la Gobernanza se incluye en la EDS2005, aún carece del desarrollo suficiente como para ser efectivo en este ámbito. Supone más una declaración de intenciones que una inclusión real de la dimensión gobernanza a pesar de la existencia ya por aquel entonces de documento European governance: White Paper, de la Comisión Europea del 2001. EUROSTAT: Measuring progress towards a more sustainable Europe, 2007. (COMISIÓN EUROPEA and EUROSTAT 2007)
} 
llamamiento a los Estados para que adoptaran medidas encaminadas a la incorporación de la estrategia con mayor rapidez, y a las empresas y particulares como actores fundamentales, ya que únicamente a través de la vía pública era posible alcanzar la sostenibilidad (MATÍAS CLAVERO 2005).

Los balances finales del proceso de Lisboa no apuntan a una mejora después de la revisión de 2005. Como quedó patente en el informe de evaluación de la ELisboa2000 publicado en 2010 al que hacemos referencia en el apartado correspondiente a la misma, ni ésta ni los posteriores complementos y modificaciones lograron conseguir las metas propuestas (COMISIÓN EUROPEA 2010b). Tras estos balances negativos y persistiendo la amenaza para la Unión Europea se hizo necesario persistir en el desarrollo de una estrategia eficaz. El ocaso de la ELisboa2000 supuso el comienzo de la "Estrategia Europa 2020" que analizaremos a continuación.

\subsubsection{Estrategia Europa 2020: Economía oculta tras la objetividad de la cuantificación}

En 2010, año en que finalizó el plazo para cumplir los objetivos de la Estrategia de Lisboa, la Unión Europea seguía manifestando problemas económicos a largo plazo. Persistía la amenaza de la competencia internacional, entre otras cosas debido a la necesidad de competir en la exportación con competidores de otros países como China o India con costes de producción mucho más bajos. Esto unido a la crisis del 2009 que contrajo la economía un 4\%, disminuyendo la producción industrial un $15 \%$ y aumentando el paro $10 \%$, mostraba pocas esperanzas en cuanto a capacidad de recuperación (FONSECA, 2010:23). La crisis se convirtió entonces en una llamada de atención más a la obligación de reconocer la incipiente necesidad de tomar medidas más eficaces para evitar pasar a un segundo plano en el orden global.

La elaboración de una nueva estrategia por parte de la Unión Europea fue la respuesta a esta situación de empeoramiento. La Estrategia Europa 2020 (E2020) tras los malos resultados obtenidos en la evaluación de la ELisboa2000, trató una vez mas de hacer frente a las carencias a las que hacían referencia los análisis para mejorar las perspectivas de la economía europea. Para ello centro su atención en alcanzar las prioridades de crecimiento inteligente, crecimiento sostenible y crecimiento integrador atendiendo igualmente a las tres dimensiones. La económica a través de la implantación de la economía del conocimiento y las TIC, la medioambiental a través de la mejora de la eficiencia en los recursos, y la social haciendo que estos cambios redundaran en empleo, equidad y cohesión (COMISIÓN EUROPEA, 2010d:7).

Si comparamos esta aproximación inicial a la de las anteriores estrategias se observan pocos cambios ya que estos principios recuerdan al crecimiento económico sostenible, cohesión social, y fomento del empleo, propios de la ELisboa2000 si añadimos la dimensión medioambiental que incluyó la EDS2001 y que continuó en la REDS2005. Y es que la diferencia más notable de esta estrategia respecto a sus predecesoras fue la intención de paliar la falta de concreción que existía en todas 
ellas y a la que una y otra vez se achacaban los problemas de eficacia. Según los informes de evaluación esta indefinición de las metas fue entre otras cosas la que propició la incapacidad de establecer un seguimiento eficaz del cumplimiento de las anteriores estrategias y por lo tanto supuso el fracaso en la implementación de las mismas.

En la "Estrategia Europa 2020" (en adelante E2020) la Comisión apostó por establecer cinco objetivos cuantificables, y por tanto fácilmente evaluables, que los organismos nacionales debían comprometerse a promover en las materias de empleo, investigación e innovación, cambio climático y energía, y educación y lucha contra la pobreza. Los objetivos pretendieron ser suficientemente ambiciosos en la evolución hacia un desarrollo sostenible, pero a la vez alcanzables y mesurables.

En la línea de crecimiento inteligente relacionado con la innovación, educación y sociedad digital, se fijaron dos objetivos cuantificables, reducir el abandono escolar por debajo del $10 \%$ y que al menos el $40 \%$ de los jóvenes tenga estudios superiores, y aumentar al $3 \%$ el porcentaje del PIB que debería ser invertido en I+D. La línea de acción de crecimiento sostenible recogía los compromisos 20/20/20 en materia de clima y energía, que implicaban la reducción de un $20 \%$ de las emisiones de $\mathrm{CO}^{2}$, el aumento de un $20 \%$ del uso de energías renovables para el 2020. Por último, la línea de crecimiento integrador recogió los objetivos cuantificables correspondientes a la dimensión social tales como el aumento de la tasa de empleo en el rango 20 a 64 años al 75\%, y disminuir en 20 millones el número de personas amenazadas por la pobreza.

La estrategia pretendía que el camino al alcance de esos objetivos mesurables desencaminara multitud de acciones a nivel nacional, comunitario e internacional, extendiendo su influencia a muchos otros ámbitos, inclinando la balanza a un nuevo modelo de desarrollo más sostenible. Sin embargo, surgieron nuevamente críticas hacia una estrategia que, a pesar de sus intenciones iniciales, no culminaría más que en otro eslabón hacia la insostenibilidad.

Una creciente oposición, tanto desde el sector social como desde el sector medioambiental, mostró una visión crítica a la estrategia que medía el éxito en función de la competitividad mundial, posicionando las materias social y medioambiental dimensiones subsidiarias en la consecución de los objetivos de crecimiento y producción global. De este modo, algunos sectores comprometidos con el medioambiente se quejaron de que el capital medioambiental tomara partido únicamente como termómetro de la sostenibilidad en lugar de incorporarlos como recurso para encaminarse a las políticas de desarrollo sostenible ${ }^{78}$. Igualmente ocurrió con los sectores comprometidos con el sector social. Y es que el "Estudio prospectivo anual sobre el crecimiento 2013" (COMISIÓN EUROPEA 2012) de la Comisión en el que se evalúan los avances obtenidos tras la aplicación de la E2020 ya se hacía eco de "la mejora experimentada por los desequilibrios

\footnotetext{
78"La Comisión acaba de lanzar su propuesta LULUCF (Land Use, Land-Use Change and Forestry) con reglas de contabilización de las emisiones y captura de carbono del sector forestal, incluyendo el secuestro de carbono en productos forestales. La propuesta trata solo de reglas de contabilidad, y aplaza para la próxima década la inserción plena de los bosques en las políticas de cambio climático".
} 
macroeconómicos"79" en contraposición a los escasos avances en materia social, donde advertían que "el desempleo se había incrementado sustancialmente y la miseria y la pobreza se estaban recrudeciendo" ${ }^{\prime 80}$.

En el informe queda patente que los avances en las diferentes dimensiones hasta entonces habían sido desiguales, especialmente acusados en materia social donde la intención inicial de reducir el desempleo y la pobreza se había visto fuertemente castigada por la crisis económica. Teniendo en cuenta que la E2020 se centraba en tres prioridades, crecimiento inteligente, crecimiento sostenible y crecimiento integrador por igual las expectativas iniciales no se estaban cumpliendo.

A pesar de que el informe enfatiza la necesidad de valorar en términos de equidad social las políticas derivadas de la estrategia, el año 2012 destacó por los avances en la estabilización del sector financiero, es decir, exclusivos de la dimensión económica y que no fueron acompañados de mejora en las dimensiones social o medioambiental, dimensiones que deberían haberse coordinado de forma integrada. Haber establecido como principal prioridad a corto plazo para el 2013 la estabilización económica hizo que se asentaran cinco objetivos que continuaban en la línea de la recuperación económica ${ }^{81}$ sin afectar en gran medida las dimensiones medioambiental ni social, al menos a corto plazo.

El propósito del informe prospectivo era establecer las prioridades económicas y sociales propiciando orientaciones a nivel comunitario y de cada estado miembro lo que hizo que esta perspectiva económica pronto llegara al ámbito nacional. Se pretendía con estas medidas alcanzar la competitividad mundial generando crecimiento a través de actividades sostenibles, con una utilización eficiente de los recursos y equidad social como objetivo a largo plazo una vez la crisis económica y financiera hubieran sido revertidas. Esto implica que nuevamente el bienestar social quedaba supeditado a que el crecimiento revierta en beneficios de índole social, dando por hecho nuevamente que ambas mejoras venían de la mano.

El 60 Informe de Evaluación de la Estrategia 2020 elaborado en octubre de 2015 volvió a hacer énfasis en el fracaso en la consecución de los objetivos fijados en

\footnotetext{
79 Los desequilibrios macroeconómicos que se habían ido acumulando a lo largo de mucho tiempo se estaban corrigiendo y algunas zonas de Europa estaban recuperando competitividad. COMUNICACIÓN DE LA COMISIÖN. "Estudio prospectivo anual sobre el crecimiento 2013", p. 1.(COMISIÓN EUROPEA 2012)

${ }^{80}$ Aunque todavía queda mucho camino por recorrer para "eliminar las divergencias en rendimiento" los avances en materia macroeconómica son notables en comparación con los avances en materia de empleo, I+D, clima/energía, educación y lucha contra la pobreza, y en conjunto Europa se está quedando rezagada respecto a sus objetivos. A la vez que destaca la necesidad de "avanzar en todos estos ámbitos para progresar hacia una economía europea inteligente, sostenible e integradora. COMUNICACIÓN DE LA COMISIÖN. "Estudio prospectivo anual sobre el crecimiento 2013", p. 1.(COMISIÓN EUROPEA 2012)

${ }^{81}$ COMUNICACIÓN DE LA COMISIÓN. "Estudio prospectivo anual sobre el crecimiento 2013", p. 3. (COMISIÓN EUROPEA 2012), Prioridades:

Proseguir la consolidación fiscal diferenciada y favorable al crecimiento.

Restablecer las condiciones normales de préstamo a la economía.

Fomentar el crecimiento y la competitividad actual y futura.

Luchar contra el desempleo y las consecuencias sociales de la crisis.

Modernizar la administración pública.
} 
2010. Y es que los avances en materia de energía, cambio climático, y educación eran algo visibles, mientras que los cambios en materia de empleo y I+D eran prácticamente inexistentes, y los problemas de igualdad social y económica entre las regiones era cada vez más evidentes, tanto entre los países miembros, como entre las capitales y resto de ciudades, así como la ciudad y sus periferias. La concentración económica tenía una repercusión territorial negativa que se manifestaba cada vez más evidente.

Todos los informes de revisión realizados de forma anual desde 2010 hacen referencia al fracaso, y establecen la necesidad de tener en cuenta la territorialidad y la contextualización, y de reforzar la cooperación entre administraciones. Estas deficiencias aparecen en el "Blueprint for a revised Europe 2020 Strategy" (COMITÉ DE LAS REGIONES 2014) elaborado ya en 2014, donde hacen una reflexión de las posibles mejoras de la E2020. Estos análisis al igual el conjunto de documentos internacionales y europeos evidenciaban la urgencia de hacer frente al desarrollo de estrategias que tuvieran en cuenta la base territorial mucho más presente para así evitar que pudieran seguir produciéndose estas desigualdades en la recepción de los beneficios que pudieran producirse en la escala macroeconómica.

Si bien es cierto que el crecimiento sigue presente como base persistiendo la vinculación entre desarrollo y bienestar, mediante este nuevo acercamiento se pretendía al menos que éste se produjera de forma más equitativa. Las estrategias de base territorial han estado presentes a lo largo de la incorporación del desarrollo sostenible, y su desarrollo ha sido paralelo a las estrategias de desarrollo sostenible a pesar de que, como mencionan los informes, poco han conseguido respecto a la perpetuación de la Europa policéntrica que describen los documentos.

\subsection{La incorporación de la base territorial en el proceso de recepción del desarrollo sostenible}

\subsubsection{Estrategia Territorial Europea 1999: el policentrismo europeo como prioridad para el reequilibrio territorial}

Al igual que las políticas públicas, las estrategias fueron tomando conciencia del marcado carácter territorial que acompañaba a los problemas para alcanzar la sostenibilidad. Para llegar a ser eficientes, las estrategias debían analizar y promover cambios superando esta visión sesgada.

La "Estrategia Territorial Europea" de 1999 (ETE1999) pretende atajar estas deficiencias(COMISIÓN EUROPEA 1999a). La falta de coordinación entre los distintos territorios estaba provocando sinergias negativas que en vez de beneficiarse de la red existente entre las ciudades europeas estaba perjudicando a los territorios. De esta forma las intervenciones hacia la sostenibilidad en ocasiones quedaban neutralizadas por producir finalmente efectos negativos en la escala europea. La ETE1999 sintonizaba con los principios acordados en 1994 de voluntad de coordinación interterritorial derivados de la "Carta de Aalborg". Y respetando las instituciones existentes y sus competencias, así como el principio de subsidiariedad, 
con la implantación de la estrategia se pretendió alcanzar la cohesión económica y social a través de la ordenación del territorio.

La incorporación de los principios de la ETE1999 requería de la intervención en tres niveles: el nivel comunitario, el nivel transnacional/nacional, el nivel regional/local, y de la implicación de todos los actores, destacando la importancia de que el ciudadano tome un papel activo. Las pautas que marcaba la estrategia europea pretendían ser englobadas en las políticas nacionales, aunque lo cierto es que esto al igual que con el resto de estrategias de desarrollo sostenible siempre dependió de la propia voluntad de cada estado de incorporar los aspectos europeos del desarrollo territorial.

Nos encontramos por tanto con una estrategia que trata de traspasar las estructuras administrativas tradicionales para responder a un territorio que ya no se corresponde con las fronteras existentes. Se basaba en la idea de que para afrontar temas económicos, sociales, naturales, y culturales de forma equilibrada era necesaria la implicación de todas las regiones de la UE asegurando un sistema policéntrico de ciudades. Toda esta coordinación para alcanzar los tres objetivos políticos fundamentales propuestos que se correspondían con la cohesión económica y social, la conservación de los recursos naturales y del patrimonio cultural, y la competitividad más equilibrada del territorio europeo (COMISIÓN EUROPEA 1999a).

Apostaban para ello por el desarrollo sostenible. Esto implicó amparar bajo la estrategia territorial la apuesta por el crecimiento según la interpretación de Brundtland, pero fomentando a la vez el reequilibrio de las externalidades positivas de este desarrollo en el territorio. Es decir, nuevamente se apoyaba en el bienestar asociado al crecimiento, y equidistribucción supeditada al desarrollo.

Independientemente de la falta de competencia comunitaria en materia de territorio, la ETE1999 sentó unas orientaciones futuras que reflejaban la voluntad de los Estados miembros por lograr nuevos acuerdos en la organización territorial. Sin embargo, la coordinación de los objetivos conocidos como la triple C, cooperación, concentración y competencia, se mostró de difícil resolución (SOUTO GONZALEZ 2006).

Por un lado la combinación de la competencia y la coordinación fue compleja, pues si bien es cierto que se establecían objetivos de equilibrio, sin una imposición de un órgano superior ningún territorio fue capaz de abandonar las desconfianzas hacia la colaboración, y es que a pesar de estas intenciones, incluso en ciudades con pactos institucionales existieron recelos (SOUTO GONZALEZ 2006). Por otro, las intenciones de reforzar las relaciones ciudad/rural con igual acceso a infraestructuras, conocimiento, etc., no acabaron por consolidarse. La mundialización continuó con la deslocalización del consumo, y por tanto la desvinculación de las ciudades del entorno productivo alejándose del sistema ecológico-sistemático y acercándose al económico-sistemático ${ }^{82}$ donde la ciudad como ecosistema perdía su significado.

82 Con económico-sistemático y ecológico-sistemático hacemos referencia a la toma de posición respecto de la visión económico-ambiental y la ecológico-ambiental respectivamente. Visiones contrapuestas que desarrollamos 
Finalmente, la cooperación trasnacional llegó a materializarse aunque con poco éxito. Ésta se llevó a cabo a través de diferentes programas que trataron problemas comunitarios que trascendían los límites de un territorio concreto. Un ejemplo es la iniciativa INTERREG, entre otras INTERREG IIC ${ }^{83}$, donde para favorecer a la cooperación trasnacional se organizaron los territorios en grupos con una cualidad común como eran: territorios con posibilidades de cooperación territorial donde se encontraba el "espacio atlántico", territorios con problemas de inundaciones comunes como el espacio Rin/Mosa, etc. De esta forma y a través de la cooperación pretendían alcanzase soluciones de forma más rápida y de manera que cada territorio pudiera beneficiarse de las estrategias de éxito de otro con la transposición a su contexto de iniciativas similares. Sin embargo, estas agrupaciones respondieron poco a la cooperación encaminada a alcanzar una Unión Europea policéntrica.

A pesar de que los avances eran poco notables la apuesta por la integración de la dimensión territorial continuó, y por tanto el desarrollo de estrategias territoriales que intentaron frenar la desintegración de la red de ciudades europeas cada vez más amenazada por la concentración y la competencia global. A continuación analizaremos los posteriores documentos desarrollados con objetivo de reforzar la dimensión territorial en el avance hacia el desarrollo sostenible.

\subsubsection{Agenda Territorial Europea 2007: Reforzando la dimensión territorial de la Estrategia de Lisboa}

En la apuesta por un desarrollo sostenible, así como en la ETE, 1999 quedaba implícita la necesidad de cohesión territorial. Sin ésta continuarían produciéndose desequilibrios que darían lugar a desigualdades sociales, exclusión (SASSEN 2011), y problemas medioambientales incoherentes con la sostenibilidad que ya habían sido descritos con anterioridad.

Tal y como ponen de manifiesto los informes de seguimiento estos desequilibrios finalmente continuaron produciéndose. El "Cuarto informe sobre la cohesión económica y social" (COMISIÓN EUROPEA 2007b), además de ensalzar los reequilibrios producidos a escala comunitaria entre los estados, recuperándose estados que por aquel entonces como España estaban en la cola en comparación con las potencias centrales, previno de una tendencia que sin embargo estaba desequilibrando los territorios nacionales en su interior. $Y$ es que los centros

con mayor profundidad en el capítulo: 1. De la sostenibilidad al desarrollo sostenible en su proyección a las políticas públicas, subcapítulo: 1.1 La huella económica en el proceso de incorporación de la dimensión ambiental. Ya mencionadas en el capítulo: 2. Consecuencias del enfoque del desarrollo sostenible en la regeneración urbana integrada, y ampliable en la publicación: (ERIAS REY \& ÁLVAREZ-CAMPANA GALLO, 2007:83).

83 La Iniciativa comunitaria INTERREG II-C, financiada por el Fondo Europeo de Desarrollo Regional (FEDER) de la Comisión Europea, tiene como principal finalidad promover la cooperación en materia de ordenación del territorio en zonas geográficas de diferentes Estados miembros para contribuir al incremento de la cohesión económica y social de la Unión. La medida C de la Iniciativa Comunitaria Interreg II busca así promocionar un desarrollo equilibrado y armónico en materia de ordenación del territorio europeo, a través de la cooperación transnacional. Esta cooperación, que requiere la participación de los Estados y de las autoridades competentes en materia de ordenación del territorio, se basa en una serie de prioridades relativas al desarrollo de los territorios y definidas, de común acuerdo, por el conjunto del espacio transnacional en cuestión. De la web: http://www.interregsudoe.org/castellano/programa/interregIIc.asp [22/12/2016].(SUDOE 2000) 
urbanos con más dinamismo estaban creciendo enormemente mientras que otros sistemas urbanos estaban decreciendo viéndose su capacidad de recuperación enormemente mermada.

A pesar de que en 1999 la ETE ya sentaba precedente sobre la gran importancia de la dimensión territorial para alcanzar la sostenibilidad, esta dimensión no fue tratada en profundidad en ninguna de las Estrategias de Desarrollo Sostenible posteriores, manteniéndose la dimensión territorial en un segundo plano a pesar de las exigencias de internacionalización ${ }^{84}$. Será la revisión de la ETE1999, que da lugar a la "Agenda Territorial Europea" de 2007 (en adelante ATE2007), la que continuó con la definición de la interpretación territorial europea comunitaria comúnmente aceptada (COMITÉ ECONÓMICO Y SOCIAL 2007). Esta agenda, resultado de la Reunión Informal de Ministros de Desarrollo Urbano y Cohesión Territorial el 24 y 25 de mayo de 2007 en Leipzig, quiso funcionar como complemento de la ELisboa2000 en la dimensión territorial.

Exponiendo que "Necesitamos que, de forma creciente, todas las personas e instituciones involucradas en el proceso de desarrollo urbano aúnen estrategias globales y coordinen sus acciones más allá del ámbito aislado de cada ciudad y comunidad", extendía el carácter territorial de las estrategias más allá de los límites administrativos. Y enfatizando la importancia de "Con el fin de alcanzar el modelo de ciudad, más sostenible y socialmente más inclusiva,...Aplicar estrategias de desarrollo urbano integrado, con una visión global y exhaustiva de la ciudad, convenientemente enmarcadas dentro de una perspectiva territorial, que promuevan armoniosamente todas las dimensiones de la sostenibilidad de un modo integrado" (COMISIÓN EUROPEA 2007a), reforzaba la apuesta por la visión policéntrica.

El mismo año que se consolida la cohesión territorial en el marco europeo, y que la "Carta de Leipzig" lucha por la consolidación del desarrollo urbano sostenible, año 2007, la ATE2007 deja asociados los desafíos de desarrollo sostenible a unos objetivos de índole territorial que ya habían sido destacados en la ETE1999 como son el desarrollo de un sistema urbano equilibrado y policéntrico, una nueva relación urbano-rural, asegurar el acceso a las infraestructuras y al conocimiento, y el desarrollo sostenible referido a la gestión prudente y protección del patrimonio natural y cultural (COMITÉ ECONÓMICO Y SOCIAL, 2007:3). Estos tres objetivos recuerdan a los que presentó más adelante la E2020 en 2010 bajo las etiquetas de crecimiento integrador, crecimiento inteligente y crecimiento sostenible, objetivos que como hemos visto no aseguraron el avance hacia la sostenibilidad por el peso concedido a la búsqueda de crecimiento, que finalmente tergiversó las metas a alcanzar.

\footnotetext{
${ }^{84}$ A pesar de que las Estrategias y Agendas Territoriales daban a conocer la importancia de la dimensión territorial, las estrategias de Desarrollo Sostenible no profundizaron en esta dimensión con la misma contundencia que hicieron con dimensiones como la ambiental, social, etc. Véase que el capítulo sobre Estrategias de Desarrollo Sostenible Europeas ya se hace referencia a esta escasa importancia concedida al proceso de internacionalización.
} 
En el año 2016, los informes referentes a la consolidación del policentrismo ${ }^{85}$ en la Unión Europea manifestaban grandes desigualdades territoriales en cuanto a la equidistribución de estructuras urbanas, accesibilidad, y cooperación territorial (ESPON 2016).

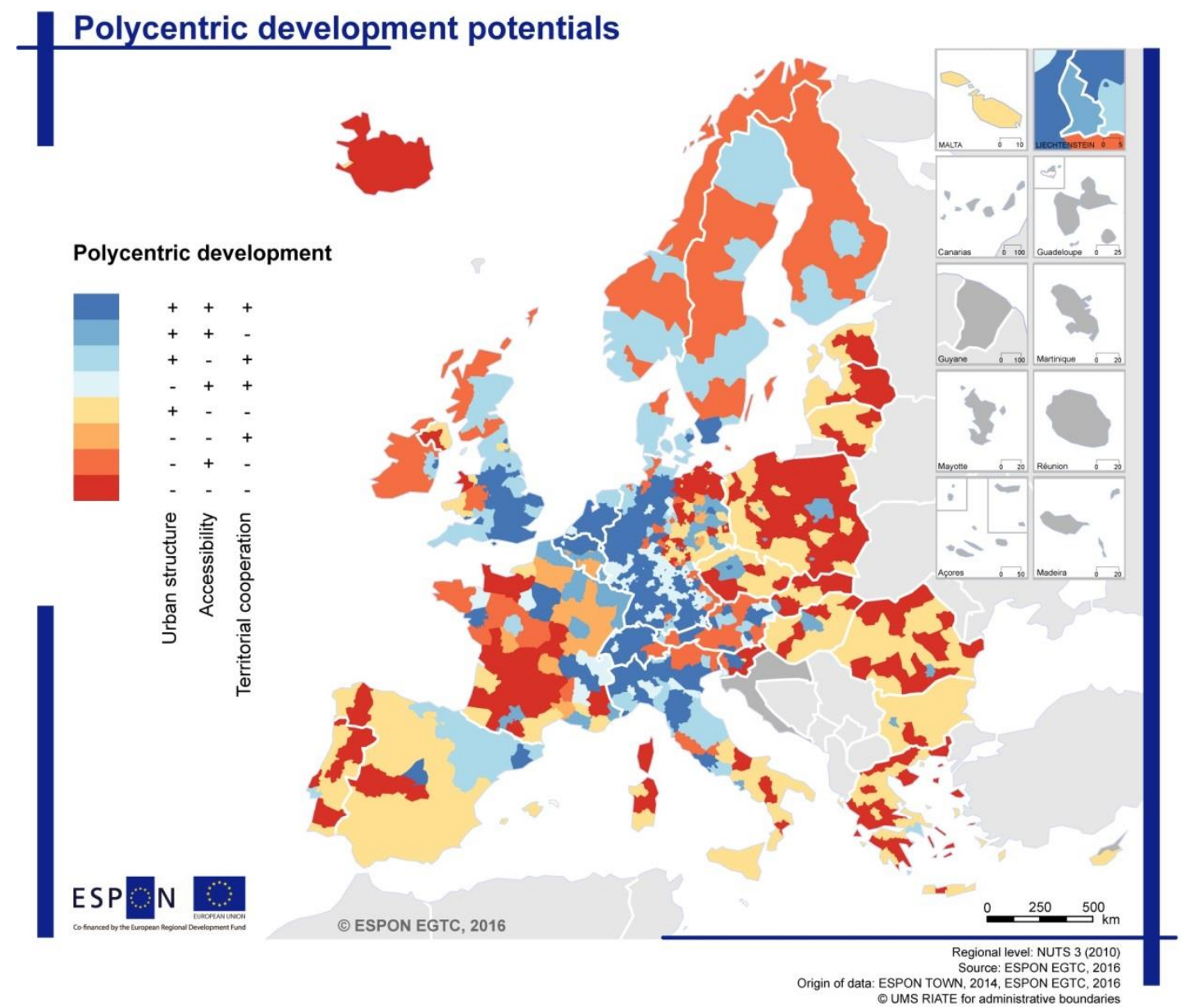

Figura 6. Desarrollo del policentrismo en la Unión Europea en 2016

Fuente:ESPON 2016

A pesar de que la ATE2007 promovió la visión del desarrollo sostenible en clave territorial al igual que lo hizo su versión posterior, la "Agenda Territorial Europea 2020" (en adelante ATE2020), el gráfico correspondiente al desarrollo del policentrismo (Figura 8) manifiesta claras deficiencias. Estas incoherencias se achacan en parte a la interpretación de la cohesión territorial, y a la falta de cooperación. El concepto cohesión en sí como requisito fue descrito desde el inicio

85 El policentrismo es un concepto que anima a las regiones y ciudades, a trabajar con territorios vecinos, explorar fortalezas comunes y revelar complementariedades potenciales, lo que aporta un valor añadido que no puede lograrse por regiones y ciudades aisladas. Es importante destacar que una aproximación policéntrica permite unir los activos existentes con el fin de aumentar su poder competitivo, recursos limitados evitando la duplicación de roles y funciones y trayendo más beneficios para habitantes locales utilizando el potencial combinado de recursos. ESPON, Policy Brief: Polycentric Territorial Structures and Territorial Cooperation, Octubre, 2016, ISBN: 978-2919777-98-3.(ESPON 2016) 
en las estrategias territoriales. Sin embargo, al igual que el término sostenibilidad encerraba gran carga de abstracción e involucraba en el a actores tan diversos que la intencionalidad en su utilización podía dar lugar a modelos territoriales muy dispares (ASCASIBAR ZUBIZARRETA 2007). Por otro lado, a pesar de las agendas también hicieron hincapié en la necesidad de cooperación y de establecer nuevas formas de gobernanza estas cooperaciones no llegaron a producirse.

Como vimos en el capítulo anterior, las evaluaciones de las estrategias dejaron patente la escasa eficacia de las mismas en la consecución de avances de reequilibrio territorial, esto refleja el escaso impacto de las agendas y estrategias territoriales en el devenir territorial europeo. La ATE2020 será la sucesora de la ATE2007 en la visión territorial del desarrollo sostenible, y por tanto la encargada de influir en la ya existente E2020.

\subsubsection{Agenda Territorial Europea 2020: un nuevo refuerzo de la dimensión territorial}

En la Reunión Informal de Ministros responsables de Ordenación del Territorio y Desarrollo Territorial de Hungría el 19 de mayo de 2011 se acuerda la "Agenda Territorial de la Unión Europea 2020. Hacia una sociedad integradora, inteligente y sostenible para una Europa de regiones diversas", en adelante ATE2020.

Con el objetivo de adaptar la ATE2007 a la realidad europea del 2011, así como a los nuevos documentos europeos sobre desarrollo sostenible, entre los que destaca la E2020, se desarrollaba la ATE2020. Las perspectivas presentadas en el "Quinto Informe sobre la cohesión económica, social y territorial" (COMISIÓN EUROPEA 2010e), momento en que ya había sido añadida la dimensión territorial, sirvieron de apoyo en la elaboración de las nuevas orientaciones para la agenda. Destacar de esta, además del refuerzo en los ámbitos establecidos por su predecesora en temas demográficos, cambio climático, energía, y desafíos medio ambientales, el hincapié con que trata los retos que la globalización estaba imponiendo en la dimensión territorial para alcanzar un desarrollo sostenible.

Y es que la mundialización estaba haciendo a las ciudades más vulnerables a interferencias externas. Esto llevó a que la ATE2020 reconociera la ambivalencia de necesariamente reforzar una serie de ciudades, áreas metropolitanas, o regiones que funcionaran de forma competitiva en el ámbito internacional, sin olvidar que estas ventajas que recibieran de su posición privilegiada debían ser compartidas con el resto de territorios que no siendo tan competitivos podían verse enriquecidos a través de la creación de redes. Esta necesidad de reequilibrio no era nueva. Sin embargo, ya cuando hablábamos sobre la triple $C^{86}$, propuesta por la ETE1999, hacíamos referencia a la dificultad para que las ciudades vencieran los recelos de cooperación.

86 Término introducido por J. Farinos en: ROMERO GONZÁLEZ, Juan y FARINÓS DASÍ, Joaquín (editores). Ordenación del territorio y desarrollo territorial. El gobierno del territorio en Europa: tradiciones, contextos, culturas y nuevas visiones, Gijón: Ediciones Trea, S.L, 2004 y al que se hace referencia en el artículo: SOUTO GONZALEZ, Xosé Manuel, La estrategia territorial europea: racionalización o privatización del espacio geográfico, Biblio 3w, Vol. XI, no 664, 20 de julio de 2006, ISSN: 1138-9796. (SOUTO GONZALEZ 2006) 
La Agenda se constituyó finalmente como complemento de la E2020 en la dimensión territorial aunque esta dimensión continúa siendo en la actualidad la asignatura pendiente. A pesar de que el crecimiento de la Unión Europea en referencia a su PIB fluctúa, los desequilibrios territoriales son crecientes, tanto entre estados miembros, como entre centro y periferia de las ciudades. ESPON desarrolló una serie de escenarios territoriales para 2050 (GAL 2014), que van del reequilibrio, al recrudecimiento de los desequilibrios territoriales. Debemos preguntarnos hacia donde queremos caminar. Actualmente los informes muestran que la Unión Europea camina hacia el recrudecimiento de las condiciones en algunos puntos del territorio en lugar de al reequilibrio. El gráfico que vemos a continuación refleja el aumento de los países con problemas de crecimiento frente al fortalecimiento del área central.

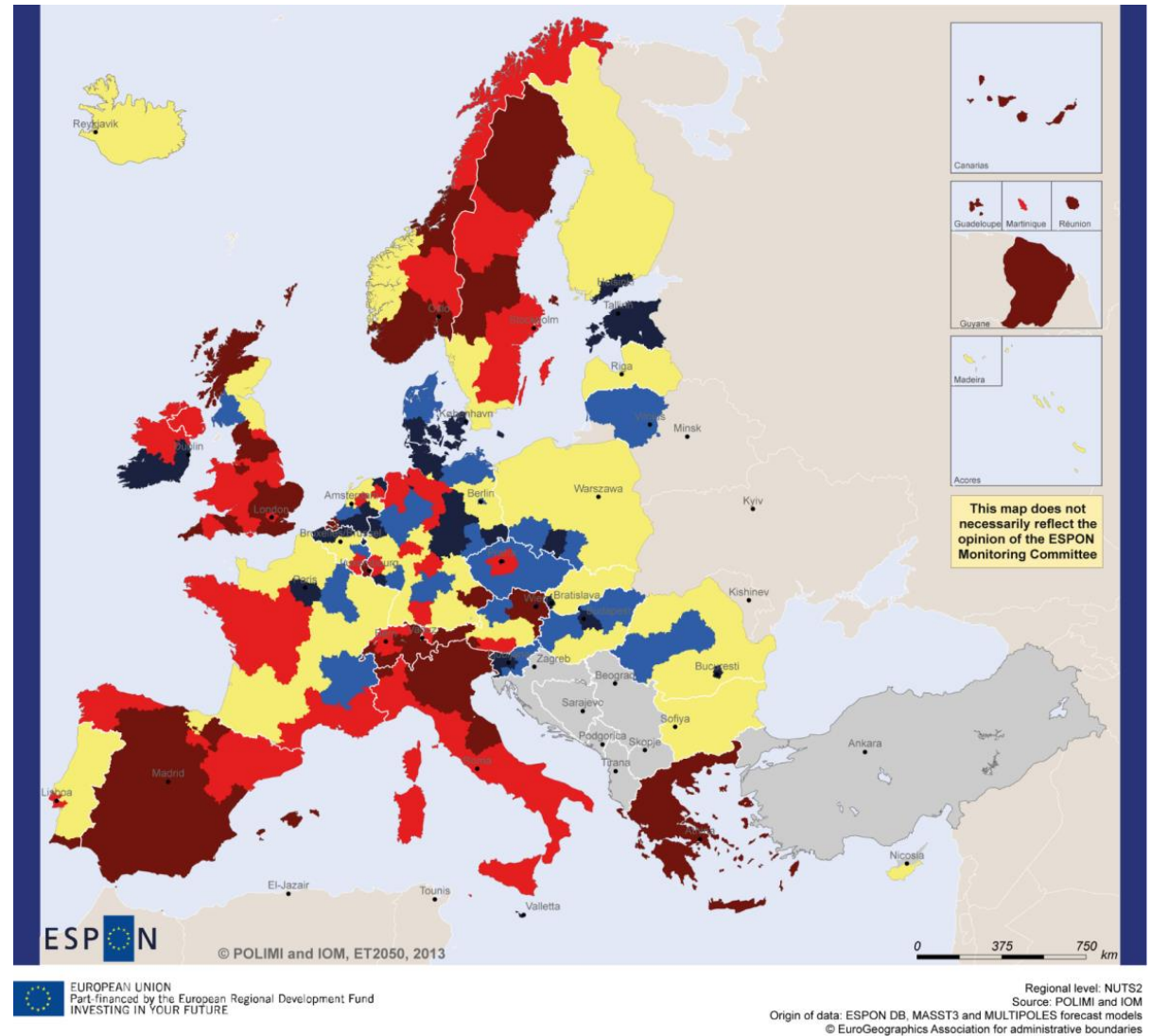

PIB. Variación Porcentual en los periodos 2010-2030.

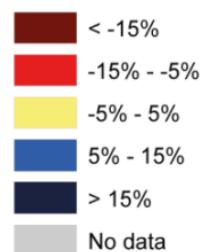

Figura 7. ESPON DATABASE: PIB variación porcentual en los periodos 2010-2030.

Fuente: GAL 2014. 
Es más que evidente que las estrategias han ido evolucionando positivamente por una parte a la par que los principios europeos de desarrollo sostenible. Las estrategias territoriales al igual que las de desarrollo tendieron a incorporar las dimensiones social y ambiental que ya consideraba por aquel entonces el desarrollo sostenible. Sin embargo, a pesar de estos avances los resultados siguen siendo insatisfactorios una y otra vez, y es que la interpretación de la sostenibilidad aparece ligada en las estrategias territoriales nuevamente a la malinterpretación del desarrollo sostenible como competencia en el crecimiento a escala global, y derivado de este, a la malinterpretación del policentrismo como competencia interna y refuerzo de los territorios de cabecera.

A pesar de la existencia de este marco territorial comunitario europeo, con líneas de actuación concretas como el empleo, el cambio climático, y de la adopción de unos objetivos concretos definidos en la E2020 como son los objetivos 20/20/20, todo el proceso estratégico no habría sido coherente si no se hubiera incorporado en otras escalas del territorio. Para acelerar el proceso de incorporación de la sostenibilidad era necesario el apoyo de todos los actores y de las administraciones que intervienen en el proceso, pues, sin su implicación y colaboración la trasposición a los Estados miembros no habría funcionado.

Sin embargo independientemente de la implicación, como veremos a continuación, en su incorporación al ámbito nacional en España los resultados de escala nacional se mostraron igualmente insatisfactorios. Muchas críticas también vienen a resaltar el ostracismo hacia las estrategias territoriales de todas aquellas legislaciones, planes o estrategias más allá de la propia política de ordenación del territorio, incluso de las propias políticas comunitarias de otros ámbitos (HILDENBRAND SCHEID 2009) a pesar de que existieron estrategias en todas las escalas.

\subsection{Estrategias españolas de desarrollo sostenible: Influencias del proceso de incorporación europea del desarrollo sostenible en el ámbito nacional}

Debemos recuperar en este epígrafe el concepto de "coordinación vertical", para comprender que las estrategias nacionales son la plasmación de esa voluntad de coordinación entre todos los niveles de la Administración con el objetivo de aumentar la eficacia de las actuaciones y del interés del ciudadano por las políticas europeas. Este concepto aparecía desarrollado con más profundidad en "Libro Blanco sobre Gobernanza Multinivel"(COMITÉ DE LAS REGIONES 2009) entendiendo la gobernanza multinivel como "la acción coordinada de la Unión, los Estados miembros y los entes regionales y locales, basada en la asociación y destinada a

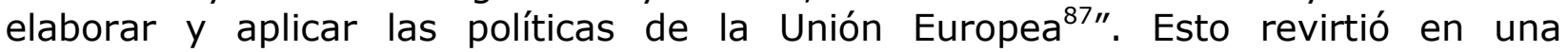

\footnotetext{
87 DICTAMEN COMITÉ DE LAS REGIONES: "Europa será fuerte, sus instituciones legítimas, sus políticas eficaces, sus ciudadanos se sentirán implicados e involucrados, si el modo de gobernanza de la misma garantiza la cooperación entre los distintos niveles de poderes a fin de aplicar la agenda comunitaria y de responder a los retos globales". "Libro Blanco sobre Gobernanza Multinivel", 2009. p.3.(COMITÉ DE LAS REGIONES, 2009:3)
} 
responsabilidad compartida de los diversos niveles de poder en cuestión pero legitimando los valores democráticos por su representatividad de los diversos agentes implicados. Por tanto, sin pretender alterar las competencias propias de cada administración, se pretendió que estas favorecieran la permeabilidad a los principios de la Unión Europea, y por tanto, a su interpretación de la sostenibilidad, del desarrollo sostenible y finalmente del policentrismo.

En 2009 el "Libro Blanco sobre Gobernanza Multinivel" destacaba que "en la Unión Europea, alrededor de 95.000 entidades territoriales ostentan poderes de primer orden en sectores clave, como la educación, el medio ambiente, el desarrollo económico, la ordenación del territorio, los transportes, los servicios públicos y las políticas sociales, y contribuyen al ejercicio de la democracia y de la ciudadanía europeas" (COMITÉ DE LAS REGIONES 2009). Esto nos da una idea de la gran importancia que supuso que las estrategias en los distintos niveles llegaran a complementarse y reforzarse mutuamente para adaptarse al nuevo contexto, en el que el Comité de las Regiones señala como principales objetivos la adaptación al mundo global sin perder la diversidad territorial, y la eliminación de barreras y unión de mercados europeos sin que esto revierta en desigualdades económicas entre los estados.

Todos los Estados miembros han ido definiendo sus propias estrategias nacionales de desarrollo sostenible. Sin embargo, los informes de evaluación apuntan que "no se había aprovechado plenamente la posibilidad de un aprendizaje mutuo que permita identificar los obstáculos y las soluciones eficaces" (COMISIÓN EUROPEA 2005). En el siguiente epígrafe desarrollaremos las estrategias españolas que trataron de traducir las estrategias europeas al contexto nacional.

\subsubsection{Estrategia Española de Desarrollo Sostenible (2007): primeros pasos hacia la REDS2005}

Atendiendo a la petición europea de trasposición de las orientaciones comunitarias en materia de desarrollo sostenible a los estados miembros en España comenzaron a elaborarse estrategias que iban acompañando a la lectura europea de desarrollo sostenible. Tomando cada vez más peso la necesidad de coordinación administrativa, "se persiguió una mayor coherencia entre las iniciativas europeas, mundiales, nacionales, regionales y locales a favor del desarrollo sostenible" (COMISIÓN EUROPEA, 2006:4).

La "Estrategia Española de Desarrollo Sostenible" de 2007 (EEDS2007) fue el primer paso hacia la incorporación de la REDS2005 al ámbito nacional ${ }^{88}$. Por aquel entonces España se encontraba en una etapa de fuerte crecimiento económico que venía acompañado de elevadas presiones sobre el medio ambiente. La EEDS2007, siguiendo las orientaciones europeas, pretendió equilibrar la balanza, fomentando el consumo y la producción sostenibles para "garantizar la prosperidad económica,

\footnotetext{
88"La modernización de nuestro país exige que asumamos colectivamente el reto y la oportunidad que ofrece un modelo de desarrollo sostenible que haga compatible una dinámica de prosperidad económica, conjuntamente con el aumento del bienestar social y la mejora del medio ambiente". MINISTERIO DE LA PRESIDENCIA: "Estrategia Española de Desarrollo Sostenible", Madrid, 2007, p. 9. (MINISTERIO DE LA PRESIDENCIA, 2007:9)
} 
asegurar la protección del medio ambiente, evitar la degradación del capital natural, fomentar una mayor cohesión social teniendo en cuenta las tendencias demográficas actuales y contribuir solidariamente al desarrollo de los países menos favorecidos en aras de la sostenibilidad global" (MINISTERIO DE LA PRESIDENCIA 2007).

En el capítulo sobre "Principales Objetivos" (MINISTERIO DE LA PRESIDENCIA, 2007:30) la estrategia definió las metas, que enmarcadas en tres epígrafes, concretaban los objetivos específicos correspondientes a la sostenibilidad ambiental, social, y global encaminados a equilibrar el balance entre las dimensiones. En el epígrafe sostenibilidad ambiental se desarrollaban los aspectos de la producción y el consumo, el cambio climático y, la conservación y gestión de recursos naturales y ordenación territorial. La sostenibilidad social desarrollaba aspectos sobre el empleo-cohesión social-pobreza, y salud pública y dependencia. Y por último la sostenibilidad global se encargaba de los objetivos de cooperación internacional para el desarrollo.

Existe una relación clara entre los objetivos de la EEDS2007 y los que había definido la REDS2005, donde además de los objetivos de la ELisboa2000, también aparecían aspectos de internacionalización. Esta correspondencia con los aspectos que trataba la estrategia europea nos muestra, por un lado la apertura a una lectura multidimensional tan demandada en el estudio de las relaciones del hombre y el medio, pero a la par la filtración de las malinterpretaciones de los términos comunitarios a la escala nacional. Ya eran conocidas en 2007 las primeras evaluaciones de la ELisboa2000 y las deficiencias que en muchos casos apuntaban a la falta de concreción de la estrategia. Sin embargo, la incorporación a la escala nacional no pareció avanzar demasiado en el grado de definición y mejora de las disfunciones de la estrategia europea.

La EEDS2007 en su desarrollo estableció siete "áreas prioritarias" con las principales amenazas de la sostenibilidad del modelo de crecimiento español. Cambio climático y energías limpias; transporte sostenible; producción y consumo sostenibles; retos de la salud pública; gestión de recursos naturales; inclusión social, demografía y migración; y lucha contra la pobreza mundial, son los epígrafes definidos por la EEDS2007, que aunque en diferente agrupación, coinciden con las establecidas por la REDS2005 ${ }^{89}$.

Para garantizar el cumplimiento de los objetivos de esta visión multidimensional, se comprometió a desarrollar políticas de crecimiento económico y empleo coherentes y a establecer lazos de colaboración con las comunidades autónomas y municipios. A pesar de los esfuerzos por concretar, numerosas fueron las voces que acusaron de conformista a la estrategia propuesta por su falta de proposición de

\footnotetext{
${ }^{89}$ Véase la similitud con los temas transversales propuestos para la "Revisión de la Estrategia para un desarrollo sostenible": establece una serie de temas transversales, cambio climático y energía limpia, salud pública, exclusión social - demografía - flujos migratorios, gestión de los recursos naturales, trasportes sostenibles, y pobreza en el mundo-retos en materia de desarrollo. COMUNICACIÓN DE LA COMISIÓN AL CONSEJO Y AL PARLAMENTO EUROPEO relativa a la "Revisión de la Estrategia para un desarrollo sostenible. Plataforma de acción", p. 613.(COMISIÓN EUROPEA 2006)
} 
unos objetivos que capacitaran la posible evaluación posterior del cumplimiento de los mismos. De esta forma dejaron en manos de la planificación sectorial (Planes de Acción posteriores, de Planes de Movilidad, Código Técnico de la Edificación, etc.) el establecimiento de unos índices, es decir, de unas metas claras.

Por otro lado debemos destacar la falta de participación en la elaboración de las estrategias. A pesar de ser como se enfatizaba en la REDS2005 una de las piezas clave en la consecución del desarrollo sostenible la necesidad de participación de actores públicos y privados a todos los niveles (COMISIÓN EUROPEA 2005), el desarrollo de los documentos siguió la línea de las normas jurídicas donde poca o ninguna intervención del ciudadano era posible.

Derivada de esa abstracción y falta de implicación, al igual que en las estrategias europeas, en el ámbito nacional nuevamente quedaba abierto el campo de la abstracción y la incoherencia con las necesidades reales. Estas deficiencias permitían nuevamente que la integración de las diferentes dimensiones pudiera verse vulnerada y que continuaran produciéndose desequilibrios. Analizaremos a continuación la "Estrategia Española de Sostenibilidad Urbana y Local" de 2009, para interpretar la perspectiva local por la que se apuesta desde el ámbito nacional.

\subsubsection{Estrategia Española de Sostenibilidad Urbana y Local 2009: avanzando a la escala local}

La "Estrategia Española de Sostenibilidad Urbana y Local" de 2009 venía a complementar a la EEDS2007 como documento de referencia en el análisis y planteamiento de objetivos y propuestas para afrontar los problemas observados en el territorio nacional en la escala local.

El "Libro Verde de Medio Ambiente Urbano"90 precedió la elaboración de esta estrategia y fue la referencia para el desarrollo de la EESUL2009 que pretendió recoger de manera pormenorizada los principios, objetivos, directrices y medidas cuya aplicación permitiera avanzar hacia la sostenibilidad a escala local.

Para ello realizó un diagnóstico incidiendo en las cuestiones "territorial y urbano; los instrumentos urbanísticos; las relacionadas con la accesibilidad, movilidad y transporte; la gestión y la gobernanza urbana; la edificación y la rehabilitación, y el cambio climático" (MINISTERIO DE AGRICULTURA, 2009:6), aspectos que se correspondían con los ámbitos temáticos que proponía la EEDS2007. Estas cuestiones primordiales se estudiaban desde una perspectiva más concreta y local atendiendo a tres parámetros que enunciaba la EESUL2009 y eran: "a. La eficacia de las medidas de conservación y mejora de la naturaleza, la flora y la fauna y de la protección del patrimonio cultural y del paisaje. b. La protección, adecuada a su carácter, del medio rural y la preservación de los valores del suelo innecesario o inidóneo para atender las necesidades de transformación urbanística. c. Un medio urbano en el que la ocupación del suelo sea eficiente, que esté suficientemente

\footnotetext{
90 Documento del Ministerio de Medio Ambiente: Libro verde de medio ambiente urbano. Documento de trabajo 2007. Tomo I, Tomo II, 2007. Accesible en: http://www.ecourbano.es/greenbook.asp, (MINISTERIO DE MEDIO AMBIENTE Y MEDIO RURAL Y URBANO ESPAÑA 2007)
} 
dotado por las infraestructuras y los servicios que le son propios y en el que los usos se combinen de forma funcional y se implanten efectivamente, cuando cumplan una función social." (MINISTERIO DE AGRICULTURA, 2009:42).

Todo este planteamiento quedó desarrollado en unas directrices que se corresponden con el punto cinco del documento la EESUL2009 "Directrices generales y medidas concretas por ámbitos temáticos" (MINISTERIO DE AGRICULTURA 2009) y pretendían servir de guía para el futuro desarrollo de los nuevos documentos de ordenación territorial. Nuevamente las acciones desarrolladas por las directrices circunscribieron sus intenciones a "fomentar, promover, favorecer, impulsar" la utilización de recursos y de una estructura urbana más sostenible sin marcar ninguna meta concreta generando gran confusión a la hora de fomentar la adaptación de cada localidad con la intención de acogerse a esta estrategia nacional.

A pesar de ello debemos destacar el esfuerzo por acometer este primer acercamiento a la escala local realizado por el Gobierno de España. Si bien es cierto, que no estableció unos objetivos clave hacia los que caminar, si impulsó el desarrollo de un sistema de redes como medio para canalizar el modelo, tanto de ámbito nacional y de temáticas sectoriales (clima, biodiversidad, etc.), como observatorios locales que llegaron a desarrollarse con apoyo municipal.

El primer acercamiento de escala nacional a los principios europeos de desarrollo sostenible se había producido. Sin embargo, los instrumentos de seguimiento que en último término debían corregir las incoherencias en la aplicación de las estrategias no fueron capaces de hacer frente a los problemas de interpretación derivados de la ambigüedad en la definición de éstas. Y al igual que en el ámbito comunitario europeo, el desarrollo sostenible de las estrategias locales continuó en la línea del crecimiento, y el policentrismo afectó a los sistemas urbanos cabecera sin que estos revirtieran sus beneficios en los territorios deprimidos.

\subsubsection{Estrategia Española de Sostenibilidad Urbana y Local 2011: reiteración en la importancia de la dimensión urbana}

La "Estrategia Española de Sostenibilidad Urbana y Local" de 2011 (EESUL2011) no es más que el desarrollo pormenorizado de la EESUL2009 enfatizándose aún más la escala territorial debido a la influencia de las ciudades en el ámbito rural y en el medioambiente ${ }^{91}$. Desde el ámbito internacional Maurice Strong, Secretario General de la Cumbre de Río de 1992, ya había hecho referencia a las repercusiones que las ciudades estaban teniendo sobre los entornos naturales no siendo estas desconocidas. Para reforzar esta visión, a las directrices de la dimensión urbana, de movilidad, gestión urbana, edificación, y cambio climático, se unirá una nueva, correspondiente a relaciones entre el mundo rural y el mundo urbano. Con ésta

\footnotetext{
91 "La EESUL incide en la base de la organización urbana futura y, por ello, incide en los fundamentos que nos deben conducir por la senda de la sostenibilidad, sabiendo que la batalla de la sostenibilidad se ganará o se perderá, en buena medida, en las ciudades; es decir: en cómo organicemos, desde hoy, la ciudad del futuro, integrada a nivel territorial, en estrecha asociación con otras ciudades y sus áreas rurales circundantes." "Estrategia Española de Sostenibilidad Urbana y Local 2011", p.11.(MINISTERIO DE AGRICULTURA 2011)
} 
trataron de romper esta dicotomía entre rural y urbano, analizando a escala territorial sin priorizar unos espacios sobre otros (MINISTERIO DE AGRICULTURA, 2011:172). La ATE2020 ya había hecho hincapié en la desintegración que se había producido entre las ciudades y su entorno o ciudades próximas derivadas de las presiones del ámbito internacional. Por ello la EESUL2011 pretendió que los núcleos con más dinamismo no dejaran de lado el ámbito rural, pues por aquel entonces se estaban viendo amenazados por crecimientos desordenados, o bien por el olvido en otros casos.

Destacar que el mayor interés de esta estrategia radica en su posicionamiento en favor de una herramienta concreta para el seguimiento de los avances en materia de sostenibilidad local. En el apartado 6.5.1 de la EESUL2011 el "Sistema Municipal de Indicadores de Sostenibilidad" y el "Sistema de Indicadores y Condicionantes para ciudades grandes y medianas" se consolidan como referentes para la evaluación de la sostenibilidad local para el conjunto de municipios españoles. Esta apuesta por un sistema concreto permite entender con más claridad cuál es el modelo urbano considerado como favorable, pues en la definición de la herramienta encontramos las pautas para la ciudad sostenible. Pautas que tal y como manifiestan los análisis dejaron margen para la coexistencia de tendencias insostenibles.

Como hemos visto a lo largo de la investigación los documentos, a todas las escalas, que sentaron los principios en busca de la sostenibilidad se vieron en lucha continua con las tendencias globales de competitividad. Las estrategias no permaneciendo ajenas a esta controversia, fueron finalmente las que consolidaron este enfoque de crecimiento por encima de las dimensiones social, medioambiental y cultural señaladas en los documentos europeos, enfoque que se trasladó posteriormente a los planes, programas y proyectos desarrollados.

Desde las Cartas y Declaraciones, así como desde las estrategias ELisboa2000, hasta la E2020, así como el conjunto de estrategias territoriales y nacionales, ninguna ha sido capaz de establecer unos objetivos tales que verdaderamente respondieran a criterios sostenibles más allá del crecimiento. Si es cierto que algunos documentos han servido para dejar patente el empeoramiento de la situación ambiental. Sin embargo muchas otras tendencias permanecen ocultas y las que se descubren no parecen tenerse en cuenta con la exhaustividad necesaria como para revertir las consecuencias que está teniendo a escala global. 


\section{CONCLUSIONES}

En el presente artículo se pone de manifiesto a través el estudio del modelo heredado lo que la visión desarrollista ha supuesto en la implementación de la sostenibilidad. El estudio hace visibles las consecuencias de este enfoque basado en el crecimiento:

Primero. El modelo "sostenible" heredado es responsable de la continuidad en las tendencias insostenibles en los sistemas urbanos.

El análisis de los documentos que incorporan el concepto de sostenibilidad a la escala internacional y europea ha puesto de manifiesto la voluntad de dar continuidad al sistema económico preexistente.

La reinterpretación que estos documentos fijan como consenso internacional para el conjunto de los países nos hace ver de qué forma desde la escala internacional se deja abierta una vía para dar continuidad a la supremacía económica. Esto afectó a los sistemas urbanos debido a que:

- Por una parte esta interpretación que mantuvo el carácter abstracto inherente al concepto de sostenibilidad permitió perpetuar tendencias insostenibles amparadas en la deficiente definición de los objetivos.

- Por otra parte la asunción del "desarrollo sostenible" derivado de la interpretación del informe Brundtland, que sustituyó al concepto "sostenibilidad", perpetuó la supremacía de la dimensión económica condicionando a los instrumentos desde la fase de creación.

Segundo.Las disfunciones del modelo "sostenible" heredado son palpables en todas las dimensiones que afectan a la sostenibilidad urbana social, ambiental, cultural y económica.

El estudio de los documentos refleja que estos aún mantienen ese carácter compartimentado en el que cada dimensión correspondía con un ámbito sectorial independiente. Por tanto, a pesar de que los documentos se presentan como un instrumento multidimensional, estos no representan más que la agregación de interpretaciones de la sostenibilidad de los ámbitos sectoriales sin responder verdaderamente a las necesidades de creación de un documento unificado que sea capaz de desarrollar resultados cruzados que manifiesten las interacciones entre las dimensiones de la sostenibilidad.

Por otro lado, la forma parcial en que los documentos abordan las dimensiones de la sostenibilidad pone de manifiesto el interés en ocultar conductas insostenibles, que aún hoy se mantienen, por el simple hecho de omisión de información.

- La escala que debía ser tenida en cuenta en los documentos fue una de las disfunciones que más repercusión tuvo en la persistencia de las tendencias insostenibles. En su aplicación mediante la representación de valores globales se estarían ocultando tendencias insostenibles de la escala micro, y viceversa. 
- La dimensión cultural pese a su valor reconocido como factor de identidad urbana y que tiene su reflejo en el concepto "Baukultur" aparece apartada de los documentos. Se mantiene por tanto su tradicional interpretación como lastre económico.

- La dimensión social aparece en los documentos desde la perspectiva de la productividad, separada de los documentos tanto en lo que corresponde a participación, como en lo que tiene que ver con la lectura social real del contexto sobre el que se aplican.

- La dimensión medioambiental a pesar de haber sido de las primeras en la incorporación de los documentos aún carece de la interpretación ecosistémica que se venía demandando, manteniéndose el carácter descriptivo en lo que a esta dimensión se refiere.

Tercero. La existencia de disfunciones en los documentos para el análisis, evaluación y propuestas sostenibles trae como consecuencia el desequilibrio entre las dimensiones ambiental, social, cultural que persiste en los sistemas urbanos.

Los desequilibrios de las diferentes dimensiones que influyen en la relación entre el hombre y el medio se consolidan como un problema con claro referente en la dimensión urbana. Que estas tendencias observadas en los sistemas urbanos, y con incidencia en la escala global, persistan, ponen de manifiesto la supervivencia de las trazas de una economía competitiva.

Estas disfunciones entre las dimensiones son representativas de la inefectividad del modelo de la sostenibilidad desarrollado hasta la actualidad en su misión de analizar, evaluar y proponer alternativas sostenibles.

Cuarto. El desacoplamiento entre economía y sostenibilidad urbana aún no se ha producido.

La ineficacia del modelo para medir el impacto real de un sistema urbano deriva en interpretaciones de lo existente que, como hemos visto, ensalzan ciudades con un consumo de recursos masivo.

La presente investigación refleja que debido a las influencias del modelo de sostenibilidad heredado, y apoyándose en las deficiencias que subyacen en éstos, la perspectiva economicista aún permanece en los instrumentos de evaluación de las políticas de regeneración urbana integrada.

Se confirma por tanto la existencia de disfunciones en los documentos y por tanto queda justificada la existencia de tendencias insostenibles en los sistemas urbanos a pesar de existir múltiples instrumentos cuya finalidad fue detectar, frenar y corregir posibles distorsiones en las relaciones del hombre y el medio. 


\section{BIBLIOGRAFÍA}

AGENCIA EUROPEA DEL MEDIO AMBIENTE. 2015. "El Medio Ambiente En Europa: Estado Y Perspectivas 2015." Copenhague: Agencia Europea del Medio Ambiente.

ALONSO IBAÑEZ, María del Rosario. 2011. "Regeneración Urbana Integrada." In Crisis Y Territorio. Aportaciones Y Conclusiones Del VI Congreso Internacional de Ordenación Del Territorio. FUNDICOT.

_-_. 2012. "De La Política Urbanística a La Política Urbana: Los Retos Actuales Del Derecho Urbanístico." Revista de Derecho Urbanístico Y Medio Ambiente 277: 1328. ISSN 0034-7639.

ASCASIBAR ZUBIZARRETA, Iñigo. 2007. "Agenda Territorial de La Unión Europea Por El Crecimiento Económico Sostenible." Ambienta: La Revista Del Ministerio de Medio Ambiente, $N^{\circ}$. 68. doi:ISSN 1577-9491.

BOUAZZA, O., G. TROVATO, and R MATA. 2010. "Por Una Gestión Y Regeneración Urbana Sostenible E Integrada." Crónica de La Conferencia de Alto Nivel Sobre Sostenibilidad Urbana Y Regeneración Urbana Integrada En Europa, Ciudad Y Territorio 164: 367-96.

BRETTON WOODS PROJECT. 2009. "Políticas de Salvaguarda Y Normas de Desempeño." BRETTON WOODS PROJECT.

BURRIEL DEVESA, Carmen, and Elda GARCÍA-POSADA GÓMEZ. 2008. Guía de La Estrategia de Lisboa. COMUNIDAD DE MADRID. Dirección General de Asuntos Europeos Y Cooperación Con El Estado.

CASTELLS, Manuel. 1976. La Cuestión Urbana. Siglo XXI de España Editores.

COMISIÓN EUROPEA. 1990. "Green Paper on the Urban Environment. COM (90) 218 Final, 27 June 1990." EU Commission - COM Document.

- - - 1997. Comunicación de La Comisión de Las Comunidades Europeas: Hacia Una Política Urbana Para La Unión Europea COM(97)197 Final. http://habitat.aq.upm.es/hpuue/.

- - - 1998. "Marco de Actuación de La Unión Europea Para Un Desarrollo Urbano Sostenible."

- - . 1999a. "Estrategia Territorial Europea. Hacia Un Desarrollo Equilibrado Y Sostenible Del Territorio de La UE." Vol. 1.

- - - 1999b. "European Spatial Development Perspective, Towards Balanced and Sustainable Development of the Territory of the European Union."

- - 2000. "Conclusiones Del Consejo Europeo de Lisboa" 2013 (07/07). http://www.europarl.europa.eu/summits/lis1_es.htm.

- - . 2001. "Desarrollo Sostenible En Europa Para Un Mundo Mejor: Estrategia de La Unión Europea Para Un Desarrollo Sostenible."

- - - 2002. "Dictamen Del Comité Económico Y Social Sobre la 'Comunicación de 
La Comisión Al Parlamento Europeo, Al Consejo, Al Comité Económico Y Social Y Al Comité de Las Regiones, Hacia Una Asociación Global En Favor Del Desarrollo sostenible' (COM(2002) 82 Final)." Diario Oficial de Las Comunidades Europeas 17.09.2002: 0087-0096.

- - - 2005. "Revisión En 2005 de La Estrategia de La Unión Europea Para Un Desarrollo Sostenible: Primer Balance Y Orientaciones Futuras COM (2005) 658 Final," 52.

--—. 2006. "Revisión de La Estrategia de La UE Para Un Desarrollo Sostenible (EDS UE)" 2006: 1-29.

- - - 2007a. "Carta de Leipzig Sobre Ciudades Europeas Sostenibles." Documento de Los Estados Miembros, no. Reunión de Ministros responsables de Desarrollo Urbano de los Estados Miembros.

_-_. 2007b. "Cuarto Informe Sobre La Cohesión Econòmica Y Social."

-_-. 2010a. "Declaración de Toledo." Reunión Informal de Los Ministros de Desarrollo Urbano. http://www.fomento.gob.es/MFOM/LANG_CASTELLANO/_ESPECIALES/SIU/OTROS_ PROYECTOS/AGENDA/DECLARACION_TOLEDO/.

- - . 2010b. "Documento de Evaluación de La Estrategia de Lisboa." Bruselas.

- - . 2010c. "Documento de Referencia de Toledo Sobre La Regeneración Urbana Integrada Y Su Potencial Estratégico Para Un Desarrollo Urbano Más Inteligente, Sostenible Y Socialmente Inclusivo En Europa." In Declaración de Toledo.

-_-. 2010d. "Europa 2020. Una Estrategia Para Un Crecimiento Inteligente, Sostenible E Integrador COM(2010) 2020 Final," 39.

-_- 2010e. "Quinto Informe Sobre La Cohesión Económica, Social Y Territorial. Invirtiendo En El Futuro de Europa."

_-_. 2012. "Estudio Prospectivo Anual Sobre El Crecimiento 2013 COM(2012) 750 Final," 16.

COMISIÓN EUROPEA, and EUROSTAT. 2007. "Measuring Progress towards a More Sustainable Europe. 2007 Monitoring Report of the EU Sustainable Development Strategy," 297.

COMISIÓN MUNDIAL SOBRE MEDIO AMBIENTE Y DESARROLLO. 1987. "Nuestro Futuro común 'Our Comon Future.'" doi:A/42/427.

COMITÉ CONSULTIVO DEL ESPACIO ECONÓMICO EUROPEO. 2003. "Resolución Sobre El Seguimiento de La Estrategia de Lisboa." DIÁRIO OFICIAL DE LA UNIÓN EUROPEA C 308/18: 18-21.

COMITÉ DE LAS REGIONES. 2009. "Libro Blanco Sobre Gobernanza Multinivel."

- - . 2014. "Blueprint for a Revised Europe 2020 Strategy."

COMITÉ ECONÓMICO Y SOCIAL. 2007. "Agenda Territorial de La Unión Europea," 
no. 6: 24-25. http://www.ecourbano.es/imag/REF Agenda Territorial_UE.pdf.

COMUNIDAD EUROPEA. 1986. "Acta Única Europea (AUE) Luxemburgo 17 de Febrero de 1986/La Haya 28 de Febrero de 1986." http://eur-lex.europa.eu/legalcontent/ES/TXT/?uri=URISERV:xy0027.

CONSEJO EUROPEO. 1999. "Conclusiones de La Presidencia de La Reunión Del Consejo Europeo de Helsinki." Oficina de Publicaciones Oficiales de Las Comunidades Europeas Luxemburgo 10 Y 11 de Diciembre de 1999. http://www.europarl.europa.eu/summits/hel1_es.htm.

CONTRERAS SIERRA, Emigdio Rafael. 2013. "El Concepto de Estrategia Como Fundamento de La Planeación Estratégica." Pensamiento Y Gestión 35: 152-81.

CREUS ANDRADE, Juan José. 1995. "Dos Ejemplos de La Clara Entelequia Que Sufre La Red de Los Pequeños Asentamientos de Galicia." Boletín Académico 19: 21-32. doi:0213-3474.

CUADRADO RUIZ, Ma Ángeles. 2010. "Derecho Y Medio Ambiente." Medio Ambiente Y Derecho: Revista Electrónica de Derecho Ambiental 21: 1-26.

CUERPO, Carlos, and Almudena KESSLER. 2011. "Impacto Macroeconómico de La Ley de Economía Sostenible." Boletín Económico Del ICE 3014.

DAC (Development Assistance Committee) - OECD. 1996. Shaping the 21st Century: The Contribution of Development Co-Operation. Mayo 1996 (París). http://www.oecd.org/dac/2508761.pdf.

ECOLOGISTAS EN ACCIÓN. 2009. "La Insostenible Ley de Economía Sostenible." ttp://www.ecologistasenaccion.org/spip.php?article16006.

ERIAS REY, Antonio, and José Manuel ÁLVAREZ-CAMPANA GALLO. 2007. Evaluación Ambiental Y Desarrollo Sostenible. Editorial Pirámide.

ESPON. 2015. "ESPON:Territorial Scenarios and Visions for Europe."

---. 2016. "Polycentric Territorial Structures and Territorial Cooperation." Policy Brief, October.

EUROPEA, DIÁRIO OFICIAL DE LA UNIÓN. 2007. Tratado de Lisboa.

FARIÑA TOJO, Jose. 2004. "Sostenibilidad Y Racionalidad de Los Procesos de Urbanización." Cuadernos de Investigación Urbanística N²2. doi:1886-6654.

---. 2013. "Ciudad Sostenible, Rehabilitación Y Regeneración Urbana." Revista Aragonesa de Administración Pública ${ }^{\circ} 15$.

FONSECA, Francisco. 2010. "Una Respuesta Duradera Para Una Crisis Global: La Iniciativa UE 2020." Boletín Económico Del ICE 2989: 23-28.

FOY, Pierre. 1998. Agenda 21: Desarrollo Sostenible: Un Programa Para La Acción. Edited by Pierre Foy Valencia. Agenda 21: Desarrollo Sostenible: Un Programa Para La Acción. Fondo Editorial PUCP.

GAL, Zoltán. 2014. "Territorial Scenarios and Visions for Europe ET2050 Eastern \& 
Danube Region." In ESPON T-2050 Budapest, 6/11/2014, 45. ESPON DATABASE 2013.

GOMEZ PIÑERO, Javier. 1989. "Acciones Y Programas Comunitarios En Materia de Medio Ambiente." Lourralde. doi:1697-3070.

GONZALEZ MEDINA, Moneyba. 2013. "La Europeización Urbana a Través de La Política de Cohesión." Revista CIDOB d'Afers Internacionals 104: 133-54.

GREGORIO HURTADO, Sonia DE. 2012. "Políticas Urbanas de La Unión Europea Desde La Perspectiva de La Planificación Colaborativa. Las Iniciativas Comunitarias URBAN, URBAN II."

HERNANDEZ AJA, Agustín. 2003. "Carta de Las Ciudades Europeas Hacia La Sostenibilidad. La Carta de Aalborg." http://habitat.aq.upm.es/doc.html.

HERRERA, Amilcar O, Hugo D SCOLNICK, Gabriela CHICHILINSKY, Gilberto C. GALLOPÍN, and Jorge E. HARDOY. 2004. Catastrofe O Nueva Sociedad?: Modelo Mundial Latinoamericano: 30 Años Después. IIED.

HILDENBRAND SCHEID, Andreas. 2009. "La Ordenación Del Territorio En La Agenda Política Europea." Agua, Territorio Y Paisaje: De Los Instrumentos Programados a La Planificación Aplicada: $V$ Congreso Internacional de Ordenación Del Territorio.FUNDICOT, 288-308.

HULME, David. 2007. "The Making of the Millenium Development Goals: Human Development Meets Results-Based Management in an Imperfect World." In Brooks World Poverty Institute Working Paper No. 16, 28.

IEG WORLDBANK. 2010. Safeguards and Sustainability Policies in a Changing World:An Independent Evaluation of World Bank Group Experience.

INSTITUTO UNIVERSITARIO DE URBANÍSTICA DE LA UNIVERSIDAD DE VALLADOLID. 2010. "Regeneración Urbana Integrada Europa. Documento de Síntesis.JUNIO 2010," 56.

IUU-UVA. 2010. "Regeneración Urbana Integrada En Europa. Documento de Síntesis." Valladolid.

JEFATURA DEL ESTADO. 2011. Ley 2/2011, de 4 de Marzo, de Economía Sostenible. BOE 555 de Marzo.

--- 2013. Ley 8/2013, de 26 de Junio, de Rehabilitación, Regeneración Y Renovación Urbanas. BOE 15327 de Junio.

JIMÉNEZ BELTRÁN, Domingo. 2002. "La Estrategia de Desarrollo Sostenible de La Unión Europea En El Contexto Global: De Río a Johannesburgo." ICE Desarrollo Sostenible 800: 97-122.

MALTHUS, Thomas Robert. 1846. Ensayo Sobre El Principio de La Población. Ediciones Akal.

MARTÍN-CONSUEGRA, F, C. ALONSO, and B. FRUTOS. 2015. "La Regeneración Urbana Integrada Y La Declaración de Toledo." Informes de La Construcción 67 (1): 
nt002.

MATESANZ PARELLADA, Ángela. 2009. "EI Suelo En La Legislación Urbanística Española." http://habitat.aq.upm.es/boletin/n51/aamat.html.

MATÍAS CLAVERO, Gustavo. 2005. "La Estrategia de Lisboa Sobre La Sociedad Del Conocimiento:la Nueva Economía." ICE 820: 169-93.

MAYOR ZARAGOZA, Federico. 2004. "Economía Basada En El Conocimiento." EL PAIS, November 26.

MAZUELOS BELLIDO, Ángeles. 2004. "Soft Law: ¿Mucho Ruido Y Pocas Nueces?" Revista Electrónica de Estudios Internacionales (REEI) n8. doi:ISSN 1697-5197.

MEADOWS, D. H., D. L. MEADOWS, J. RANDERS, and W. W. BEHRENS. 1972. "Los Límites Del Crecimiento: Informe Al Club de Roma Sobre El Predicamento de La Humanidad. Fondo de Cultura Económica."

MiNISTERIO DE AGRICULTURA, ALIMENTACIÓN Y MEDIO AMBIENTE. 2009. "Estrategia Española de Sostenibilidad Urbana Y Local 2009."

- - . 2011. "Estrategia Española de Sostenibilidad Urbana Y Local."

MINISTERIO DE FOMENTO. 2017. "Las Políticas Urbanas a Nivel Europeo - Portal SIU." Portal de Suelo $Y$ Políticas Urbanas. http://siu.vivienda.es/portal/index.php?option=com_content\&view=article\&id=91\&I temid $=145 \&$ lang $=$ es.

MINISTERIO DE LA PRESIDENCIA. 2007. Estrategia Española de Desarrollo Sostenible. Madrid.

MINISTERIO DE LA VIVIENDA ESPAÑA. 2008. Real Decreto Legislativo 2/2008, de 20 de Junio, Por El Que Se Aprueba El Texto Refundido de La Ley de Suelo. BOE 154 26 de Junio.

- - . 2010. "Integrated Urban Regeneration in the European Union: Toledo Informal Ministerial Meeting on Urban Development." In Toledo Informal Ministerial Meeting on Urban Development, 857.

MINISTERIO DE MEDIO AMBIENTE UE. 2001. Medio Ambiente En La UE En El Umbral Del Siglo XXI. Edited by MINISTERIO DE MEDIO AMBIENTE.

MINISTERIO DE MEDIO AMBIENTE Y MEDIO RURAL Y URBANO ESPAÑA. 2007. "Libro Verde de Medio Ambiente Urbano." Documento de Trabajo 2007. Tomo I Y II. http://www.ecourbano.es/greenbook.asp.

MORATILLA, Fernando Esteban. 1999. Las Políticas Europeas Para El Desarrollo de Las Ciudades. Documentación Oficial Del Comité Hábitat II España, Hoja Informativa.

NACIONES UNIDAS. 1945. Carta de Las Naciones Unidas En Conferencia de Las Naciones Unidas Sobre Organización Internacional 26 de Junio de 1945, San Francisco (EEUU). Naciones Unidas. 
---. 1968a. "Resolución 1346 (XVL) Del 45 Periodo de Sesiones Del Consejo Económico $Y$ Social de Las Naciones Unidas." Naciones Unidas. http://www.un.org/es/comun/docs/?symbol=e/res/1346(XLV).

---. 1968b. "Resolución 2398 (XXIII) Del 23 Periodo de Sesiones de La Asamblea General de Las Naciones Unidas."

-_-. 1972. "Declaración de Estocolmo Sobre El Medio Humano 1972." Conferencia de Las Naciones Unidas Sobre El Medio Ambiente Humano. Estocolmo. http://www.upv.es/contenidos/CAMUNISO/info/U0579218.pdf.

- - . 1976. "Declaración de Vancouver Sobre Asentamientos Humanos."

-_-. 1992a. "Declaración de Río Sobre El Medioambiente Y El Desarrollo."

---. 1992b. "Programa 21."

---. 1996. "Conferencia de Las Naciones Unidas Sobre Los Asentamientos Humanos." Estambul (Turquía).

---. 2000a. "Resolución A/RES/55/2. Declaración Del Milenio." Declaración Naciones Unidas. New York. http://www2.ohchr.org/spanish/bodies/hrcouncil/docs/gaA.RES.60.1_Sp.pdf.

-- . 2000b. "We the People." UNITED NATIONS. Nueva York.

---. 2005. "Un Concepto Más Amplio de La Libertad: Desarrollo, Seguridad Y Derechos Humanos Para Todos." In Informe Del Secretario General de Las Naciones Unidas En El 59 Periodo de Sesiones de La Asamblea General 21 de Marzo de 2005, Nueva York, 68.

---. 2006. "Declaración de Riga."

---. 2016. "Habitat III New Urban Agenda: Quito Declaration on Sustainable Cities and Human Settlements for All." Habitat III Conference. http://www.eukn.eu/news/detail/agreed-final-draft-of-the-new-urban-agenda-isnow-available/.

- $2018 . \quad$ "Objetivos de Desarrollo Sostenible." http://www.undp.org/content/undp/es/home/sustainable-development-goals.html.

NAREDO, José Manuel. 1996. "Sobre El Origen, El Uso Y El Contenido Del Término Sostenible." Documentación Social 41: 7-18. http://bit.ly/1Dk63SG.

ORGANISATION FOR ECONOMIC CO-OPERATION AND DEVELOPMENT. 2001. "The DAC Guidelines. Strategies for Sustainable Development: Guidance for Development Co-Operation." http://www.oecd.org/dac/environment-development/2669958.pdf.

PARKINSON, Michael. 2014. "Regeneración Urbana Integrada En 2014: Nada Nuevo Bajo El Sol." Ciudad Y Territorio XLVI, Ministerio de Fomento 179: 11-27.

PARNEL, Susan. 2016. "Defining a Global Urban Development Agenda." World Development 78: 529-40.

PEDROSA SANZ, Rosario. 2009. "El Desarrollo Histórico de La Política Social de La 
Unión Europea Y Su Estado Actual." Estudios de Economía Aplicada 27 (3): 613-38. PRADO LALLANDE, Juan Pablo. 2006. "La ONU Y El Desarrollo: Una Reflexión Crítica Y Propositiva." Foro Internacional XLVI (2 Abril-Junio): 262-90.

QUESADA DÍEZ, SILVIA. 2010. "La Acción Social En La Unión Europea: Evolución Histórica," 221-32.

RADAELLI, Claudio M. 2003. "The Europeanization of Public Policy." In The Politics of Europeanization, 320. Oxford University Press.

REVI, Aromar, and Cynthia ROSENZWEIG. 2013. "The Urban Opportunity: Enabling Transformative and Sustainable Development." High-Level Panel of Eminent Persons on the Post-2015 Development Agenda.

SASSEN, Saskia. 2011. "Conferencia: Ciudad Global." Universidad de Los Andes (Bogotá, Colombia). http://www.uniandes.edu.co/component/content/article/568saskia-sassen.

SMITH, James, and Emma Michelle TAYLOR. 2013. "MDGs and NTDs: Reshaping the Global Health Agenda." PLOS Neglected Tropical Diseases 7 (12). http://dx.doi.org/10.1371/journal.pntd.0002529.

SOUTO GONZALEZ, Xose Manuel. 2006. "La Estrategia Territorial Europea: Racionalización O Privatización Del Espacio Geográfico." Biblio 3W XI (664).

SUBIRATS HUMET, Joan. 2017. "El Municipalismo Del Común." Santiago de Compostela.

SUDOE, INTERREG. $2000 . \quad$ "INTERREG." http://www.interregsudoe.org/castellano/programa/interregIIc.asp.

TIRADO, Sergio. 2016. "Una Nueva Agenda Urbana: Reflexiones Críticas En Torno a 'Habitat III' En Quito." El Huffington Post. http://www.huffingtonpost.es/sergiotirado/una-nueva-agenda-urbana-r_b_12639726.html.

UNIÓN EUROPEA. 1992. "Tratado de Mastritch." DIÁRIO OFICIAL DE LA UNIÓN EUROPEA. http://eur-lex.europa.eu/homepage.html.

---. 2010. "Tratado de Funcionamiento de La Unión Europea. Versión consolidada.30 de Marzo de 2010.DOUE-Z-2010-70006." Diario Oficial de La Unión Europea 83: 74-199. https://www.boe.es/buscar/doc.php?id=DOUE-Z-2010-70006.

---. 2018. "UNION EUROPEA HISTORIA." https://europa.eu/europeanunion/about-eu/history/1970-1979/1972_es.

URBAN-Future. 2005. "The 'Acquis URBAN' Using Cities' Best Practises for European Cohesion Policy." Common Declaration of URBAN Cities and Players at the European Conference "URBAN Future" on June 8th and 9th, 2005 in Saarbrücken (Germany).

VILLAFÁÑEZ SAGARDOY, Diego. 2015. "Voces Críticas Con El Fondo Monetario Internacional Y El Banco Mundial." Derecho Y Cambio Social, 1-15. 
LOS CUADERNOS DE INVESTIGACIÓN URBANÍSTICA El departamento de Urbanística y Ordenación del Territorio de la Escuela Técnica Superior de Arquitectura de Madrid, lleva publicando desde el año 1993 la revista Cuadernos Investigación Urbanística, (Ci[ur]), para dar a conocer trabajos de investigación realizados en el área del Urbanismo, la Ordenación Territorial, el Medio Ambiente, la Planificación Sostenible y el Paisaje. Su objetivo es la difusión de estos trabajos. La lengua preferente utilizada es el español, aunque se admiten artículos en inglés, francés, italiano y portugués.

La publicación presenta un carácter monográfico. Se trata de amplios informes de la investigación realizada que ocupan la totalidad de cada número sobre todo a aquellos investigadores que se inician, y que permite tener accesibles los aspectos más relevantes de los trabajo y conocer con bastante precisión el proceso de elaboración de los mismos. Los artículos constituyen amplios informes de una investigación realizada que tiene como objeto preferente las tesis doctorales leídas relacionadas con las temáticas del Urbanismo, la Ordenación Territorial, el Medio Ambiente, la Planificación Sostenible y el Paisaje en las condiciones que se detallan en el apartado "Publicar un trabajo".

La realización material de los Cuadernos de Investigación Urbanística está a cargo del Departamento de Urbanística y Ordenación del Territorio de la Escuela Técnica Superior de Arquitectura de Madrid. El respeto de la propiedad intelectual está garantizado, ya que el registro es siempre en su totalidad propiedad del autor $y$, en todo caso, con autorización de la entidad pública o privada que ha subvencionado la investigación. Está permitida su reproducción parcial en las condiciones establecidas por la legislación sobre propiedad intelectual citando autor, previa petición de permiso al mismo, y procedencia.

Con objeto de verificar la calidad de los trabajos publicados los originales serán sometidos a un proceso de revisión por pares de expertos pertenecientes al Comité Científico de la Red de Cuadernos de Investigación Urbanística (RCi[ur]). Cualquier universidad que lo solicite y sea admitida por el Departamento de Urbanística y Ordenación del Territorio de la Universidad Politécnica de Madrid (DUYOT) puede pertenecer a esta red. Su único compromiso es el nombramiento, como mínimo, de un miembro de esa universidad experto en el área de conocimiento del Urbanismo, la Ordenación Territorial, el Medio Ambiente, la Planificación Sostenible y el Paisaje para que forme parte del Comité Científico de la revista y cuya obligación es evaluar los trabajos que se le remitan para verificar su calidad.

A juicio del Consejo de Redacción los resúmenes de tesis o partes de tesis doctorales leídas ante el tribunal correspondiente podrán ser exceptuados de esta revisión por pares. Sin embargo dicho Consejo tendrá que manifestarse sobre si el resumen o parte de tesis doctoral responde efectivamente a la aportación científica de la misma.

\section{NORMAS DE PUBLICACIÓN}

Las condiciones para el envío de originales se pueden consultar en la página web: http://www2.aq.upm.es/Departamentos/Urbanismo/publicaciones/ciurpublicar.html

\section{FORMATO DE LAS REFERENCIAS}

Monografías: APELLIDOS (S), Nombre (Año de edición). Título del libro (No de edición). Ciudad de edición: Editorial (Traducción castellano, (Año de edición), Título de la traducción, No de la edición. Ciudad de edición: editorial).

Partes de monografías: APELLIDOS (S), Nombre (Año de edición). "Título de capítulo". En: Responsabilidad de la obra completa, Título de la obra (No de edición). Ciudad de edición: Editorial. Artículos de publicaciones en serie: APELLIDOS (S), Nombre (Año de publicación). "Título del artículo", Título de la publicación, Localización en el documento fuente: volumen, número, páginas. Se deberá indicar el DOI de todas las publicaciones consultadas que dispongan del mismo. Así como el número ORCID del autor. 


\section{CONSULTA DE NÚMEROS ANTERIORES/ACCESS TO PREVIOUS WORKS}

La colección completa se puede consultar en color y en formato pdf en siguiente página web:

The entire publication is available in pdf format and full colour in the following web page:

http://www2.aq.upm.es/Departamentos/Urbanismo/institucional/publicaciones/ciur/numeros-

publicados/

\section{ÚLTIMOS NÚMEROS PUBLICADOS:}

117 Inmaculada Martín Portugués: "Mértola Vila Museu. Modelo rural de difusión del patrimonio cultural", 80 páginas, abril 2018.

116 Reyes Gallegos Rodríguez: "Hacia un urbanismo emergente: La ciudad viva", 84 páginas, febrero 2018.

115 Carmen Moreno Balboa: "Urbanismo colaborativo", 100 páginas, diciembre 2017.

114 Ricardo Alvira Baeza: "Segregación espacial por renta. Concepto, medida y evaluación de 11 ciudades españolas", 101 páginas, octubre 2017.

113 Carlos Alberto Tello Campos: "Revitalización urbana y calidad de vida en el sector central de las ciudades de Montreal y México", 69 páginas, agosto 2017.

112 Andrea González: "Valores compositivos fundamentales del jardín privado chino o la mirada urbana sobre el paisaje a lo largo de su historia hasta la Revolución de 1949", 74 páginas, junio 2017.

111 Pedro Górgolas Martín: "Burbujas inmobiliarias y planeamiento urbano en España: Una amistad peligrosa", 71 páginas, abril 2017.

110 Lourdes Jiménez: "Dinámicas de ocupación urbana del anillo verde metropolitano de Madrid", 80 páginas, febrero 2017.

109 Manuel Fernández González: "La Smart-city como imaginario socio-tecnológico", 72 páginas, noviembre 2016.

108 Narges Bazarjani: "Espacio público: conflicto y poder en la ciudad de Teherán", 70 páginas, septiembre 2016.

107 Ricardo Alvira Baeza: "Proyecto Haz(Otea)", 84 páginas, julio 2016.

106 Gloria Gómez Muñoz: "Intervención en el alojamiento con criterios ecológicos", 90 páginas, mayo 2016.

105 Irene Zúñiga Sagredo: "La forma del límite en las ciudades medias españolas", 66 páginas, marzo 2016. 


\author{
COORDINADORA DEL MÁSTER: Ester Higueras García \\ PERIODO DE DOCENCIA: Septiembre - Julio \\ MODALIDAD: Presencial y tiempo completo \\ NUMERO DE PLAZAS: 40 plazas \\ CREDITOS: 60 ECTS
}

El Máster se centra en la comprensión, análisis, diagnóstico y solución de los problemas y la identificación de las dinámicas urbanas y territoriales en curso, atendiendo a las dos dimensiones fundamentales del fenómeno urbano actual: por un lado, el proceso de globalización y, por otro lado, las exigencias que impone la sostenibilidad territorial, económica y social. Estos objetivos obligan a insistir en aspectos relacionados con las nuevas actividades económicas, el medio físico y natural, el compromiso con la producción de un espacio social caracterizado por la vida cívica y la relación entre ecología y ciudad, sin olvidar los problemas recurrentes del suelo, la vivienda, el transporte y la calidad de vida. Estos fines se resumen en la construcción de un espacio social y económico eficiente, equilibrado y sostenible. En ese sentido la viabilidad económica de los grandes despliegues urbanos y su metabolismo se confrontan con modelos más maduros, de forma que al estudio de las técnicas habituales de planificación y gestión se añaden otras nuevas orientaciones que tratan de responder a las demandas de complejidad y sostenibilidad en el ámbito urbano.

El programa propuesto consta de un Máster con dos especialidades:

- Especialidad de Planeamiento Urbanístico (Profesional)

- Especialidad de Estudios Urbanos (Investigación Académica)

Se trata de 31 asignaturas agrupadas en tres módulos:

MÓDULO A. Formación en Urbanismo.

MÓDULO B. Formación en Estudios Urbanos e Investigación.

MÓDULO C. Formación en Planeamiento.

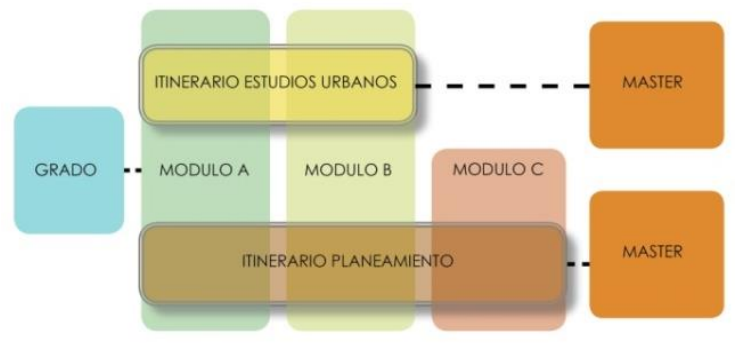

PROFESORADO:

Eva Álvarez de Andrés

Carmen Andrés Mateo

Sonia de Gregorio Hurtado

José María Ezquiaga Domínguez

José Fariña Tojo
Beatriz Fernández Águeda

José Miguel Fernández Güell

Isabel González García

Agustín Hernández Aja

Ester Higueras García

Francisco José Lamiquiz
Emilia Románn López

Inés Sánchez de Madariaga

Llanos Masiá González

Javier Ruiz Sánchez

Álvaro Sevilla Buitrago

ENTIDADES COLABORADORAS:

CONTACTO: masterplaneamiento.arquitectura@upm.es www.aq.upm.es/Departamentos/Urbanismo/masters/index.html 
Otros medios divulgativos del Departamento de Urbanística y Ordenación del Territorio:

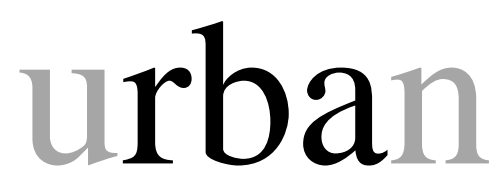

\section{REVISTA del DEPARTAMENTO de URBANÍSTICA Y ORDENACIÓN del TERRITORIO} ESCUELA TÉCNICA SUPERIOR DE ARQUITECTURA

\section{PRESENTACión SEgUNDA ÉPOCA}

DESDE el año 1997, URBAN ha sido vehículo de expresión de la reflexión urbanística más innovadora en España y lugar de encuentro entre profesionales y académicos de todo el mundo. Durante su primera época la revista ha combinado el interés por los resultados de la investigación con la atención a la práctica profesional, especialmente en el ámbito español y la región madrileña. Sin abandonar dicha vocación de saber aplicado y localizado, la segunda época se centra en el progreso de las políticas urbanas y territoriales y la investigación científica a nivel internacional.

\section{CONVOCATORIA PARA LA RECEPCIÓN DE ARTÍCULOS:}

Urban mantiene abierta una convocatoria permanente para la remisión de artículos de temática relacionada con los objetivos de la revista: Para más información:

http://www2.aq.upm.es/Departamentos/Urbanismo/institucional/publicaciones/urban/ns/instrucciones-para-autores/

Por último, se recuerda que, aunque La revista URBAN organiza sus números de manera monográfica mediante convocatorias temáticas, simultáneamente, mantiene siempre abierta de forma contínua una convocatoria para artículos de temática libre.

\section{DATOS DE CONTACTO}

Envío de manuscritos y originales a la atención de Javier Ruiz Sánchez: urban.arquitectura@upm.es

Página web:

http://www2.aq.upm.es/Departamentos/Urbanismo/institucional/publicaciones/urban/ns/presentacion/

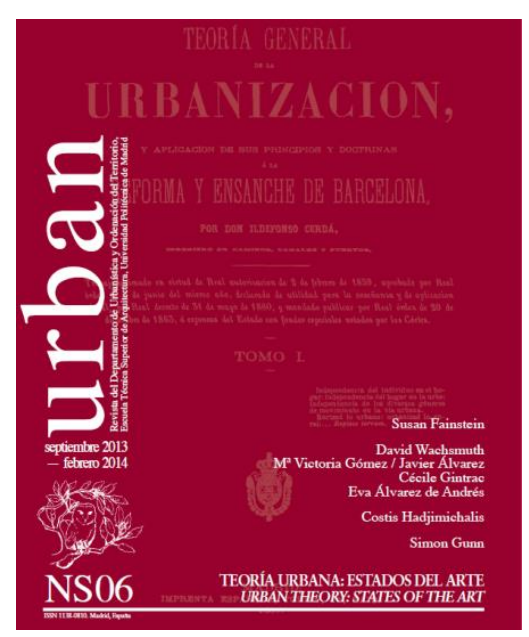

Consulta y pedido de ejemplares: ciur.urbanismo.arquitectura@upm.es Web del Departamento de Urbanística y Ordenación del Territorio: http://www.aq.upm.es/Departamentos/Urbanismo 
Donde figuran todas las actividades docentes, divulgativas y de investigación que se realizan en el Departamento con una actualización permanente de sus contenidos.

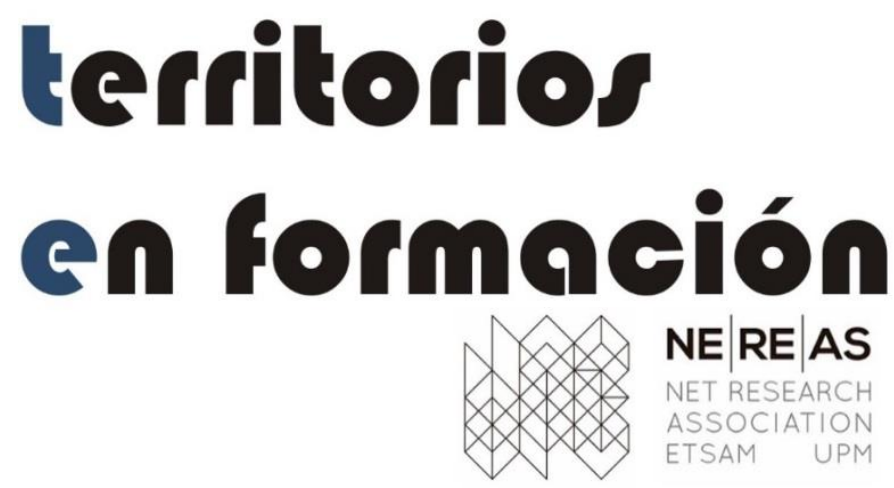

ESCUELA TÉCNICA SUPERIOR DE ARQUITECTURA

Territorios en formación constituye una plataforma de divulgación de la producción académica relacionada con los programas de postgrado del Departamento de Urbanística y Ordenación del Territorio de la ETSAM-UPM proporcionando una vía para la publicación de los artículos científicos y los trabajos de investigación del alumnado y garantizando su excelencia gracias a la constatación de que los mismos han tenido que superar un tribunal fin de máster o de los programas de doctorado del DUyOT.

Así, la publicación persigue dos objetivos: por un lado, pretende abordar la investigación dentro del ámbito de conocimiento de la Urbanística y la Ordenación del Territorio, así como la producción técnica de los programas profesionales relacionados con ellas; por otro, promueve la difusión de investigaciones o ejercicios técnicos que hayan sido planteados desde el ámbito de la formación de postgrado. En este caso es, principalmente, el Departamento de Urbanística y Ordenación del Territorio el que genera esta producción, gracias a la colaboración con la asociación Ne.Re.As. (Net Research Association / Asociación Red Investiga, asociación de investigadores de urbanismo y del territorio de la UPM), que, por acuerdo del Consejo de Departamento del DUyOT, es la encargada de la edición de la revista electrónica.

\section{DATOS DE CONTACTO}

Ana Zazo Moratalla (Editora): territorios.arquitectura@upm.es

Página web: http://www2.aq.upm.es/Departamentos/Urbanismo/institucional/publicaciones/territorios-enformacion/

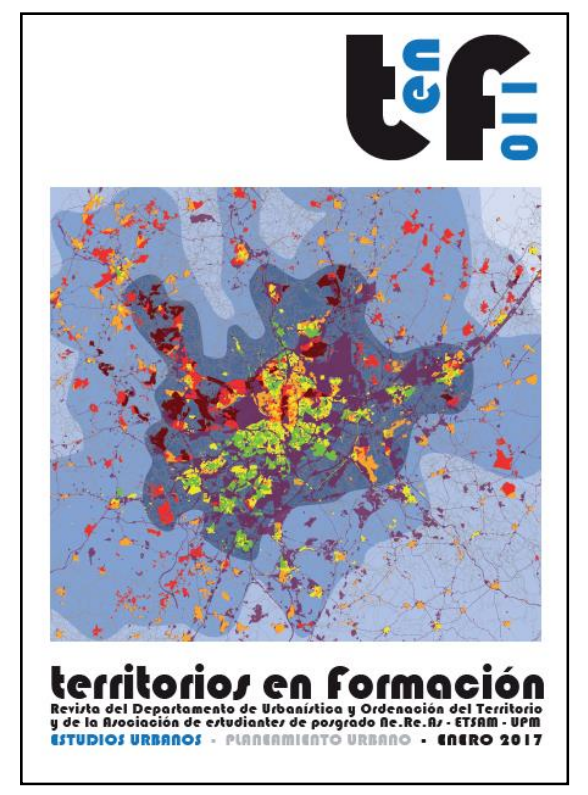

